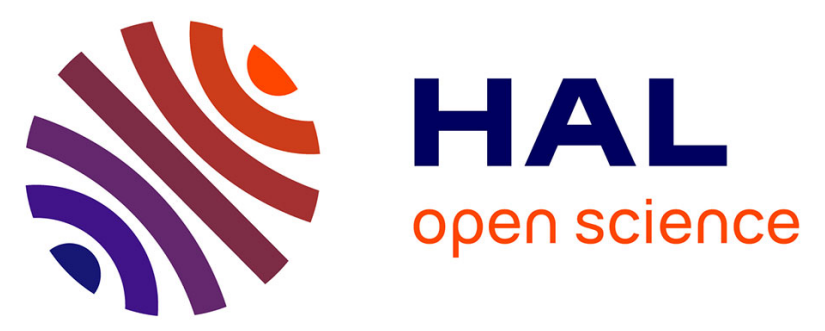

\title{
Core microbial communities of lacustrine microbialites sampled along an alkalinity gradient
}

\author{
Miguel Iniesto, David Moreira, Guillaume Reboul, Philippe Deschamps, \\ Karim Benzerara, Paola Bertolino, Aurélien Saghaï, Rosaluz Tavera, \\ Purificación López-García
}

\section{To cite this version:}

Miguel Iniesto, David Moreira, Guillaume Reboul, Philippe Deschamps, Karim Benzerara, et al.. Core microbial communities of lacustrine microbialites sampled along an alkalinity gradient. Environmental Microbiology, 2021, 23, pp.51-68. 10.1111/1462-2920.15252 . hal-02988545

\section{HAL Id: hal-02988545 https://hal.science/hal-02988545}

Submitted on 4 Dec 2020

HAL is a multi-disciplinary open access archive for the deposit and dissemination of scientific research documents, whether they are published or not. The documents may come from teaching and research institutions in France or abroad, or from public or private research centers.
L'archive ouverte pluridisciplinaire HAL, est destinée au dépôt et à la diffusion de documents scientifiques de niveau recherche, publiés ou non, émanant des établissements d'enseignement et de recherche français ou étrangers, des laboratoires publics ou privés. 


\section{Core microbial communities of lacustrine microbialites sampled along an alkalinity}

\section{gradient}

5

Miguel Iniesto ${ }^{1}$, David Moreira ${ }^{1}$, Guillaume Reboul ${ }^{1}$, Philippe Deschamps ${ }^{1}$, Karim Benzerara ${ }^{2}$, Paola

Bertolino ${ }^{1}$, Aurélien Saghai ${ }^{1,3}$, Rosaluz Tavera ${ }^{4}$ and Purificación López-García ${ }^{1}$

${ }^{1}$ Unité d'Ecologie Systématique et Evolution, CNRS, Université Paris-Saclay, AgroParisTech, Orsay,

10 France

${ }^{2}$ Institut de Minéralogie, de Physique des Matériaux et de Cosmochimie, CNRS, Muséum National d'Histoire Naturelle, Sorbonne Université, Paris, France

${ }^{3}$ Department of Forest Mycology and Plant Pathology, Swedish University of Agricultural Sciences, Sweden

$15{ }^{4}$ Departamento de Ecología y Recursos Naturales, Universidad Nacional Autónoma de México, DF Mexico, Mexico

For correspondence: puri.lopez@u-psud.fr

Running title: Microbialite core communities in crater lakes 


\section{Originality and Significance Statement}

Microbialites are rocks formed by microbial communities under particular physicochemical conditions.

30 Although they are important as the oldest reliable life traces and for their capacity to sequester $\mathrm{CO}_{2}$ as biomass and carbonates, the specific drivers influencing carbonatogenesis are not well understood. We compare the prokaryotic and eukaryotic communities associated to microbialites sampled in lakes of increasing alkalinity in the Trans-Mexican volcanic belt. We identify a conserved core microbial community populating microbialites that is more abundant in the most conspicuous microbialites, which occur in lakes with the highest alkalinity. This helps constraining microbialite formation conditions and opens interesting perspectives for the use of subsampled core communities for carbon sequestration experiments. 


\section{Summary}

Microbialites are usually carbonate-rich sedimentary rocks formed by the interplay of phylogenetically and metabolically complex microbial communities with their physicochemical environment. Yet, the biotic and abiotic determinants of microbialite formation remain poorly constrained. Here, we analyzed the structure of prokaryotic and eukaryotic communities associated with microbialites occurring in several crater lakes of the Trans-Mexican volcanic belt along an alkalinity gradient. Microbialite size and community structure correlated with lake physicochemical parameters, notably alkalinity. Although microbial community composition varied across lake microbialites, major taxa-associated functions appeared quite stable with both, oxygenic and anoxygenic photosynthesis and, to less extent, sulfate reduction, as major putative carbonatogenic processes. Despite inter-lake microbialite community differences, we identified a microbial core of 247 operational taxonomic units conserved across lake microbialites, suggesting a prominent ecological role in microbialite formation. This core mostly encompassed Cyanobacteria and their typical associated taxa (Bacteroidetes, Planctomycetes) and diverse anoxygenic photosynthetic bacteria, notably Chloroflexi, Alphaproteobacteria (Rhodobacteriales, Rhodospirilalles), Gammaproteobacteria (Chromatiaceae), and minor proportions of Chlorobi. The conserved core represented up to $40 \%$ (relative abundance) of the total community in lakes Alchichica and Atexcac, displaying the highest alkalinities and the most conspicuous microbialites. Core microbialite communities associated with carbonatogenesis might be relevant for inorganic carbon sequestration purposes.

Keywords: 16S/18S rRNA metabarcoding; stromatolite; carbonate precipitation; biomineralization; colonization; cyanobacteria; anoxygenic photosynthesis 


\section{Introduction}

Microbialites are organosedimentary structures formed under the influence of phylogenetically and functionally diverse microbial communities in particular physicochemical environments (Riding, 2000; Dupraz and Visscher, 2005). These geobiological structures have a double interest in ecology and evolution. First, these lithifying microbial mats are easily preserved in the fossil record and, when laminated at the macroscale (stromatolites), provide a simple morphological diagnosis for biogenicity. Applying this criterion, fossil stromatolites from the early Archaean ( $\sim 3.5 \mathrm{Ga}$ ) are included among the oldest (almost) unambiguous life traces on Earth (Awramik, 1990; Altermann, 2004; Tice and Lowe, 2004; Allwood et al., 2006; Allwood et al., 2009). Second, formed by conspicuous photosynthetic microbial communities and being generally carbonate-rich, they constitute carbon reservoirs in the form of both, biomass and carbonates. Yet, although microbialites are thought to result from the interplay of biotic and abiotic factors (Dupraz et al., 2009), the specific identity and functions of associated microorganisms and the local environmental conditions resulting in their formation are still poorly understood.

In modern systems, both the trapping and binding of detritic particles and the in situ precipitation of minerals, mostly carbonates, contribute to microbialite growth. Carbonate precipitation in microbialites requires nucleation centers as well as solutions supersaturated with carbonate mineral phases, i.e. relatively rich in carbonate anions and e.g. $\mathrm{Ca}^{2+}$ and/or $\mathrm{Mg}^{2+}$ cations (Dupraz and Visscher, 2005). Exopolymeric substances (EPS), abundantly produced by many cyanobacteria, may be a source of both, cations (liberated during their degradation) and nucleation centers (Benzerara et al., 2006; Dupraz et al., 2009; Obst et al., 2009). Some microbial activities, such as oxygenic and anoxygenic photosynthesis (Dupraz and Visscher, 2005; Bundeleva et al., 2012), sulfate reduction (Visscher et al., 2000; Gallagher et al., 2012), nitrate-driven sulfide oxidation (Himmler et al., 2018) or anaerobic methane oxidation coupled to sulfate reduction (Michaelis et al., 2002), can increase the $\mathrm{pH}$ and/or alkalinity $\left(\left[\mathrm{HCO}_{3}^{-}\right]\right)$and, hence, the local supersaturation of the solution with carbonate phases and the precipitation kinetics. The occurrence of these activities in microbialites can be recorded in the form of isotopic signatures. Values of $\delta^{13} \mathrm{C}$ in modern microbialites from lakes Clifton (Southwestern Australia) \{Warden, $2016 \# 9360\}$ and Alchichica (Mexico) \{Chagas, $2016 \# 8393\}$, and of $\delta^{13} \mathrm{C}$ and $\delta^{18} \mathrm{O}$ from Highborne Cay microbialites (Bahamas) \{Louyakis, 2017 \#9618\} support the implication of these microbial activities (e.g. oxygenic and anoxygenic photosynthesis) in the formation of these lithified structures. On the contrary, other metabolisms, such as aerobic respiration, complete sulfide oxidation to sulfates and fermentation (Dupraz and Visscher, 2005) tend to promote dissolution by acidification. Carbonate precipitation would result from the balance of the different metabolisms in complex microbial communities. However, although very different taxa can display metabolisms potentially sustaining such an 'alkalinity engine', microbialite-associated microbial communities are extremely 
diverse (e.g. (Mobberley et al., 2012; Russell et al., 2014; Saghaï et al., 2015; Suosaari et al., 2016)) and it is difficult to determine which members have an effective role in microbialite formation. For instance, both oxygenic (cyanobacteria, eukaryotic microalgae) and anoxygenic (Chloroflexi, Chlorobi, some Alphaproteobacteria and Gammaproteobacteria) photosynthesizers should favor carbonate 105 precipitation (Saghaï et al., 2015). However, some cyanobacterial species do favor carbonate dissolution (Guida and Garcia-Pichel, 2016; Cam et al., 2018) and others, such as cyanobacteria from the order Pleurocapsales, seem significantly more carbonatogenic than others in some systems (Couradeau et al., 2013; Gerard et al., 2013), suggesting taxon-specific effects.

Currently growing microbialites are found in a few marine sites (Logan, 1961; Dravis, 1983; 110 Awramik and Riding, 1988; Reid and Browne, 1991; Casaburi et al., 2016; Suosaari et al., 2016) and in a variety of inland water bodies. These include saline lagoons (Saint Martin and Saint Martin, 2015), thalassohaline crater lakes (Gerard et al., 2018) and hypersaline ponds (Farias et al., 2013; Farias et al., 2014) but also freshwater systems. Freshwater microbialites raise particular interest because they appear to be more abundant in the fossil record than initially thought (e.g., (Fedorchuk et al., 2016))

115 and they form essentially by in situ mineral precipitation, like many Archean microbialites (Grotzinger, 1990). By contrast, modern marine microbialite formation involves considerable particle trapping and binding (Awramik and Riding, 1988; Reid et al., 2000). The number of discovered living microbialites in freshwater lakes is continuously increasing, with reports of microbialites displaying different morphologies and microfabrics in more than 50 lakes worldwide. Examples exist in karst areas, such as

120 the Pavilion Lake (Laval et al., 2000), Cuatro Ciénegas (Breitbart et al., 2009) or Ruidera Pools (Santos et al., 2010), but also in volcanic terrains, such as Lake Van in Turkey (Kempe et al., 1991; López-García et al., 2005) or crater lakes (Couradeau et al., 2011; Kazmierczak et al., 2011; Zeyen et al., 2015; Johnson et al., 2018) and lagoons \{Johnson, 2018 \#10319\} in Mexico. Freshwater microbialites form in lakes with very diverse hydrochemistries and usually contain one or several carbonate phases (monohydrocalcite,

125 hydromagnesite, aragonite, calcite, dolomite) (Arp et al., 1999; Kazmierczak et al., 2011; Last et al., 2012) and often, authigenic Mg-silicates (e.g. (Arp et al., 2003; López-García et al., 2005; Souza-Egipsy et al., 2005; Reimer et al., 2009; Zeyen et al., 2015; Gerard et al., 2018; Zeyen et al., 2019)). Some studies have tried to relate microbialite mineralogy and water chemistry in individual lakes (e.g. (Lim et al., 2009; Power et al., 2011)) but comparative analyses including microbial diversity analyses are rare and limited

130 to few systems (Centeno et al., 2012; Valdespino-Castillo et al., 2018), such that inferring possible universal mechanisms derived from the interplay between biotic and abiotic factors is still lacking.

In a recent survey, Zeyen and co-workers (Zeyen et al., 2017) identified the occurrence of microbialites in several crater lakes (maars) from the Trans-Mexican volcanic belt exhibiting contrasted chemical conditions (e.g., $\mathrm{pH}$, alkalinity, $\mathrm{Mg} / \mathrm{Ca}$ ratios, $\left[\mathrm{SO}_{4}{ }^{2-}\right]$ ). The intensity of microbialite formation 135 and their mineralogical composition (Mg-calcite vs aragonite vs monohydrocalcite vs hydromagnesite) 
strongly correlated with lake hydrochemistry (Zeyen et al., 2017). Among these lakes, the most conspicuous microbialites formed in Lake Alchichica, an alkaline $\left(\mathrm{pH}^{\sim 9}\right.$ and $\left.\left[\mathrm{HCO}_{3}^{-}\right]^{\sim 40} \mathrm{mM}\right)$ and relatively $\mathrm{Mg}$-rich $\left(\left[\mathrm{Mg}^{2+}\right] \sim 17 \mathrm{mM}\right)$ crater lake located at high altitude $(2,300 \mathrm{~m}$ above sea level). Lake Alchichica microbialites are dominated by hydromagnesite $\left(\mathrm{Mg}_{5}\left(\mathrm{CO}_{3}\right)_{4}(\mathrm{OH})_{2} .4\left(\mathrm{H}_{2} \mathrm{O}\right)\right)$ and aragonite

$140\left(\mathrm{CaCO}_{3}\right)$ (Kazmierczak et al., 2011; Couradeau et al., 2013), and several studies have focused on the associated microbial communities (Couradeau et al., 2011; Valdespino-Castillo et al., 2018) and their functional potential derived from metagenomic analyses (Saghaï et al., 2016). Here, we characterize the prokaryotic and eukaryotic community composition of microbialites detected in several Trans-Mexican volcanic belt crater lakes following an alkalinity gradient (Zeyen et al., 2017) by massive 16S/18S rRNA gene amplicon sequencing. Comparative analyses reveal the existence of a common core of microbial taxa associated with these microbialites, which might play a determinant role in their formation.

\section{Experimental procedures}

150

\section{Sampling}

Microbialite samples were identified and collected during two field trips (January 2012 and May 2014) from 9 out of 11 visited lakes located in the Trans-Mexican volcanic belt (Fig. 1 and Supporting Information Fig.S1). The physicochemical parameters of lake waters (Supporting Information Table S1) were measured in situ using a multiparameter probe (Multi 350i, WTW). Alkalinity and cation/anion concentrations were analyzed from water samples collected during the 2014 expedition and reported by Zeyen et al. (Zeyen et al., 2017). Parameters for Rincon del Parangueo were obtained from Armienta et al. (Armienta et al., 2008). To limit potential biases linked to microbialite heterogeneity, microbialite fragments were collected in replicates and, for some lakes, at different locations along the shore and/or at different depths or season, with the help of a hammer and sterile chisels/forceps. In total, we collected and analyzed 30 microbialite and mineral-associated biofilm samples (Table 1) as well as two non-calcifying microbial mat samples from Rincon del Parangueo. Sample fragments were fixed in situ with $\mathrm{EtOH}(>80 \% \mathrm{v} / \mathrm{v})$ and subsequently stored at $-20^{\circ} \mathrm{C}$.

\section{DNA purification and amplicon sequencing}

Microbialite fragments were ground using a sterile agate mortar. DNA purification was carried out as previously described (Saghaï et al., 2015), using the Power Biofilm ${ }^{\mathrm{TM}}$ DNA Isolation Kit (MoBio, Carlsbad, CA, USA) with extended incubation in the kit resuspension buffer ( $>2 \mathrm{~h}$ at $4^{\circ} \mathrm{C}$ for rehydration) and beadbeating steps. Archaeal and bacterial 16S rRNA gene fragments ( 290 bp long) covering the V4hypervariable region were amplified using the prokaryote-specific primer set U515F (5'- 
GTGCCAGCMGCCGCGGTAA) and U806R (5'-GGACTACVSGGGTATCTAAT). Eukaryotic 18S rRNA gene fragments ( 600 bp long) also encompassing the V4-hypervariable region were PCR amplified using the primers EK-448F (5'- CTGAYWCAGGGAGGTAGTRA) and 18s-EUK-1134-R_UNonMet (5'TTTAAGTTTCAGCCTTGCG) biased against Metazoa (Bower et al., 2004). Forward and reverse primers

175 were tagged with different 10-bp molecular identifiers (MIDs) to allow pooling and later identification of amplicons from different samples. The $25-\mu \mathrm{l}$ PCR-amplification reaction contained 0.5-3 $\mu$ l of eluted DNA, $1.5 \mathrm{mM} \mathrm{MgCl}, 0.2 \mathrm{mM}$ of deoxynucleotide (dNTP) mix, $0.3 \mu \mathrm{M}$ of each primer and $0.5 \mathrm{U}$ of the hot-start Platinum Taq DNA Polymerase (Invitrogen, Carlsbad, CA). PCR reactions were carried out for 35 cycles $\left(94^{\circ} \mathrm{C}\right.$ for $30 \mathrm{~s}, 55-58^{\circ} \mathrm{C}$ for $30-45 \mathrm{~s}, 72^{\circ} \mathrm{C}$ for $\left.90 \mathrm{~s}\right)$ preceded by 2 min denaturation at $94^{\circ} \mathrm{C}$, and followed by 5 additional minutes of polymerization at $72^{\circ} \mathrm{C}$. To minimize PCR bias, 5 different PCR reactions were pooled for each sample. Amplicons were then purified using the QIAquick PCR purification kit (Qiagen, Hilden, Germany). Amplicons were massively sequenced using Illumina MiSeq (2x300 bp, paired-end) by Eurofins Genomics (Ebersberg, Germany). Sequences have been deposited in GenBank under the BioProject number PRJNA625182. Individual biosample accessions are listed in Supporting Information Table S2.

\section{Sequence analysis}

We obtained 2270503 and 4886605 sequence-reads of 16S and 18S rDNA amplicons, respectively. Raw sequences were processed using an in-house bioinformatic pipeline. High-quality raw 16S rDNA paired-end reads were merged together according to strict criterions using FLASH (Magoc and Salzberg, 2011). Cleaned merged reads with correct MIDs at each extremity were attributed to their original samples and pruned of primer+MID sequences using 'cutadapt' (Martin, 2011). In the case of 18S rDNA sequences, we used high-quality forward reads since, due to the amplicon size, too few read pairs could be assembled reliably. High-quality (merged) reads were dereplicated to retain unique sequences for further analyses while keeping trace of their corresponding amounts using VSEARCH (Rognes et al., 2016). Chimeric high-quality reads were detected de novo with VSEARCH and excluded from further analyses. Non-chimeric (merged) high-quality reads were then pooled together in order to define intersample Operational Taxonomic Units (OTUs) using SWARM (Mahe et al., 2015) and CD-HIT (Fu et al., 2012) at 97 and 98\% sequence identity (Table 1; Supporting Information Table S2). The number of prokaryotic OTUs obtained was of the same order of magnitude for the two approaches. However, CDHIT resulted in an inflation of eukaryotic OTUs as compared with SWARM and previous results based on whole Alchichica microbialite metagenomes (Saghaï et al., 2016). Therefore, we chose SWARM-derived OTUs for subsequent analyses. Singletons (OTUs composed of one sequence) were removed from subsequent analyses. OTUs were phylogenetically classified based on sequence similarity with sequences from cultured/described organisms and environmental surveys retrieved from SILVAv128 for 
prokaryotic and eukaryotic rDNA sequences (Quast et al., 2013) and additionally from PR2v4.5 for eukaryotic rDNA, (Guillou et al., 2013) and stored in a local database. OTUs corresponding to chloroplasts, mitochondria and Metazoa were removed from subsequent analyses. Sequences with low identity values were manually blasted and assigned to their best hit's taxon when they combined coverage and identity values $>80 \%$ and $>85 \%$, respectively. Prokaryotic OTUs (103) whose identity with their best hit ranged between 75 and 85\% were placed in a reference phylogenetic tree and, upon manual inspection to verify their placement within a robust monophyletic group, reassigned accordingly (trees in Newick format are provided as supplementary files). To this end, 16S/18S rDNA reference sequences covering the tree-of-life diversity (Hug et al., 2016) and near-complete OTU best-hit sequences were aligned using MAFFT (Katoh and Standley, 2013); ambiguously aligned sites were removed from the alignment using trimAl (Capella-Gutierrez et al., 2009). The reference phylogenetic tree was then built with IQtree (Nguyen et al., 2015) using the GTR+G+I model of sequence evolution. To align our OTU reads to the reference alignment, we used the --addfragments function of MAFFT (with the highly accurate option L-INS-I). Finally, reads were placed into the reference phylogenetic tree using the alignment files and the reference tree with the EPA-ng tool (Barbera et al., 2019). Genesis library (Czech et al., 2020) was used to create a NEWICK format tree out of the resulting EPA-ng JPLACE-format tree. When the phylogenetic affiliation in the reference tree was not conclusive, the OTUs remained 'uncertain'.

\section{Predictive functional profiling of microbial communities}

Several microbial taxa (down to the family or genus) are systematically associated to particular broad metabolisms and their relative abundance can be therefore used for tentative metabolic prediction \{Langille, 2013 \#10592\} (Martiny et al., 2015). Based on this approach, we established 10 broad metabolic categories readily attributable to specific taxa: oxygenic photosynthesis, anoxygenic photosynthesis (subdivided according to whether it was carried out by green non-sulfur bacteria (GNSB, Chloroflexi), purple sulfur bacteria (PSB, photosynthetic Gammaproteobacteria) or purple non-sulfur bacteria (PNSB, photosynthetic Alphaproteobacteria), sulfate reduction, nitrification, denitrification, hydrogen oxidation, heterotrophy and fermentation. The different OTUs, including relative abundance data, were subsequently distributed in these categories based on the known metabolism of the family or genus it was confidently affiliated to (Supporting Tables S4-S5). Whenever this was not confidently possible they were included in one additional category comprising OTUs of uncertain metabolism.

\section{Statistical analyses}

Statistical analyses were carried out in R (R Development Core Team, 2017). Diversity indexes and nonmetric multidimensional scaling (NMDS) ordination analyses were conducted using the 'Vegan' $\mathrm{R}$ package (Oksanen et al., 2011). Community structures across microbialite samples were compared using 
Bray-Curtis (BC) dissimilarities (Bray and Curtis, 1957) based on Wisconsin-standardized OTU relative frequencies to balance the weight of abundant versus rare OTUs. To test whether microbial diversity was significantly correlated to environmental variables, we carried out a Mantel test (Legendre and Legendre, 1998) between the BC distance matrix and a matrix of Euclidean distances of physicochemical parameters (mineral composition and depth) using the 'Vegan' package. Canonical Correspondence Analyses (CCA) to explore the cross-variance of our datasets were calculated with the 'Ade4' package (Dray and Dufoour, 2007 ). Permutational multivariate analysis of variance (PERMANOVA) (Legendre and Legendre, 1998) tests were also carried out with 'Vegan' to quantify the influence of individual variables on community structure.

\section{Results and discussion}

\section{Microbialites in lakes of the Trans-Mexican volcanic belt}

Microbialites in the alkaline $(\mathrm{pH} \sim 9)$ crater Lake Alchichica are meter-sized and their chemical and mineralogical composition, microbial diversity and metagenome-derived functional potential have been studied for several years (Couradeau et al., 2011; Kazmierczak et al., 2011; Centeno et al., 2012; Couradeau et al., 2013; Gerard et al., 2013; Saghaï et al., 2015; Saghaï et al., 2016; Valdespino-Castillo et al., 2018; Zeyen et al., 2019). However, calcifying microbial communities in other alkaline lakes with comparable hydrochemistry from the same volcanic area (Armienta et al., 2008; Mancilla Villa et al., 2014; Zeyen et al., 2017) remain largely understudied. We carried out two field campaigns to explore and eventually collect microbialites from other lakes in the Trans-Mexican volcanic belt. In total, we visited eleven lakes in the Puebla and Michoacan regions, nine of which harbored calcifying microbial structures (Fig.1; Supporting Information Fig.S1 and Table S1). Based on their hydrochemistry, these lakes locate along an alkalinity gradient (Zeyen et al., 2017) (Fig.1), with more developed microbialites in lakes showing a higher alkalinity (e.g. Alchichica, Atexcac). Lower alkalinity systems, such as La Alberca de Michoacan, harbored calcifying biofilms growing on basalt rocks. Neither Lake Zirahuen, with the lowest alkalinity value, nor Rincon del Parangueo, an almost completely evaporated lake with residual hypersaline ponds (conductivity $165 \mathrm{mS} / \mathrm{cm}$; Table S1), harbored actively growing calcifying communities (Rincon del Parangueo exhibited subfossil, dried microbialites) (Supporting Information

270 Fig.S1 and Table S1). We analyzed samples of floating, non-calcifying halophilic microbial mats from Rincon del Parangueo, as well as 30 microbialite samples from microbialite-containing lakes. These samples included replicates and, in some cases, were collected at different depths and location along the shore (Table 1). This allowed comparing microbial community composition across lakes with different hydrochemistries and studying the abiotic factors determining it. 


\section{Overall microbialite community structures}

After DNA purification from microbialite samples, we amplified and high-throughput-sequenced $16 \mathrm{~S}$ and $18 \mathrm{~S}$ rRNA gene amplicons. High-quality sequences were used to define operational taxonomic units (OTUs), with a total of 17559 prokaryotic OTUs (766 archaeal, 16793 bacterial) and 3769 eukaryotic OTUs, excluding singletons (Table 1; Supporting Information Tables S2,S4-S5). The diversity of microbialite communities was high and even, as reflected by indices of richness (chao1 and ACE), diversity (Shannon and Simpson) and evenness (Pielou) (Supporting Information Table S3). For both, prokaryotes and eukaryotes, the relative proportions of OTUs belonging to high-rank taxa were more similar than the relative abundance of reads (Fig.2). This likely reflects the high heterogeneity of these structures with local abundance (but not OTU diversity) changing at local spatial scale. Nonetheless, in general, replicate samples exhibited consistent profiles reflecting similar trends in terms of community structure.

We identified OTUs belonging up to 112 different prokaryotic phyla or equivalent high-rank taxa, most of them bacterial. Four major groups dominated, albeit in different proportions, three of which

290 include photosynthetic members: Cyanobacteria, Alphaproteobacteria, Chloroflexi and Planctomycetes. Altogether, they averaged $66 \pm 16 \%$ of total reads, with a maximum of $88 \%$ at Alberca de los Espinos. However, in some microbialites other groups were also relatively abundant (up to ca. 15-25\%), such as Gammaproteobacteria in Tecuitlapa, Deltaproteobacteria in La Preciosa and Actinobacteria in La Alberca de Michoacan (Fig.2A). Cyanobacteria were, on average, the most represented group, especially 295 in lakes Alchichica and Atexcac, often comprising more than 50\% of the reads. We identified 712 cyanobacterial OTUs mostly belonging to the Oscillatoriales and diverse lineages in the polyphyletic order Synechococcales (notably Leptolyngbya) (Supporting Information Fig.S2A and Table S3). Pleurocapsales were present, but were not the most abundant cyanobacterial group in the collected surface microbialites. This agreed with previous observations in Alchichica showing that members of 300 this group increased in abundance at higher lake depth (Couradeau et al., 2011; Saghaï et al., 2015). Alphaproteobacteria were highly diverse and included an important proportion (often $>50 \%$ ) of likely photosynthetic Rhodobacterales and Rhodospirillales (Supporting Information Fig.S2B). In addition, many other bacterial lineages appeared in smaller amounts, including anoxygenic photosynthetic Chlorobi and various typically heterotrophic taxa (Supporting Information Fig.S3A). Archaea were 305 detected only in very minor proportions (generally $<1$ to $5 \%$ ), in agreement with previous observations (Saghaï et al., 2015; Saghaï et al., 2016). However, in a few replicate samples (Alberca de los Espinos, Patzcuaro) they represented up to $\sim 10 \%$. Diverse Euryarchaeota (including several methanogenic lineages), Thaumarchaeota and Woesearchaeota were the most abundant archaea (Supporting Information Fig.S3B). 
Microbial eukaryotes (metazoan sequences were excluded from the analysis) were also very diverse, although they represent a minor fraction (ca. 5-10\%) of the bacteria-dominated microbialite communities, as shown by metagenomic studies in Alchichica (Saghaï et al., 2015; Saghaï et al., 2016), (Fig.2C-D; Supporting Information Fig.S4). Photosynthetic lineages dominated (>50\%) both in terms of OTU diversity and, especially, relative sequence read abundance in most microbialites. Chlorophyta 315 (Archaeplastida) and Ochrophyta (Stramenopila, mostly diatoms) were highly represented. Dinoflagellates, haptophytes and euglenozoans were also present. Only in the case of Alberca de Michoacan, the relative amount of reads in the two replicates suggested a higher dominance of heterotrophic eukaryotes, consistent with a high grazing activity and the presence of relatively thin calcifying biofilms (Supporting Information Fig.S1H). Ciliates were the most abundant grazers (although their diversity and abundance were likely inflated by the presence of intraspecific variation and multiple gene copies (Wang et al., 2017), followed by cercozoans and heterotrophic stramenopiles, depending on samples. Together with ciliates, fungi were the most abundant eukaryotic heterotrophs (Fig.2). The observed eukaryotic diversity needs to be interpreted with caution due to potential intra-species or intracellular 185 rRNA gene variation (Weisse, 2002; Decelle et al., 2014).

The overall observed community composition across microbialite samples is consistent with that observed by previous studies of Lake Alchichica microbialites (Saghaï et al., 2015; Saghaï et al., 2016). At the level of high-rank taxa, the high relative abundance of Cyanobacteria and Alphaproteobacteria within bacteria, green algae and diatoms within eukaryotes and the minor presence of archaea are general trends observed in marine and other lacustrine microbialites (López-García et al., 2005; 330 Papineau et al., 2005; Havemann and Foster, 2008; Foster and Green, 2011; Centeno et al., 2012) but also in many non-lithifying microbial mats (Harris et al., 2013; Wong et al., 2016; Gutierrez-Preciado et al., 2018). In the non-calcifying mats sampled in the terminal desiccating system of Rincon del Parangueo, although Cyanobacteria were the most abundant bacterial group, Firmicutes and Deinococcus-Thermus were also very abundant, together with Bacteroidetes and

335 Gammaproteobacteria (Supporting Information Fig.S5). Since the diversity of these non-calcifying mats was significantly different from that of microbialites in other Trans-Mexican crater lakes, these samples were excluded from subsequent comparisons.

\section{Comparison of microbialite community structures across lakes and influence of abiotic parameters}

340 To evaluate the degree of similarity of microbial communities associated with the different Mexican microbialites, we built a correlation matrix using Bray-Curtis (BC) distances taking into account OTU presence/absence and frequency (Supporting Information Fig.S6). We then applied ordination methods based on these BC distances, such as NMDS and hierarchical cluster analysis (HCA). NMDS showed most microbialite samples scattered between the two main axes, although there is a clear trend distributing 
345 lake samples according to their relative alkalinity along axis 1 (Fig.3; Supporting Information Fig.S7). Notably, all Alchichica and Atexcac samples were situated on the left of axis 1, with two Atexcac samples tightly clustered with Alchichica microbialites (Fig.3A). This trend was equally observed in the cluster analysis. Replicate samples always clustered together (Fig.3B). PERMANOVA tests showed that differences between microbialites from different lakes were significant ( $p$-value $<0.001, R^{2}=0.8499$ ). Differences between microbialites of the various lakes were associated with differences in their prokaryotic communities. Indeed, HCA and NMDS excluding eukaryotic taxa from the test resulted in almost the same ordination and clustering pattern. By contrast, ordination analysis of eukaryotic OTUs produced mixed patterns instead (Supporting Information Fig.S8). This likely reflects the more random capture of grazing protists in the different samples, which superposes to that of the integral members of the microbialite biofilms (e.g. green algae, diatoms).

A Mantel test showed a significant correlation between the physicochemical parameters and the prokaryotic community structure matrices $(p$-value $=0.006)$. Canonical Correspondence Analyses $(C C A)$ further revealed the influence of different physicochemical parameters on the microbialite community structure across the different lakes. The correlations observed were mostly driven by the response of prokaryotic communities, as shown by CCA including or excluding the eukaryotic component and taking into account all the measured abiotic parameters (Supporting Information Fig.S9). Among the measured physicochemical parameters of the lakes, $\mathrm{pH}$, conductivity, alkalinity (i.e. $\left[\mathrm{HCO}_{3}^{-}\right]$), $\left[\mathrm{Ca}^{2+}\right]$ and the $\left[\mathrm{Mg}^{2+}\right] /\left[\mathrm{Ca}^{2+}\right]$ ratio appeared the most relevant, explaining up to $22.7 \%$ of the variance (Fig.4). The microbial community composition in Alchichica and Atexcac microbialites was most influenced by high conductivities and alkalinities. The difference in microbial community structure of Alberca de los Espinos and Patzcuaro microbialites compared with other microbialites correlated with $\left[\mathrm{Ca}^{2+}\right]$, while the structures of the microbialite communities in Alberca de Michoacan correlated with $\mathrm{pH}$.

\section{Taxon-based metabolic profiling of microbialite communities}

Some microbial metabolisms, notably photosynthesis and sulfate reduction, can promote carbonate precipitation, based on the general consideration that they usually consume protons (Dupraz et al., 2009) as well as observations in the field (Visscher et al., 2000; Couradeau et al., 2013; Gerard et al., 2013; Pace et al., 2016). These metabolisms, unlike others, can be phylogenetically associated with

375 specific microbial taxa (Martiny et al., 2015). Recent studies showed a strong correlation between the phylogenetic composition of microbial communities and their predicted metabolic activities (Morrissey et al., 2019). These predictions of broad metabolic classes (photosynthesis, sulfate reduction, heterotrophy) are consistent with predictions made from protein-coding genes in previous metagenomic analyses of Alchichica microbialites (Saghaï et al., 2015; Saghaï et al., 2016). Therefore, 
taxon-based metabolic profiling provides a reasonable working hypothesis about dominant metabolisms, which should be further validated by metagenomic and/or metatranscriptomic analyses. As shown in Fig.5A, potential carbonatogenic metabolisms (essentially photosynthesis and sulfate reduction in our microbialites) were clearly dominant ( $>50 \%$ reads and up to $~ 70 \%)$ in several lakes, including Atexcac and Alchichica, harboring the most apparent microbialites, but also Quechulac and 385 Alberca de los Espinos. Microbialites from Alberca de Michoacan, Aljojuca and La Preciosa harbored between $40-50 \%$ of prokaryotes carrying out typical carbonatogenic metabolisms, whereas Patzcuaro showed the lowest values (25\%). These are minimal values, since part of the organisms within the "uncertain" category might also promote carbonate precipitation. Also, although eukaryotes represent relatively minor proportions (5-10\%) of the total community, at least in Alchichica microbialites (Saghaï et al., 2015), photosynthetic eukaryotes may also contribute to it. At the same time, these values only correspond to metabolic potential and need to be taken as cautionary proxies for carbonatogenesis for two reasons. First, not all the organisms carrying out one of those metabolic activities do actually promote carbonate precipitation in situ (for instance, some cyanobacterial borers dissolve rather than trigger carbonate precipitation). Second, these values correspond to the relative abundance of OTU sequence reads (as a proxy for organisms) and not to direct activity. Although in principle dominant community members are likely active in the community, the intensity of these activities may vary and, therefore, transcriptomic or direct metabolic measurements will be needed to validate or refine their actual contribution to these different metabolisms.

It is interesting to note that anoxygenic photosynthesis was well represented in all the observed microbialites, with photosynthetic Chloroflexi and Alphaproteobacteria members appearing as dominant players, except in Tecuitlapa, a more eutrophic, less oxygenated lake, where photosynthetic gammaproteobacteria (Chromatiaceae) slightly dominated over photosynthetic alphaproteobacteria. Actually, the relative contribution of anoxygenic over oxygenic photosynthesis seemed more important in some systems (Quechulac, La Preciosa, Tecuitlapa). Overall, our observations in Transmexican belt volcanic lake microbialites confirm and extend previous studies suggesting an important potential contribution of anoxygenic photosynthesis to microbialite formation (Ionescu et al., 2014; Saghaï et al., 2015; Gerard et al., 2018).

Based on BC distances calculated on metabolic profiles, microbialite samples appeared interspersed in NMDS analysis (Fig.5B). In agreement, differences in the metabolic potential profiles 410 between lakes were not significant according to pairwise PERMANOVA tests (Supporting Information Table S6). The same trend was observed when microbialites were grouped in categories according to their massiveness (well developed -Alchichica and Atexcac-, medium-to-modest structures -Alberca de Ios Espinos, La Preciosa, Aljojuca, Quechulac, Patzcuaro and Tecuitlapa-, and thin calcifying biofilms Alberca de Michoacan-)(Supporting Information Table S7). These observations suggest a stability of 
415 broad metabolic functions expressed at the microbialite ecosystem level, despite variations of microbialite communities between the different crater lakes (Fig.3). Similar trends have been observed in other types of settings (Louca et al., 2016). Our metabolic profile results complement others obtained in marine systems and collectively highlight the importance of community metabolisms in interplay with local conditions for microbialite formation (Casaburi et al., 2016; Ruvindy et al., 2016). In addition, the influence of photosynthesis (both oxygenic and anoxygenic) or sulfate reduction (especially at Tecuitlapa, La Preciosa and Aljojuca) is consistent with isotopic signatures detected in modern microbialites \{Chagas, 2016 \#8393\}\{Louyakis, 2017 \#9618\}\{Foster, 2020 \#10593\} from different locations.

\section{Shared microbial core across lake microbialites}

Although the microbialite-associated prokaryotic and eukaryotic communities were different among lakes (Figs.2-4), we asked whether a conserved microbial core existed across these calcifying communities as this core might play a relevant role in microbialite formation. To limit biases due to local heterogeneity, we compared the collection of microbialite-associated OTUs collectively identified in each lake (only 10 OTUs were actually shared by the 30 samples considered independently). We detected a 'restricted core' of 106 microbialite-associated OTUs shared by the nine lakes (24 prokaryotic, 82 eukaryotic; Fig.6). We then slightly relaxed our criteria and search for OTUs shared by microbialites from eight out of the nine sampled lakes. This defined an 'extended core' comprising 247 OTUs (91 prokaryotes, 156 eukaryotes; Fig.6). The prokaryotic extended core included 17 cyanobacterial

435 OTUs (7 Leptolyngbya-related, 2 Synechococcus-like, 1 member of Pleurocapsales) and 13 alphaproteobacterial OTUs (with at least 6 OTUs from families of anoxygenic photosynthesizers), among others, including one methanogenic archaeon (Supporting Information Table S8). In total, 23 OTUs corresponded to prokaryotes carrying out potentially carbonatogenic metabolisms (essentially oxygenic and anoxygenic photosynthesis). Interestingly, OTUs belonging to the prokaryotic core represented up to $\sim 40 \%$ in relative abundance of the total microbialite community in lakes Alchichica and Atexcac, where the most massive structures are found (Fig.6A). These values fell to 20-25\% for Tecuitlapa, La Preciosa, Alberca de los Espinos and Alberca de Michoacan and 15\% or less in Aljojuca, Quechulac and Patzcuaro. This suggests that those OTUs represent community members associated with actively growing microbialites. Some of them might actually trigger carbonatogenesis via their metabolic

445 activities, notably the photosynthetic members, but other core OTUs, such as those of Planctomycetes or Bacteroidetes, might simply be specifically associated with the core photosynthetic OTUs as degraders of exopolymeric substances.

The extended eukaryotic core included 82 OTUs of photosynthetic members, mostly diatoms and green algae, but also a few representatives of other groups (stramenopiles, dinoflagellates, haptophytes 
and cryptophytes; Supporting Information Table S9). The rest of eukaryotic OTUs corresponded to some fungi and to typical grazers that are not strictly associated with the microbialites but might be common predators on biofilm surfaces in the different crater lakes. The shared eukaryotic OTUs represented a high proportion of the total eukaryotic community ( $>60$ and up to $~ 90 \%$ reads; Fig.6B). However, eukaryotes are likely minor components $(<5-10 \%)$ in the total community as suggested by metagenomic studies in Alchichica microbialites (Saghaï et al., 2015; Saghaï et al., 2016). In addition, the relatively high diversity of core eukaryotic OTUs associated with microbialites might be inflated due to 18S rDNA intraspecific (Weisse, 2002) and/or intracellular variation (Decelle et al., 2014) and the higher number of eukaryotic sequences analyzed.

The occurrence of a distinct microbial core in microbialites as compared to plankton has been previously noted in some freshwater systems (White et al., 2016). However, to our knowledge, this is the first time that a core of prokaryotic and eukaryotic OTUs is detected in microbialites from lakes of varying physicochemistries using the same criteria across samples treated in the same way, thus minimizing confounding factors. Therefore, the identified microbial core across freshwater microbialites is ecologically relevant and corresponds to microorganisms that are intimately associated with calcifying mats, some of which likely trigger carbonatogenesis (e.g. photosynthesizers), and others specifically depending on them (EPS-degraders, calcifying biofilm grazers). A similar approach has been applied to the study of coral microbiomes to identify important microbial components in coral holobionts, also including potentially carbonatogenic members (karHernandez-Agreda et al., 2017).

\section{$470 \quad$ Concluding remarks}

Microbialite formation results from the fine-tuned interplay of biotic and abiotic factors. To better understand and constrain those factors, we have analyzed the composition of both, prokaryotic and eukaryotic communities associated with microbialites sampled in a series of crater lakes from the TransMexican volcanic belt that follow an alkalinity gradient. We identify a clear correlation between the

475 composition of calcifying communities and lake alkalinity, accompanying the observation that more massive structures actively form in high-alkalinity lakes Alchichica and Atexcac (Figs.1 and 3). Although the microbial communities differ across lake microbialites, there are conserved trends. These include the high relative abundance of Cyanobacteria and their typical EPS-degrading associated taxa (Bacteroidetes, Planctomycetes) and that of anoxygenic photosynthetic bacteria, notably Chloroflexi 480 and some Alphaproteobacteria (Rhodobacterales, Rhodospirillales), but also some Gammaproteobacteria (Chromatiaceae) and minor proportions of Chlorobi. Green algae and diatoms, together with ciliate and cercozoan grazers are the most relatively abundant eukaryotes. Based on the metabolic potential of the dominant microbial taxa, it clearly appears that both, oxygenic and anoxygenic photosynthesis are important players in carbonatogenesis, with minor contributions from 
sulfate reduction (Fig.5). However, although the photosynthesis-related carbonatogenic metabolic potential appears higher in the most conspicuous microbialites (Alchichica, Atexcac), it is also the case in other, less massive calcifying structures. This suggests that local physicochemical conditions play a crucial role and that the specific components of the microbial community contribute differently to carbonatogenesis, either due to different phylogenetic components and/or to different expression levels. Transcriptomic and/or functional analyses in situ should help to better constrain these contributions (Mobberley et al., 2015). Despite these differences, we identified a shared conserved core of prokaryotic and eukaryotic OTUs across lake microbialites. Interestingly, this microbial core represents a higher relative abundance (up to $40 \%$ of the total community) in lakes with more conspicuous microbialites (Fig.6). This advocates for a relevant, if not causal, role of these microorganisms in microbialite formation.

The identification of microbialite communities that actively favor carbonate precipitation under certain abiotic conditions has potential applied implications in the context of global climate change. Capture and storage of carbon is a serious option to mitigate the effects of atmospheric greenhouse gas emission and climate change. While some vegetated ecosystems are active carbon sinks (Blue Carbon ecosystems), the contribution of microbial communities is not yet well constrained (Macreadie et al., 2019). The ability of microbialite communities to fix $\mathrm{CO}_{2}$ as biomass and, especially, carbonates makes them interesting as potential sequestration systems. The biomineralization of calcium carbonates by bacteria has long been used for the remediation of concrete and damaged heritage buildings (Dhami et al., 2013; Seifan and Berenjian, 2019) and some tests using cyanobacterial mats favoring hydromagnesite precipitation have been carried out in laboratory (McCutcheon et al., 2014). Our study suggests that microbial consortia similar to the microbial core community identified in Mexican microbialites may be used for carbon sequestration following a more biomimetic approach than the use of axenic strains. For that purpose, future studies should identify which of the two strategies, axenic culture versus consortium-based, are the most efficient in carbon sequestration.

Acknowledgments We thank Anabel Lopez-Archilla, Nina Zeyen and Eleonor Cortes for help and discussions during the 2014 field trip. This research was funded by the European Research Council Grants ProtistWorld (322669, PL-G) and PlastEvol (787904, DM) and the French ANR project Microbialites (ANR-18-CE02-0013-01; PL-G/KB).

Conflict of interest The authors declare that they have no conflicts of interest.

\section{References}


Allwood, A.C., Walter, M.R., Kamber, B.S., Marshall, C.P., and Burch, I.W. (2006) Stromatolite reef from the Early Archaean era of Australia. Nature 441: 714-718.

Allwood, A.C., Grotzinger, J.P., Knoll, A.H., Burch, I.W., Anderson, M.S., Coleman, M.L., and Kanik, I. (2009) Controls on development and diversity of Early Archean stromatolites. Proc Natl Acad Sci U S A 106: 9548-9555.

Altermann, W. (2004) Precambrian stromatolites: problems in definition, classification, morphology and stratigraphy. In The Precambrian Earth: Tempos and Events. Eriksson, P.G., Altermann, W., Nelson, D.R., Mueller, W.U., and Catuneanu, O. (eds). Amsterdam: Elsevier, pp. 564-574.

Armienta, M.A., Vilaclara, G., De la Cruz-Reyna, S., Ramos, S., Ceniceros, N., Cruz, O. et al. (2008) Water chemistry of lakes related to active and inactive Mexican volcanoes. Journal of Volcanology and Geothermal Research 178: 249-258.

530 Arp, G., Reimer, A., and Reitner, J. (1999) Calcification in cyanobacterial biofilms of alkaline salt lakes. Eur J Phycol 34: 393 - 403.

Arp, G., Reimer, A., and Reitner, J. (2003) Microbialite formation in seawater of increased alkalinity, Satonda crater lake, Indonesia. Journal of Sedimentary Research 73: 105-127.

535 (eds). Oxford: Blackwell Scientific Publications, pp. 336-341.

Awramik, S.M., and Riding, R. (1988) Role of algal eukaryotes in subtidal columnar stromatolite formation. Proc Natl Acad Sci U S A 85: 1327-1329.

Barbera, P., Kozlov, A.M., Czech, L., Morel, B., Darriba, D., Flouri, T., and Stamatakis, A. (2019) EPA-ng: Massively parallel evolutionary placement of genetic sequences. Syst Biol 68: 365-369.

540 Benzerara, K., Menguy, N., Lopez-Garcia, P., Yoon, T.H., Kazmierczak, J., Tyliszczak, T. et al. (2006) Nanoscale detection of organic signatures in carbonate microbialites. Proc Natl Acad Sci U S A 103: 9440-9445.

Bower, S.M., Carnegie, R.B., Goh, B., Jones, S.R., Lowe, G.J., and Mak, M.W. (2004) Preferential PCR amplification of parasitic protistan small subunit rDNA from metazoan tissues. J Eukaryot Microbiol

\section{$545 \quad$ 51: 325-332.}

Bray, J.R., and Curtis, J.T. (1957) An ordination of the upland forest communities of Southern Wisconsin. Ecological Monographs 27: 325-349.

Breitbart, M., Hoare, A., Nitti, A., Siefert, J., Haynes, M., Dinsdale, E. et al. (2009) Metagenomic and stable isotopic analyses of modern freshwater microbialites in Cuatro Cienegas, Mexico. Environ

\section{$550 \quad$ Microbiol 11: 16-34}

Bundeleva, I.A., Shirokova, L.S., Benezeth, P., Pokrovsky, O.S., Kompantseva, E.I., and Balor, S. (2012) Calcium carbonate precipitation by anoxygenic phototrophic bacteria. Chemical Geology 291: 116131.

Cam, N., Benzerara, K., Georgelin, T., Jaber, M., Lambert, J.F., Poinsot, M. et al. (2018) Cyanobacterial formation of intracellular Ca-carbonates in undersaturated solutions. Geobiology 16: 49-61.

Capella-Gutierrez, S., Silla-Martinez, J.M., and Gabaldon, T. (2009) trimAl: a tool for automated alignment trimming in large-scale phylogenetic analyses. Bioinformatics 25: 1972-1973.

Casaburi, G., Duscher, A.A., Reid, R.P., and Foster, J.S. (2016) Characterization of the stromatolite microbiome from Little Darby Island, The Bahamas using predictive and whole shotgun metagenomic $560 \quad$ analysis. Environ Microbiol 18: 1452-1469.

Centeno, C.M., Legendre, P., Beltran, Y., Alcantara-Hernandez, R.J., Lidstrom, U.E., Ashby, M.N., and Falcon, L.I. (2012) Microbialite genetic diversity and composition relate to environmental variables. FEMS Microbiol Ecol 82: 724-735.

Couradeau, E., Benzerara, K., Moreira, D., Gerard, E., Kazmierczak, J., Tavera, R., and Lopez-Garcia, P. 565 (2011) Prokaryotic and eukaryotic community structure in field and cultured microbialites from the alkaline Lake Alchichica (Mexico). PLoS ONE 6: e28767.

Couradeau, E., Benzerara, K., Gérard, E., Estève, I., Moreira, D., Tavera, R., and López-García, P. (2013) In situ microscale cyanobacterial calcification in modern microbialites. Biogeosciences 10: 52555266. 
Czech, L., Barbera, P., and Stamatakis, A. (2020) Genesis and Gappa: processing, analyzing and visualizing phylogenetic (placement) data. Bioinformatics.

Decelle, J., Romac, S., Sasaki, E., Not, F., and Mahe, F. (2014) Intracellular diversity of the V4 and V9 regions of the $18 \mathrm{~S}$ rRNA in marine protists (radiolarians) assessed by high-throughput sequencing. PLoS One 9: e104297.

575 Dhami, N.K., Reddy, M.S., and Mukherjee, A. (2013) Biomineralization of calcium carbonates and their engineered applications: a review. Front Microbiol 4: 314.

Dravis, J.J. (1983) Hardened subtidal stromatolites, Bahamas. Science 219: 385-386.

Dray, S., and Dufoour, A.B. (2007) The ade4 Package : Implementing the duality diagram for ecologists. Journal of Statistical Software 22-4.

Dupraz, C., and Visscher, P.T. (2005) Microbial lithification in marine stromatolites and hypersaline mats. Trends Microbio/ 13: 429-438.

Dupraz, C., Reid, R.P., Braissant, O., Decho, A.W., Norman, R.S., and Visscher, P.T. (2009) Processes of carbonate precipitation in modern microbial mats. Earth-Science Reviews 96: 141-162.

Farias, M.E., Contreras, M., Rasuk, M.C., Kurth, D., Flores, M.R., Poire, D.G. et al. (2014) Characterization of bacterial diversity associated with microbial mats, gypsum evaporites and carbonate microbialites in thalassic wetlands: Tebenquiche and La Brava, Salar de Atacama, Chile. Extremophiles 18: 311329.

Farias, M.E., Rascovan, N., Toneatti, D.M., Albarracin, V.H., Flores, M.R., Poire, D.G. et al. (2013) The discovery of stromatolites developing at $3570 \mathrm{~m}$ above sea level in a high-altitude volcanic lake Socompa, Argentinean Andes. PLoS One 8: e53497.

Fedorchuk, N.D., Dornbos, S.Q., Corsetti, F.A., Isbell, J.L., Petryshyn, V.A., Bowles, J.A., and Wilmeth, D.T. (2016) Early non-marine life: Evaluating the biogenicity of Mesoproterozoic fluvial-lacustrine stromatolites. Precambrian Research 275: 105-118.

Foster, J.S., and Green, S.J. (2011) Microbial diversity in modern stromatolites. In Stromatolites: Interaction of microbes with sediments. Tewari, V.C., and Seckbach, J. (eds): Springer Science \& Business Media, pp. 383-405.

Fu, L., Niu, B., Zhu, Z., Wu, S., and Li, W. (2012) CD-HIT: accelerated for clustering the next-generation sequencing data. Bioinformatics 28: 3150-3152.

Gallagher, K.L., Kading, T.J., Braissant, O., Dupraz, C., and Visscher, P.T. (2012) Inside the alkalinity engine: the role of electron donors in the organomineralization potential of sulfate-reducing bacteria. Geobiology 10: 518-530.

Gerard, E., Menez, B., Couradeau, E., Moreira, D., Benzerara, K., Tavera, R., and Lopez-Garcia, P. (2013) Specific carbonate-microbe interactions in the modern microbialites of Lake Alchichica (Mexico). ISME J 7: 1997-2009.

605 Gerard, E., De Goeyse, S., Hugoni, M., Agogue, H., Richard, L., Milesi, V. et al. (2018) Key role of Alphaproteobacteria and Cyanobacteria in the formation of stromatolites of Lake Dziani Dzaha (Mayotte, Western Indian Ocean). Front Microbio/ 9: 796.

Grotzinger, J.P. (1990) Geochemical model for Proterozoic stromatolite decline. Amer J Sci 290-A: 80103.

610 Guida, B.S., and Garcia-Pichel, F. (2016) Extreme cellular adaptations and cell differentiation required by a cyanobacterium for carbonate excavation. Proceedings of the National Academy of Sciences of the United States of America 113: 5712-5717.

Guillou, L., Bachar, D., Audic, S., Bass, D., Berney, C., Bittner, L. et al. (2013) The Protist Ribosomal Reference database (PR2): a catalog of unicellular eukaryote Small Sub-Unit rRNA sequences with 615 curated taxonomy. Nucleic Acids Res 41: D597-D604.

Gutierrez-Preciado, A., Saghai, A., Moreira, D., Zivanovic, Y., Deschamps, P., and Lopez-Garcia, P. (2018) Functional shifts in microbial mats recapitulate early Earth metabolic transitions. Nat Ecol Evol 2: 1700-1708.

620 stratigraphy in the Guerrero Negro hypersaline microbial mat. ISME J 7: 50-60. 
Havemann, S.A., and Foster, J.S. (2008) Comparative characterization of the microbial diversities of an artificial microbialite model and a natural stromatolite. Appl Environ Microbiol 74: 7410-7421.

Himmler, T., Smrzka, D., Zwicker, J., Kasten, S., Shapiro, R.S., Bohrmann, G., and Peckmann, J. (2018) Stromatolites below the photic zone in the northern Arabian Sea formed by calcifying chemotrophic microbial mats. Geology 46: 339-342.

Hug, L.A., Baker, B.J., Anantharaman, K., Brown, C.T., Probst, A.J., Castelle, C.J. et al. (2016) A new view of the tree of life. Nat Microbiol 1: 16048.

Ionescu, D., Spitzer, S., Reimer, A., Schneider, D., Daniel, R., Reitner, J. et al. (2014) Calcium dynamics in microbialite-forming exopolymer-rich mats on the atoll of Kiritimati, Republic of Kiribati, Central Pacific. Geobiology doi: 10.1111/gbi.12120. [Epub ahead of print].

Johnson, D.B., Beddows, P.A., Flynn, T.M., and Osburn, M.R. (2018) Microbial diversity and biomarker analysis of modern freshwater microbialites from Laguna Bacalar, Mexico. Geobiology 16: 319-337.

karHernandez-Agreda, A., Gates, R.D., and Ainsworth, T.D. (2017) Defining the core microbiome in corals' microbial soup. Trends Microbiol 25: 125-140.

635 Katoh, K., and Standley, D.M. (2013) MAFFT multiple sequence alignment software version 7: improvements in performance and usability. Mol Biol Evol 30: 772-780.

Kazmierczak, J., Kempe, S., Kremer, B., López-García, P., Moreira, D., and Tavera, R. (2011) Hydrochemistry and microbialites of the alkaline crater lake Alchichica, Mexico. Facies 57: 543-570.

Kempe, S., Kazmierczak, J., Landmann, G., Konuk, T., Reimer, A., and Lipp, A. (1991) Largest known microbialites discovered in Lake Van, Turkey. Nature 349: 605-608.

Last, F.M., Last, W.M., and Halden, N.M. (2012) Modern and late Holocene dolomite formation: Manito Lake, Saskatchewan, Canada. Sedimentary Geology 281: 222-237.

Laval, B., Cady, S.L., Pollack, J.C., McKay, C.P., Bird, J.S., Grotzinger, J.P. et al. (2000) Modern freshwater microbialite analogues for ancient dendritic reef structures. Nature 407: 626-629.

645 Legendre, P., and Legendre, L. (1998) Numerical ecology. Amsterdam: Elsevier Science BV.

Lim, D.S.S., Laval, B.E., Slater, G., Antoniades, D., Forrest, A.L., Pike, W. et al. (2009) Limnology of Pavilion Lake, B. C., Canada - Characterization of a microbialite forming environment. Fundamental and Applied Limnology 173: 329-351.

Logan, B.W. (1961) Cryptozoon and associated stromatolites from the Recent, Shark Bay, Western Australia. J Geol 69: 517-533.

López-García, P., Kazmierczak, J., Benzerara, K., Kempe, S., Guyot, F., and Moreira, D. (2005) Bacterial diversity and carbonate precipitation in the giant microbialites from the highly alkaline Lake Van, Turkey. Extremophiles 9: 263-274.

Louca, S., Jacques, S.M.S., Pires, A.P.F., Leal, J.S., Srivastava, D.S., Parfrey, L.W. et al. (2016) High

655 taxonomic variability despite stable functional structure across microbial communities. Nat Ecol Evol 1: 15.

Macreadie, P.I., Anton, A., Raven, J.A., Beaumont, N., Connolly, R.M., Friess, D.A. et al. (2019) The future of Blue Carbon science. Nat Commun 10: 3998.

Magoc, T., and Salzberg, S.L. (2011) FLASH: fast length adjustment of short reads to improve genome assemblies. Bioinformatics 27: 2957-2963.

Mahe, F., Rognes, T., Quince, C., de Vargas, C., and Dunthorn, M. (2015) Swarm v2: highly-scalable and high-resolution amplicon clustering. PeerJ 3: e1420.

Mancilla Villa, O.R., Bautista Olivas, A.L., Ortega Escobar, H.M., Sánchez Bernal, E.I., Can Chulim, Á., Guevara Gutiérrez, R.D., and Ortega Mikolaev, Y.M. (2014) Hidrogeoquímica de salinas Zapotitlán y

665 los lagos-cráter Alchichica y Atexcac, Puebla and Atexcac, Puebla. Idesia (Arica) 32: 55-69.

Martin, M. (2011) Cutadapt removes adapter sequences from high-throughput sequencing reads. EMBnetJournal 17: 10-12.

Martiny, J.B., Jones, S.E., Lennon, J.T., and Martiny, A.C. (2015) Microbiomes in light of traits: A phylogenetic perspective. Science 350: aac9323.

670 McCutcheon, J., Power, I.M., Harrison, A.L., Dipple, G.M., and Southam, G. (2014) A greenhouse-scale photosynthetic microbial bioreactor for carbon sequestration in magnesium carbonate minerals. Environ Sci Technol 48: 9142-9151. 
Michaelis, W., Seifert, R., Nauhaus, K., Treude, T., Thiel, V., Blumenberg, M. et al. (2002) Microbial reefs in the Black Sea fueled by anaerobic oxidation of methane. Science 297: 1013-1015.

675 Mobberley, J.M., Ortega, M.C., and Foster, J.S. (2012) Comparative microbial diversity analyses of modern marine thrombolitic mats by barcoded pyrosequencing. Environ Microbiol 14: 82-100.

Mobberley, J.M., Khodadad, C.L., Visscher, P.T., Reid, R.P., Hagan, P., and Foster, J.S. (2015) Inner workings of thrombolites: spatial gradients of metabolic activity as revealed by metatranscriptome profiling. Sci Rep 5: 12601.

680 Morrissey, E.M., Mau, R.L., Hayer, M., Liu, X.A., Schwartz, E., Dijkstra, P. et al. (2019) Evolutionary history constrains microbial traits across environmental variation. Nat Ecol Evol 3: 1064-1069.

Nguyen, L.T., Schmidt, H.A., von Haeseler, A., and Minh, B.Q. (2015) IQ-TREE: a fast and effective stochastic algorithm for estimating maximum-likelihood phylogenies. Mol Biol Evol 32: 268-274.

Obst, M., Dynes, J.J., Lawrence, J.R., Swerhone, G.D.W., Benzerara, K., Karunakaran, C. et al. (2009) Precipitation of amorphous $\mathrm{CaCO} 3$ (aragonite-like) by cyanobacteria: A STXM study of the influence of EPS on the nucleation process. Geochimica Et Cosmochimica Acta 73: 4180-4198.

Oksanen, J., Blanchet, G., Kindt, R., Legendre, P., O'Hara, R.B., Simpson, G.L. et al. (2011) Vegan: Community Ecology Package. $R$ package version 1.17-9. In. http://CRAN.Rproject.org/package=vegan (ed): http://CRAN.R-project.org/package=vegan .

690 Pace, A., Bourillot, R., Bouton, A., Vennin, E., Galaup, S., Bundeleva, I. et al. (2016) Microbial and diagenetic steps leading to the mineralisation of Great Salt Lake microbialites. Scientific Reports 6.

Papineau, D., Walker, J.J., Mojzsis, S.J., and Pace, N.R. (2005) Composition and structure of microbial communities from stromatolites of Hamelin Pool in Shark Bay, Western Australia. Appl Environ Microbiol 71: 4822-4832.

695 Power, I.M., Wilson, S.A., Small, D.P., Dipple, G.M., Wan, W.K., and Southam, G. (2011) Microbially mediated mineral carbonation: roles of phototrophy and heterotrophy. Environmental Science \& Technology 45: 9061-9068.

Quast, C., Pruesse, E., Yilmaz, P., Gerken, J., Schweer, T., Yarza, P. et al. (2013) The SILVA ribosomal RNA gene database project: improved data processing and web-based tools. Nucleic Acids Res 41: D590$700 \quad 596$.

R Development Core Team (2017) R: A language and environment for statistical computing. In. http://www.r-project.org (ed). Vienna, Austria: R Foundation for Statistical Computing.

Reid, R.P., and Browne, K.M. (1991) Intertidal stromatolites in a fringing Holocene reef complex in the Bahamas. Geology 19: 15-18.

705 Reid, R.P., Visscher, P.T., Decho, A.W., Stolz, J.F., Bebout, B.M., Dupraz, C. et al. (2000) The role of microbes in accretion, lamination and early lithification of modern marine stromatolites. Nature 406: 989-992.

Reimer, A., Landmann, G., and Kempe, S. (2009) Lake Van, Eastern Anatolia, Hydrochemistry and History. Aquatic Geochemistry 15: 195-222.

710 Riding, R. (2000) Microbial carbonates: the geological record of calcified bacterial-algal mats and biofilms. Sedimentology 47: 179-214.

Rognes, T., Flouri, T., Nichols, B., Quince, C., and Mahe, F. (2016) VSEARCH: a versatile open source tool for metagenomics. PeerJ 4: e2584.

Russell, J.A., Brady, A.L., Cardman, Z., Slater, G.F., Lim, D.S., and Biddle, J.F. (2014) Prokaryote populations of extant microbialites along a depth gradient in Pavilion Lake, British Columbia, Canada. Geobiology 12: 250-264.

Ruvindy, R., White, R.A., 3rd, Neilan, B.A., and Burns, B.P. (2016) Unravelling core microbial metabolisms in the hypersaline microbial mats of Shark Bay using high-throughput metagenomics. ISME J 10: 183196.

720 Saghaï, A., Zivanovic, Y., Moreira, D., Benzerara, K., Bertolino, P., Ragon, M. et al. (2016) Comparative metagenomics unveils functions and genome features of microbialite-associated communities along a depth gradient. Environ Microbiol 18: gut4990-5004. 
Saghaï, A., Zivanovic, Y., Zeyen, N., Moreira, D., Benzerara, K., Deschamps, P. et al. (2015) Metagenomebased diversity analyses suggest a significant contribution of non-cyanobacterial lineages to carbonate precipitation in modern microbialites. Front Microbiol 6: 797.

Saint Martin, J.P., and Saint Martin, S. (2015) Discovery of calcareous microbialites in coastal ponds of Western Sardinia, Italy. Geo-Eco-Marina 21: 35-53.

Santos, F., Pena, A., Nogales, B., Soria-Soria, E., Del Cura, M.A., Gonzalez-Martin, J.A., and Anton, J. (2010) Bacterial diversity in dry modern freshwater stromatolites from Ruidera Pools Natural Park, Spain. Syst App/ Microbio/ 33: 209-221.

Seifan, M., and Berenjian, A. (2019) Microbially induced calcium carbonate precipitation: a widespread phenomenon in the biological world. Appl Microbiol Biotechnol 103: 4693-4708.

Souza-Egipsy, V., Wierzchos, J., Ascaso, C., and Nealson, K.H. (2005) Mg-silica precipitation in fossilization mechanisms of sand tufa endolithic microbial community, Mono Lake (California). Chemical Geology 217: 77-87.

Suosaari, E.P., Reid, R.P., Playford, P.E., Foster, J.S., Stolz, J.F., Casaburi, G. et al. (2016) New multi-scale perspectives on the stromatolites of Shark Bay, Western Australia. Sci Rep 6: 20557.

Tice, M.M., and Lowe, D.R. (2004) Photosynthetic microbial mats in the 3,416-Myr-old ocean. Nature 431: 549-552.

740 Valdespino-Castillo, P.M., Hu, P., Merino-Ibarra, M., Lopez-Gomez, L.M., Cerqueda-Garcia, D., GonzalezDe Zayas, R. et al. (2018) Exploring biogeochemistry and microbial diversity of extant microbialites in Mexico and Cuba. Front Microbio/ 9: 510.

Visscher, P.T., Reid, P.R., and Bebout, B.M. (2000) Microscale observations of sulfate reduction: Correlation of microbial activity with lithified micritic laminae in modern marine stromatolites. Geology 28: 919-922.

Wang, C., Zhang, T., Wang, Y., Katz, L.A., Gao, F., and Song, W. (2017) Disentangling sources of variation in SSU rDNA sequences from single cell analyses of ciliates: impact of copy number variation and experimental error. Proc Roy Soc B 284: 20170425.

Weisse, T. (2002) The significance of inter- and intraspecific variation in bacterivorous and herbivorous protists. Antonie Van Leeuwenhoek 81: 327-341.

White, R.A., 3rd, Chan, A.M., Gavelis, G.S., Leander, B.S., Brady, A.L., Slater, G.F. et al. (2016) Metagenomic analysis suggests modern freshwater microbialites harbor a distinct core microbial community. Front Microbiol 6: 1531.

Wong, H.L., Ahmed-Cox, A., and Burns, B.P. (2016) Molecular ecology of hypersaline microbial mats: current insights and new directions. Microorganisms 4.

Zeyen, N., Daval, D., Lopez-Garcia, P., Moreira, D., Gaillardet, J., and Benzerara, K. (2017) Geochemical conditions allowing the formation of modern lacustrine microbialites. Procedia Earth and Planetary Science 17: 380-383.

Zeyen, N., Benzerara, K., Li, J., Groleau, A., Balan, E., Robert, J.-L. et al. (2015) Formation of low-T hydrated silicates in modern microbialites from Mexico and implications for microbial fossilization. Frontiers in Earth Science 3: 64.

Zeyen, N., Benzerara, K., Menguy, N., Brest, J., Templeton, A.S., Webb, S.M. et al. (2019) Fe-bearing phases in modern lacustrine microbialites from Mexico. Geochim Cosmochim Acta 253: 201-230. 


\section{Figure legends}

Fig.1. Mexican lakes sampled for this study. A, location of the different lakes on the Trans-Mexican volcanic belt (pink area). B, Mexican lakes displaying microbialites (green-shaded area) as a function of alkalinity and conductivity. All lakes except Zirahuen and Patzcuaro are crater (maar) lakes.

Fig.2. Histograms showing the phylogenetic diversity and relative proportion of $16 \mathrm{~S}$ and $18 \mathrm{~S}$ rRNA genes amplified from microbialite samples collected from Mexican lakes along an alkalinity gradient. A, relative abundance of prokaryotic sequences. B, relative abundance of prokaryotic operational taxonomic units (OTUs). C, relative abundance of eukaryotic sequences. D, relative abundance of eukaryotic OTUs. Detailed histograms of the categories 'Other Bacteria', Archaea and 'Other eukaryotes' are provided in, respectively, Supporting Information Figs. S3A, 3B and S4. Sample descriptions are provided in Table 1.

780 Fig.3. Comparison of microbialite samples according to their associated prokaryotic and eukaryotic communities based on Bray Curtis distances. A, Non-metric multidimensional scaling (NMDS) biplot. A variant of this figure including a projection of the most influential parameters is shown in Fig. S7. B, Hierarchical clustering based on 16S and 18S rRNA gene-based community composition. The greenshaded area indicates closely grouping samples from Alchichica and Atexcac SE samples.

785

Fig.4. Canonical-correlation analysis biplot showing the studied microbialite samples as a function of $\mathrm{pH}$, conductivity (Cond), alkalinity $\left[\mathrm{HCO}_{3}{ }^{-}\right],\left[\mathrm{Ca}^{2+}\right]$ and the ratio $\left[\mathrm{Mg}^{2+}\right] /\left[\mathrm{Ca}^{2+}\right]$. CCAs showing additional abiotic parameters are shown in Supporting Information Fig.S9. Microbialites from the different lakes are colorcoded as indicated.

Fig.5. Taxon-based metabolic profiling of microbialite-associated prokaryotic communities across different Mexican crater lakes. A, phylogeny-based relative abundance of different metabolic pathways potentially influencing microbialite formation inferred from the number of 165 rRNA genes reads for specific taxa known to carry out a particular metabolism. Values correspond to average proportions

795 from replicate samples for each lake. Metabolic categories to the left of 'Uncertain' are potentially carbonatogenic, those on the right, favor carbonate dissolution. B, NMDS biplot showing the distribution of the different samples according to their inferred metabolic pattern. Anox., anoxygenic; GNSB, green non-sulfur bacteria; PNSB, purple non-sulfur bacteria; PSB, purple sulfur bacteria.

800 Fig.6. Prokaryotic and eukaryotic core communities shared by Trans-Mexican volcanic belt lake microbialites. A, UpSet plot showing prokaryotic OTUs shared by the different lake microbialites. The number, phylogenetic affiliation and relative abundance of OTUs within the core shared by all the lakes 
or all the lakes but one (light grey dot) are provided in the upper histogram. The histogram on the right shows the relative proportion (sequence reads) of the prokaryotic core community in the total

805 prokaryotic community of each lake microbialite. B, UpSet plot as in (A) showing eukaryotic OTUs shared by the different lake microbialites. 
A

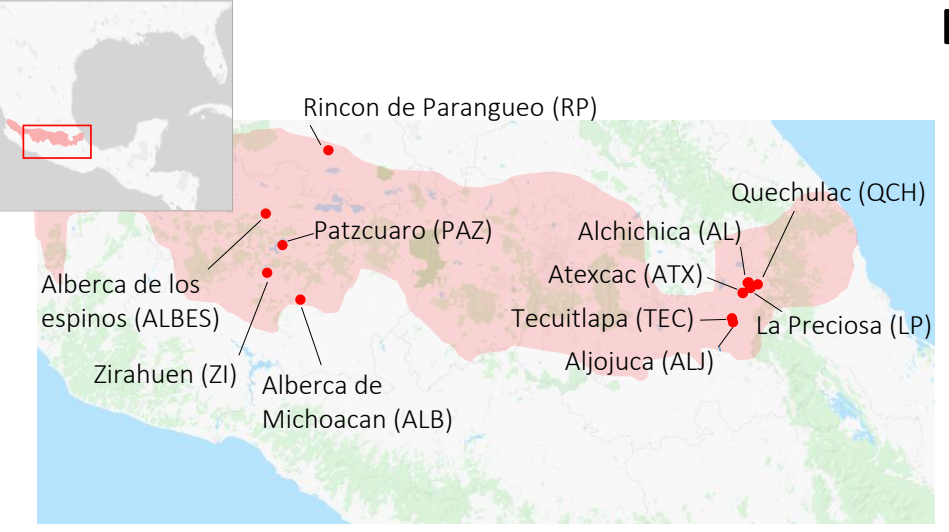

B

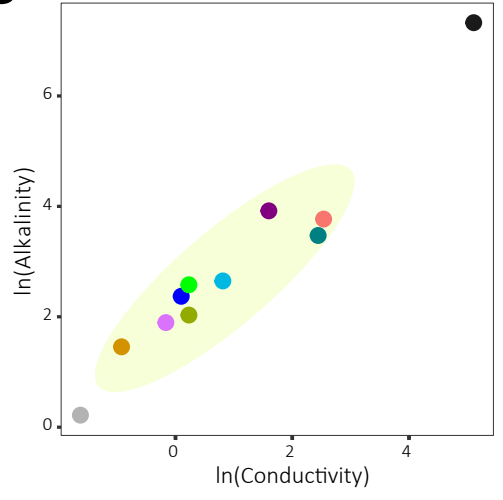

With microbialites:

Alb.Espinos

- Alb.Michoacán

- Alchichica

- Aljojuca

- Atexcac

- La Preciosa

- Pátzcuaro

- Quechulac

- Tecuitlapa

Without microbialites:

- Rincón de Parangueo

- Zirahuén

Figure 1. Iniesto et al. 

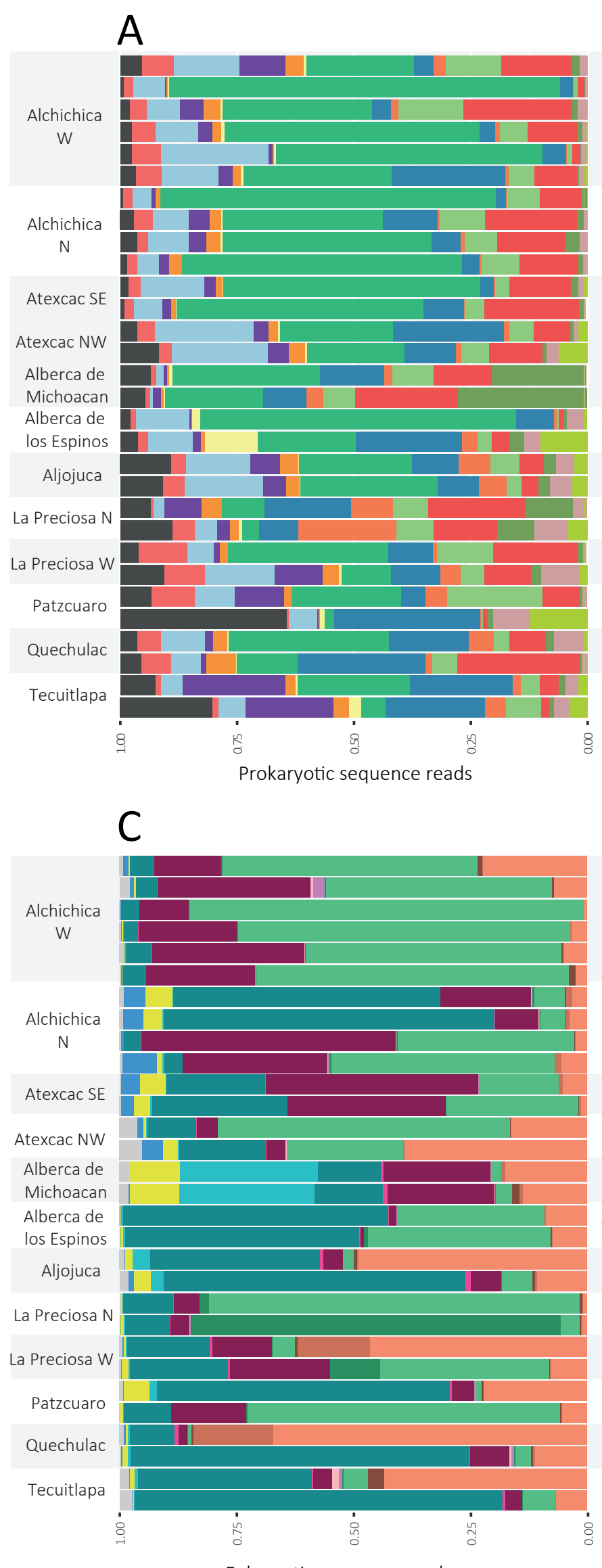

Eukaryotic sequence reads sample B

ALW_01

ALW_02

ALW_03

ALW_04

ALW_05

ALW $05 B$

ALN_01

ALN_02

ALN_03

ALN_04

ATX_01

ATX_02

ATX_03

ATX_04

ALB_01A

ALB_01B

ALBES_01A

ALBES_01B

AL_01A

AL_01B

LPR_01

LPR_02

LPR_03

LPR_04

PAZ_01

PAZ_02

$\mathrm{QCH}$ 01

QCH_02

TEC_01

TEC_02

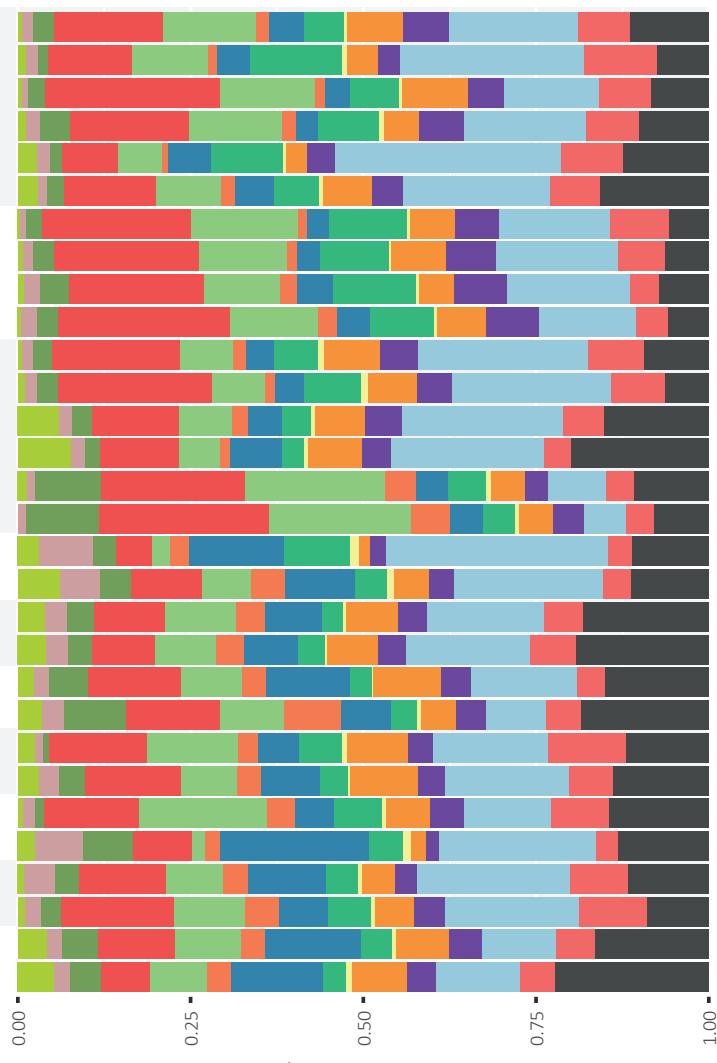

Prokaryotic OTUs

\section{Sample D}

ALW_01

ALW_02

ALW_03

ALW_04

ALW_05

ALW_05B

ALN_01

ALN_02

ALN_03

ALN_04

ATX_01

ATX_02

ATX_03

ATX_04

ALB_01A

ALB_01B

ALBES_01A

ALBES_01B

AL $01 \mathrm{~A}$

AL_01B

LPR_01

LPR_02

LPR_03

LPR_04

PAZ_01

PAZ_02

QCH_01

QCH_02

TEC_01

TEC_02

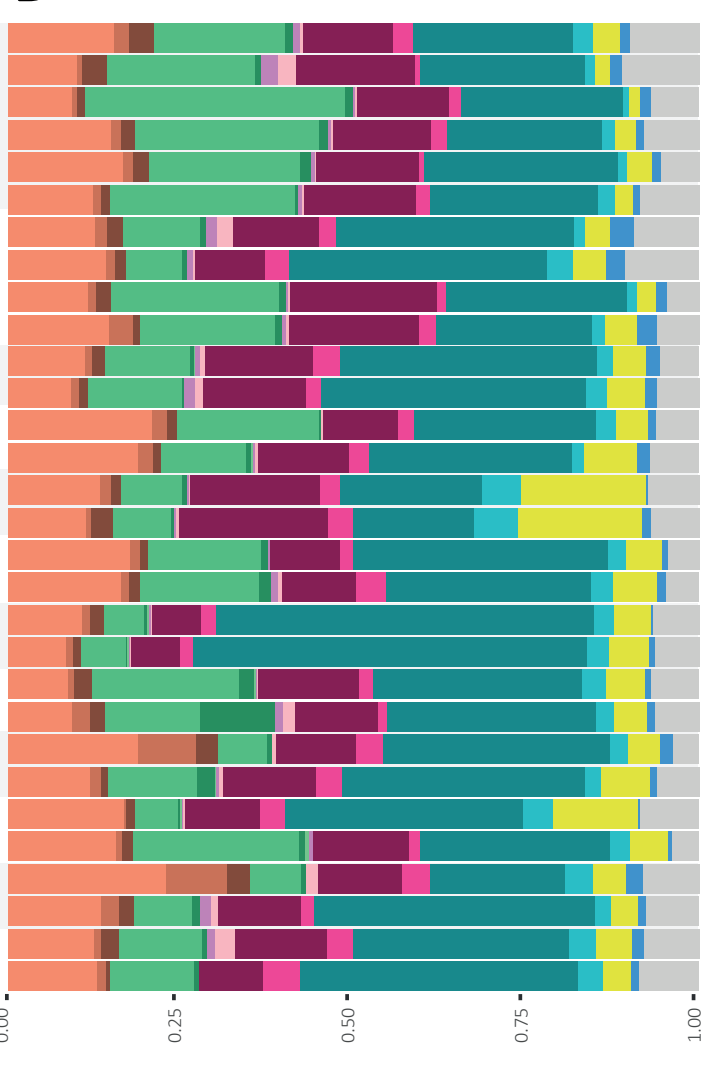

Alveolata

Ciliophora

Dinophyta

Other Alveolata

Archaeplastida

Chlorophyta

Streptophyta

Other Archaepl.

Excavata

Euglenozoa

Other Excavata

Opisthokonta

Fung

Other Opist.

Stramenopiles

Ochrophyta

Heterotrophic

stramenopiles

Other eukaryotic taxa

Cercozoa

Haptophyta

Other Eukaryotes

Eukaryotic OTUs

Figure 2. Iniesto et al. 
A

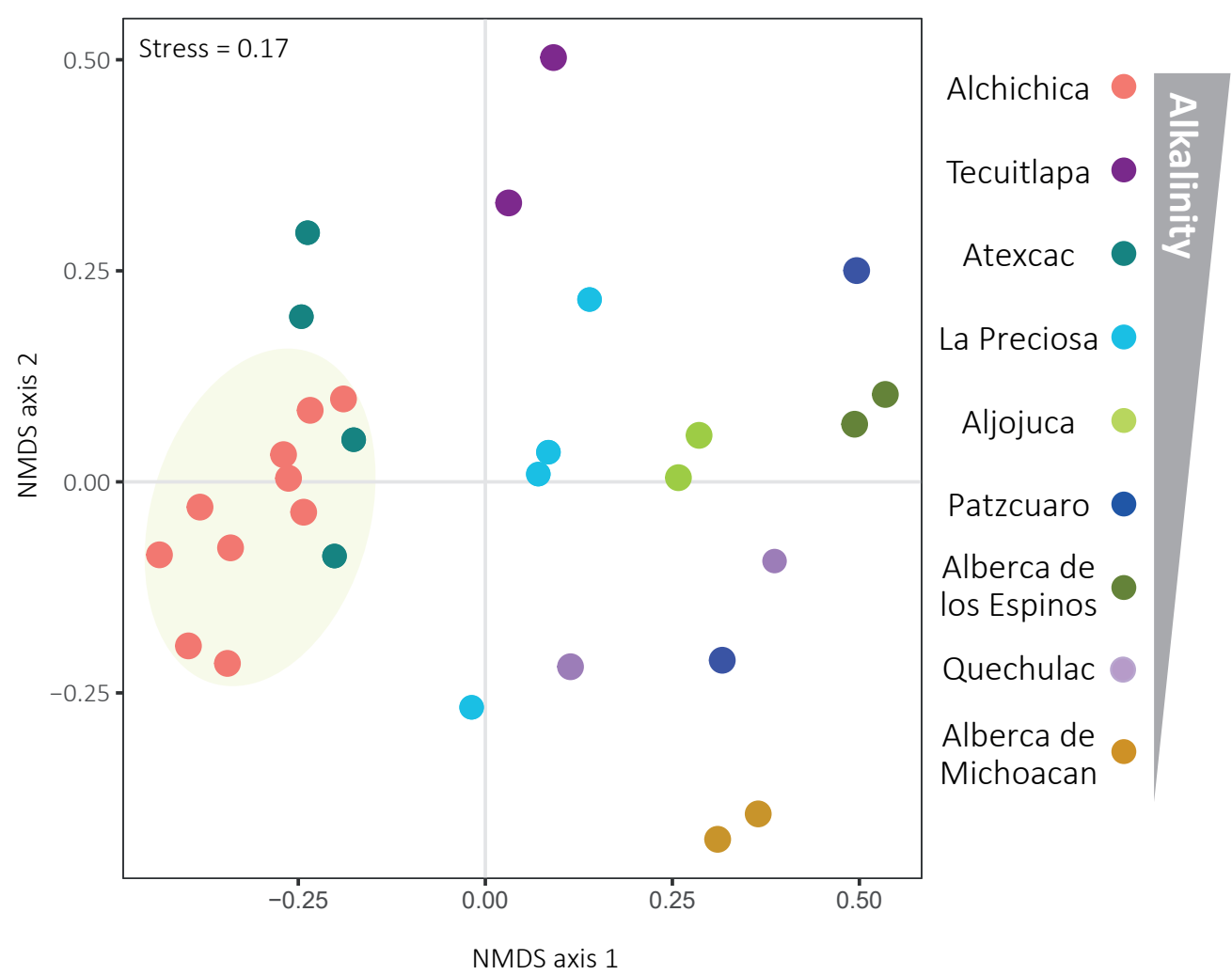

B

Height $\quad 0.5 \quad 0.7 \quad 0.9$

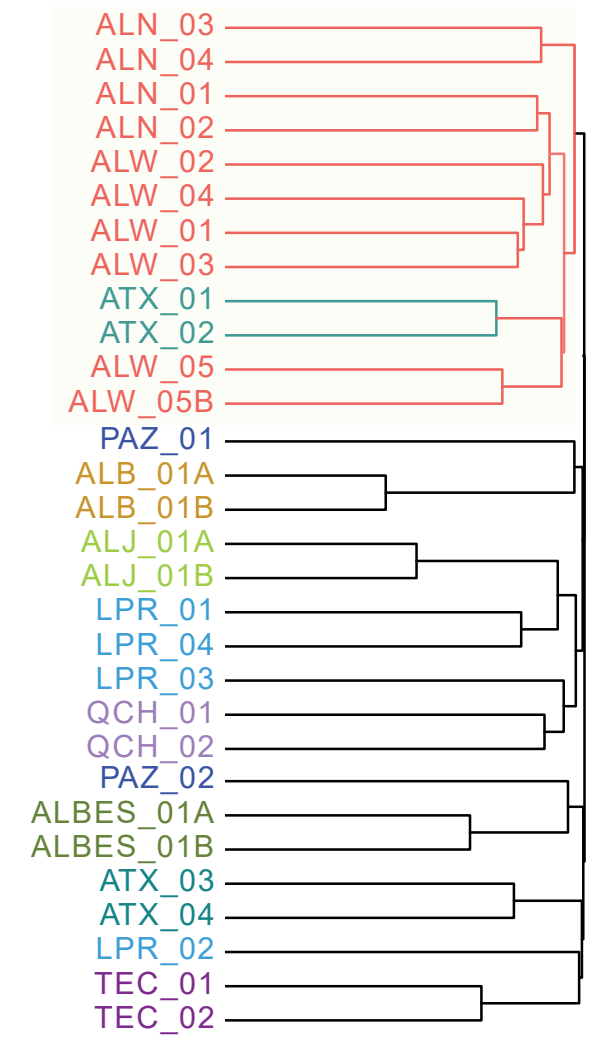

Figure 3. Iniesto et al. 


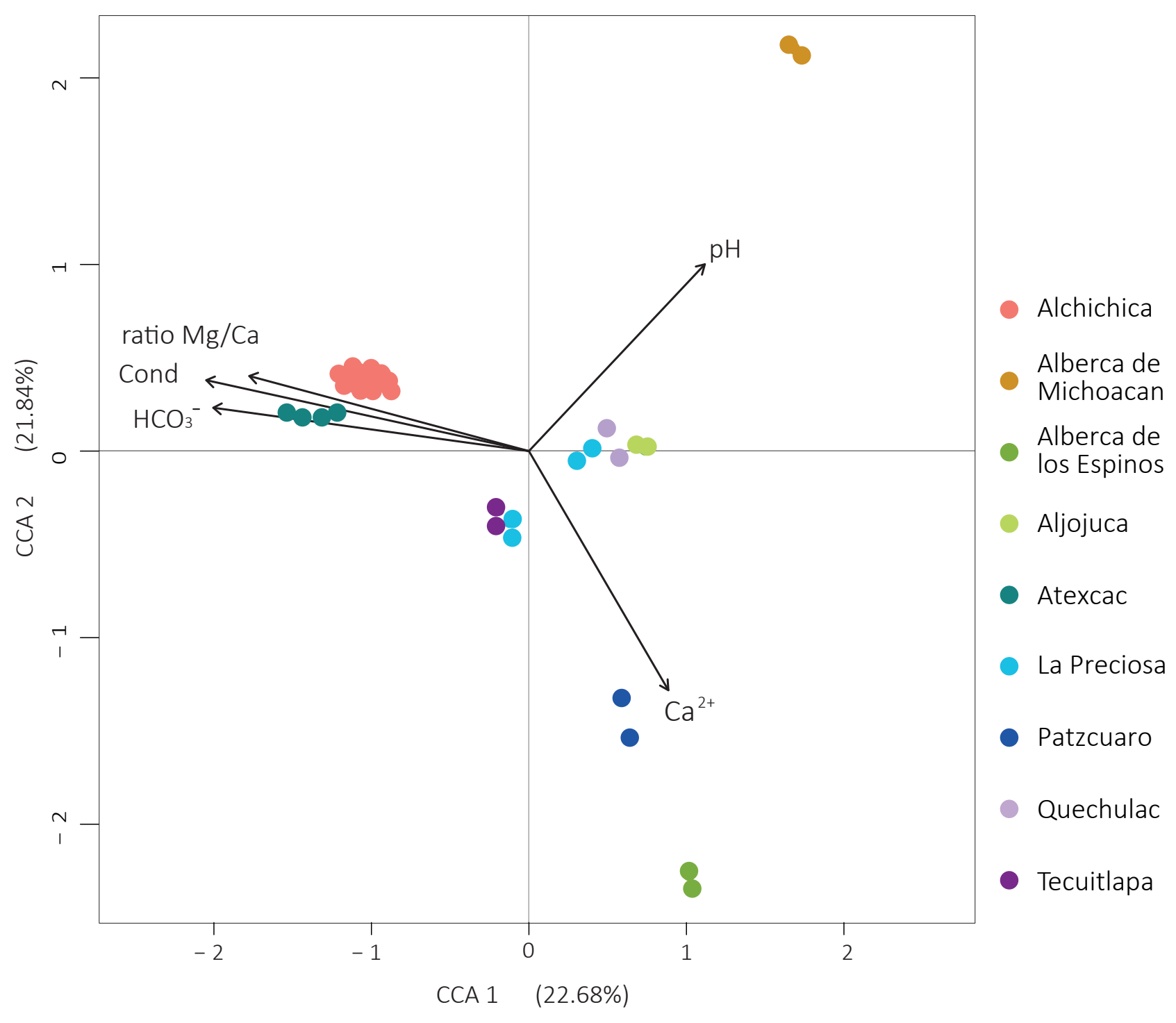

Figure 4. Iniesto et al. 
A
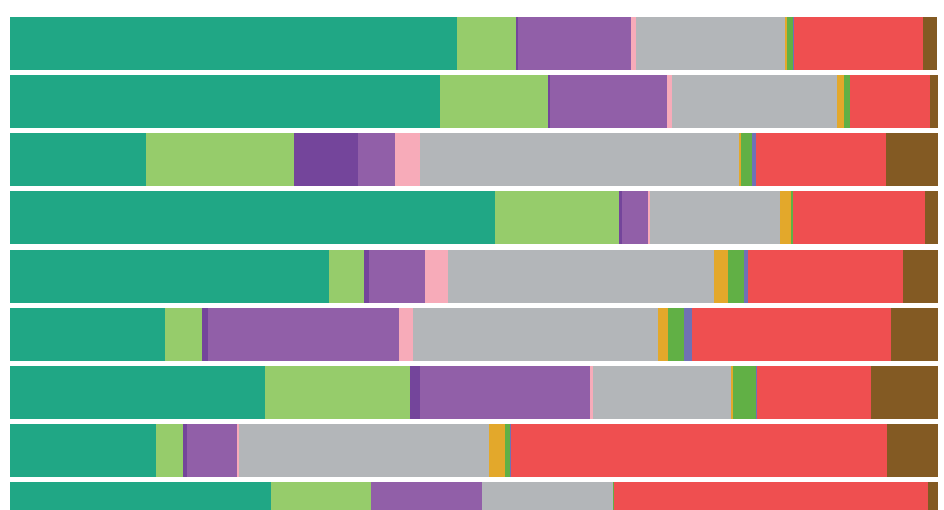

$\dot{8}$ i্র

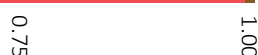

Metabolic potential (frequency of reads)

Oxygenic photosynthesis

Anox. photosynthesis (GNSB)

- Anox. photosynthesis (PSB)

Anox. photosynthesis (PNSB)

- Sulfate reduction

\section{B}

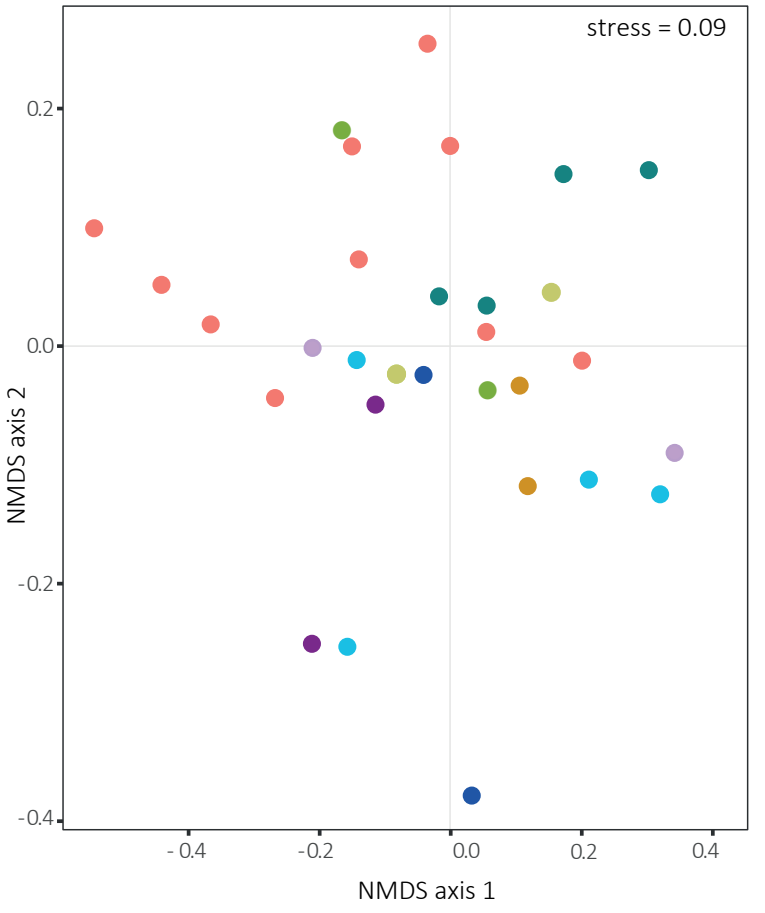

Figure 5. Iniesto et al. 
A

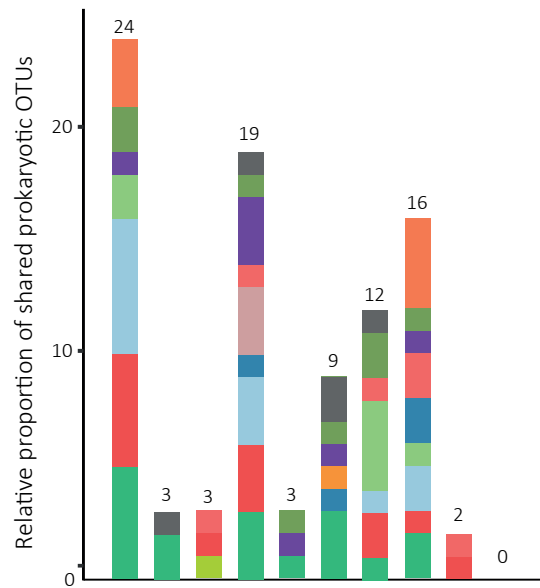

Cyanobacteria

Alphaproteobacteria

Planctomycetes

Bacteroidetes

Chloroflexi

Acidobacteria

- Verrucomicrobia

Deltaproteobacteria

Gammaproteobacteria

Actinobacteria

Betaproteobacteria

Other Bacteria

Archaea

Not shared
B

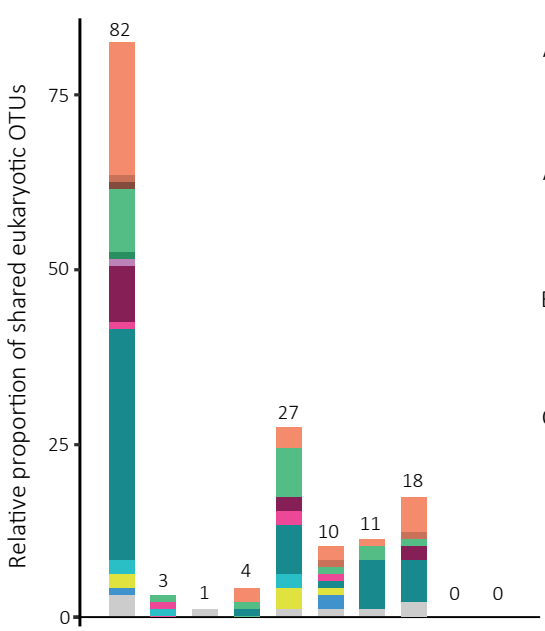

Proportion of the prokaryotic core

Tecuitlapa

Alb. Espinos

Patzcuaro

Quechulac

Alb. Michoacan

Atexcac

La Preciosa

Aljojuca

Alchichica
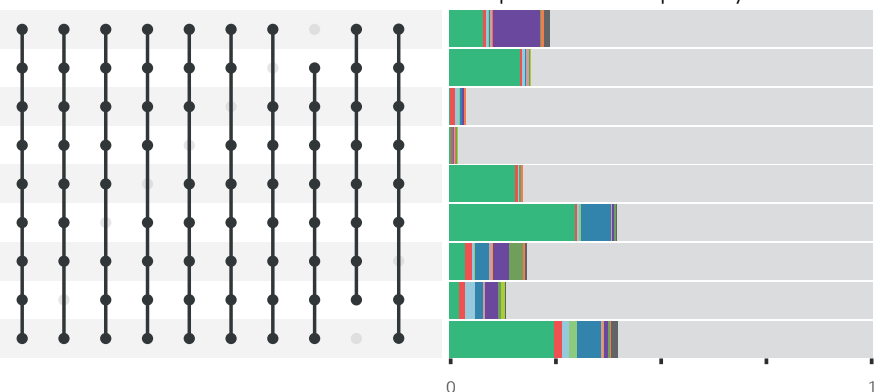
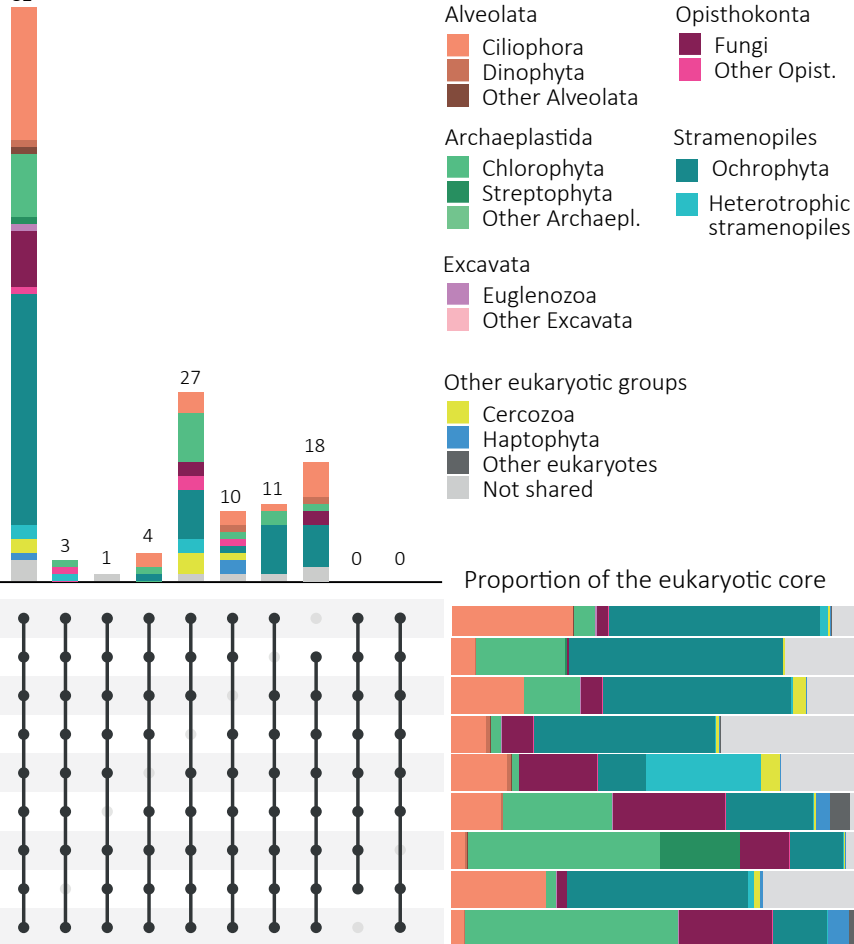

Proportion of the eukaryotic core

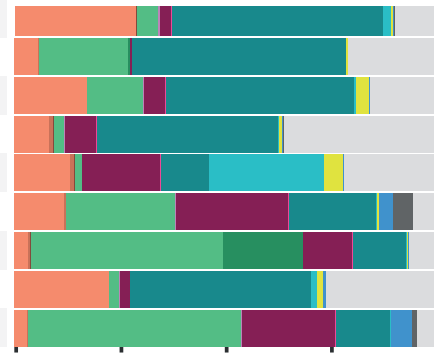

Figure 6. Iniesto et al. 


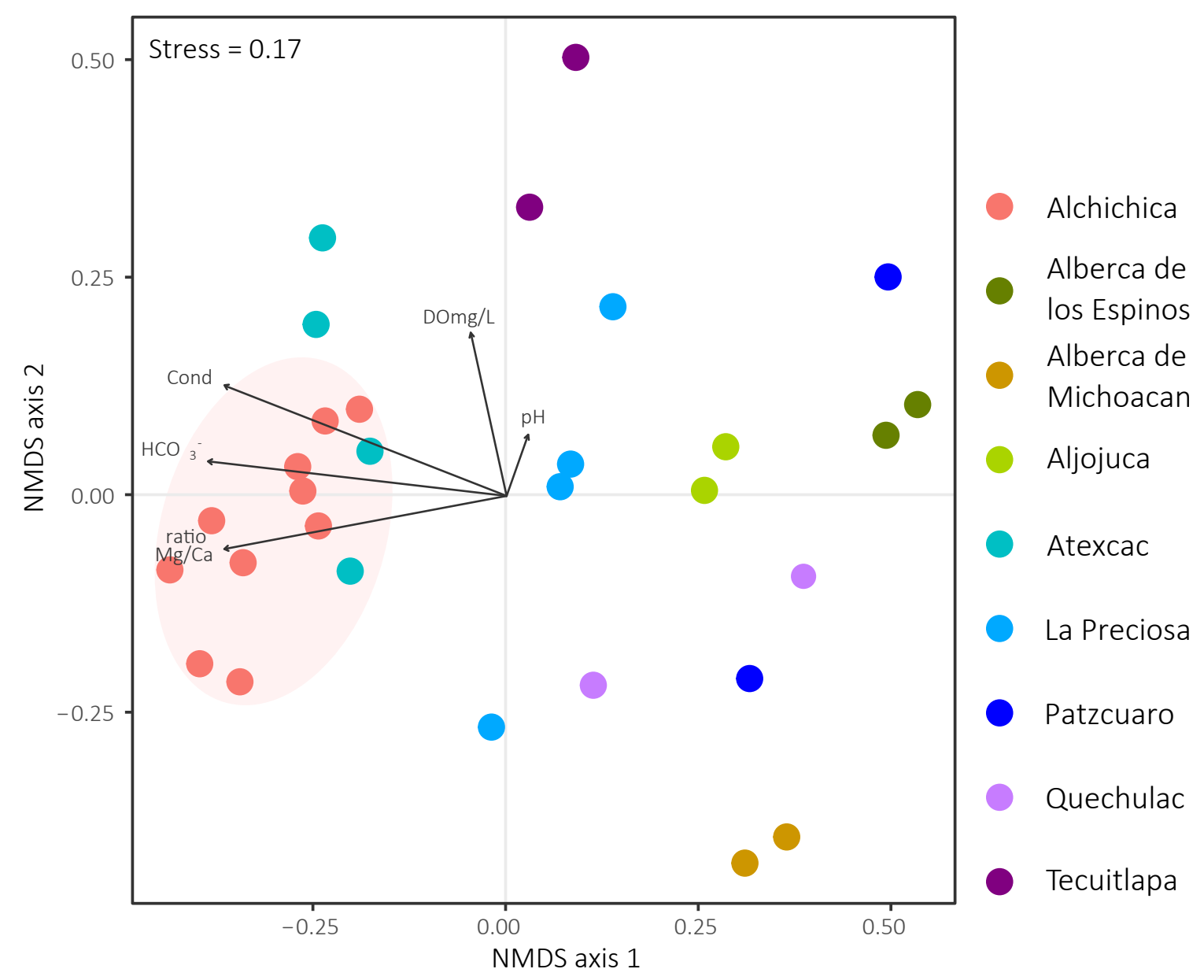

Fig. S7. Non-metric multidimensional scaling (NMDS) biplot of microbialite communities including a projection of the most influential parameters. The original NMDS is seen in Fig.3. 


\section{Supporting Information}

Core microbial communities of lacustrine microbialites sampled along an alkalinity gradient

Miguel Iniesto, David Moreira, Guillaume Reboul, Philippe Deschamps, Karim Benzerara, Paola Bertolino, Aurélien Saghaï, Rosaluz Tavera and Purificación López-García 


\section{A. Alchichica}

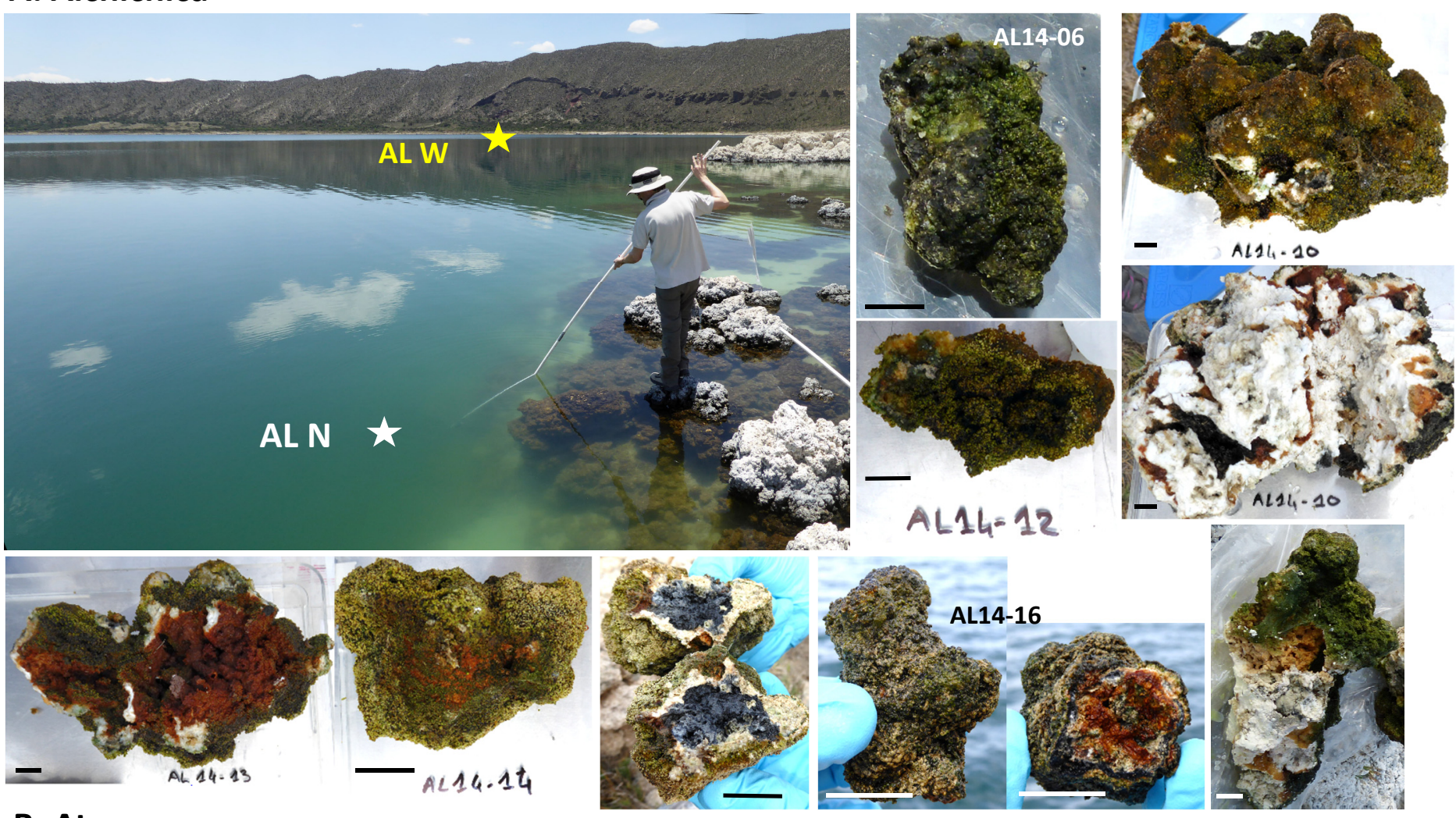

\section{B. Atexcac}
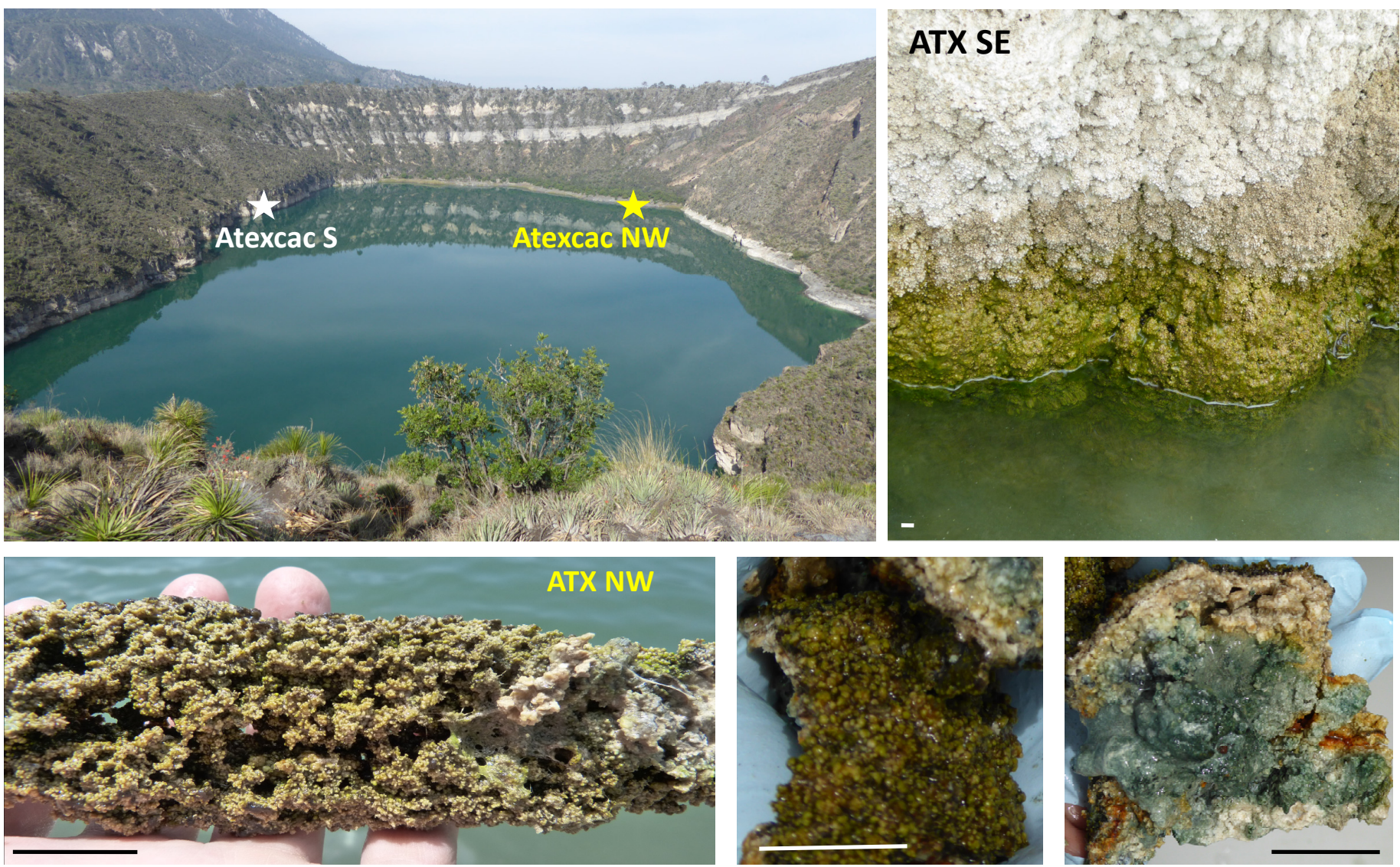

Figure S1. Mexican crater lakes visited during this study. Sampling points in the lakes are indicated by stars and representative microbialite samples collected at the different lakes are shown. Scale bar, $2 \mathrm{~cm}$. A. Alchichica. B, Atexcac. C, La Preciosa. D, Quechulac. E, Tecuitlapa. F, Aljojuca. H, Alberca de Michoacan. I, Alberca de los Espinos. J, Rincon de Parangueo. K, Zirahuen. 


\section{La Preciosa}
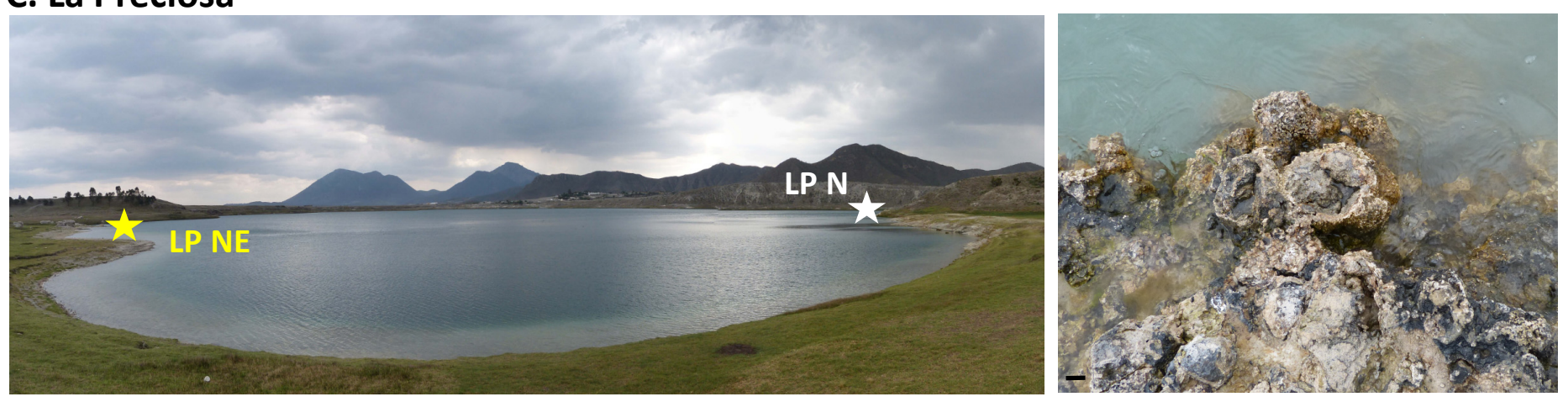

\section{Quechulac}
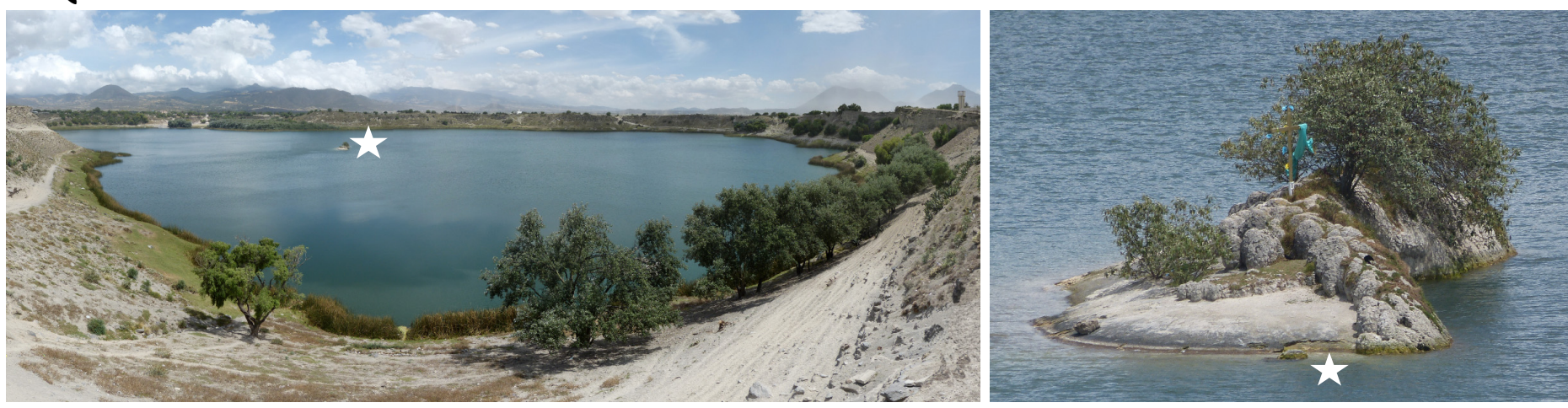

\section{E. Tecuitlapa}
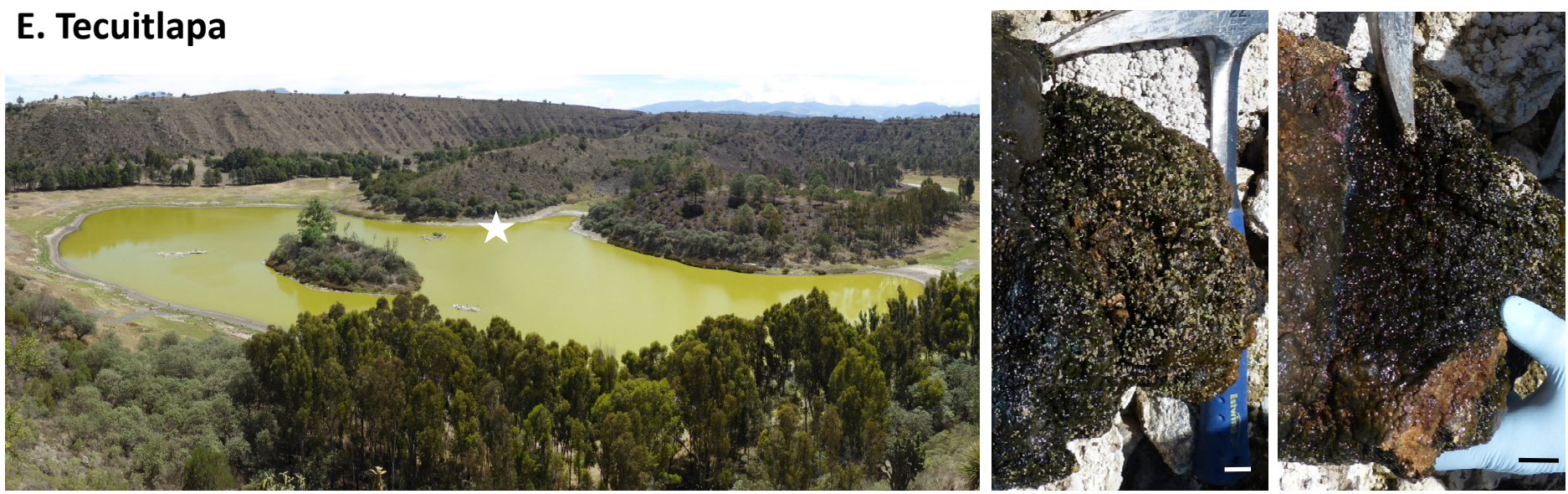

\section{F. Aljojuca}
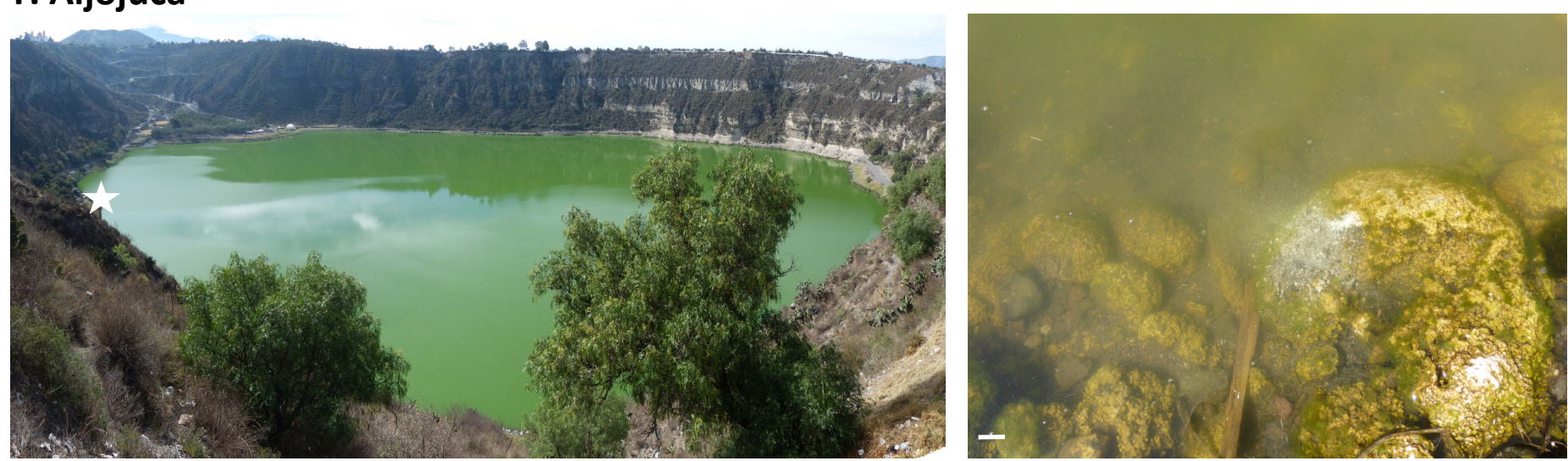

Figure S1 (cont.). Mexican crater lakes visited during this study. Sampling points in the lakes are indicated by stars and representative microbialite samples collected at the different lakes are shown. Scale bar, $2 \mathrm{~cm}$. A. Alchichica. B, Atexcac. C, La Preciosa. D, Quechulac. E, Tecuitlapa. F, Aljojuca. H, Alberca de Michoacan. I, Alberca de los Espinos. J, Rincon de Parangueo. K, Zirahuen. 


\section{G. Patzcuaro (San Andres)}
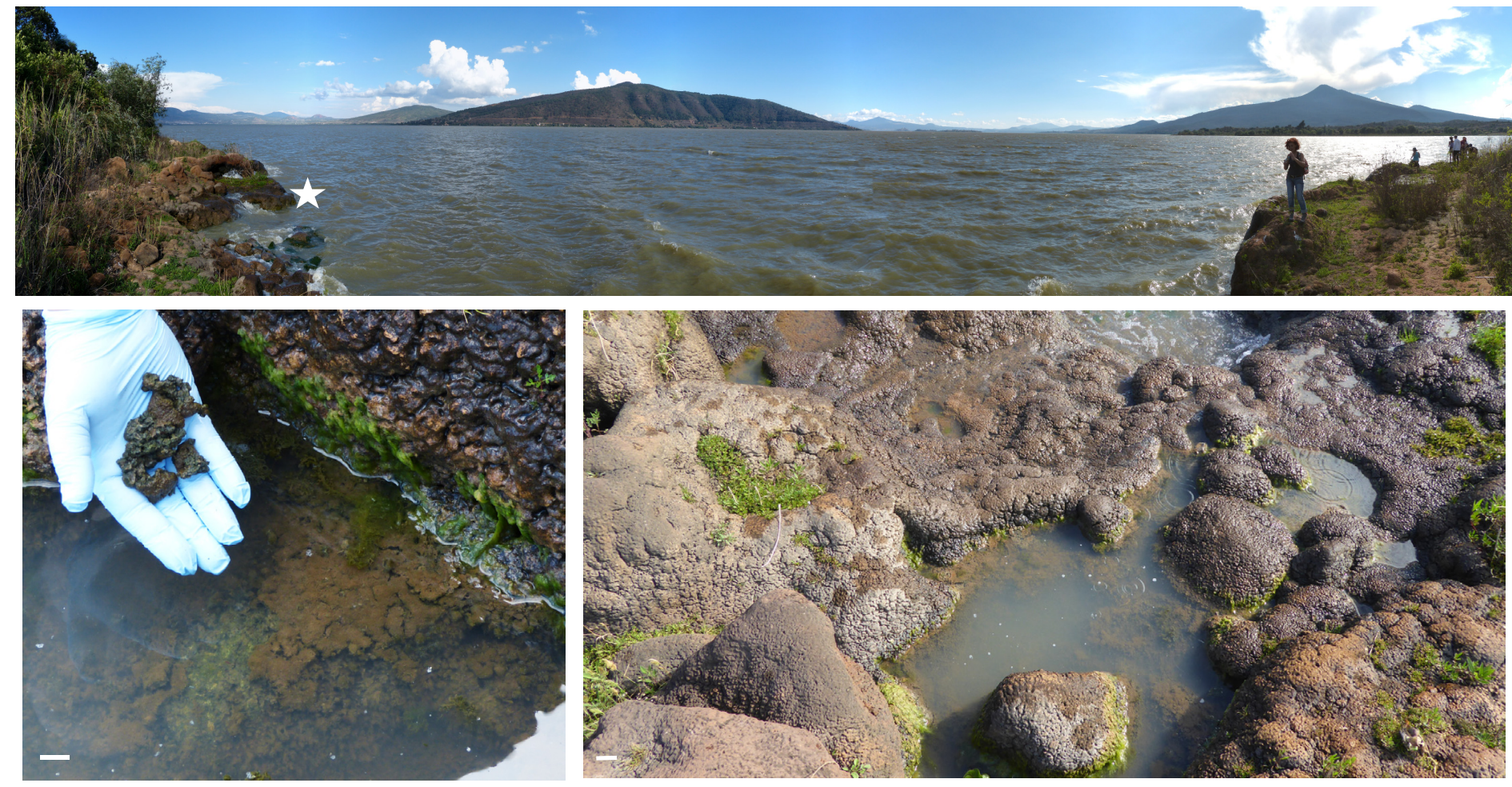

\section{H. Alberca de Michoacan}
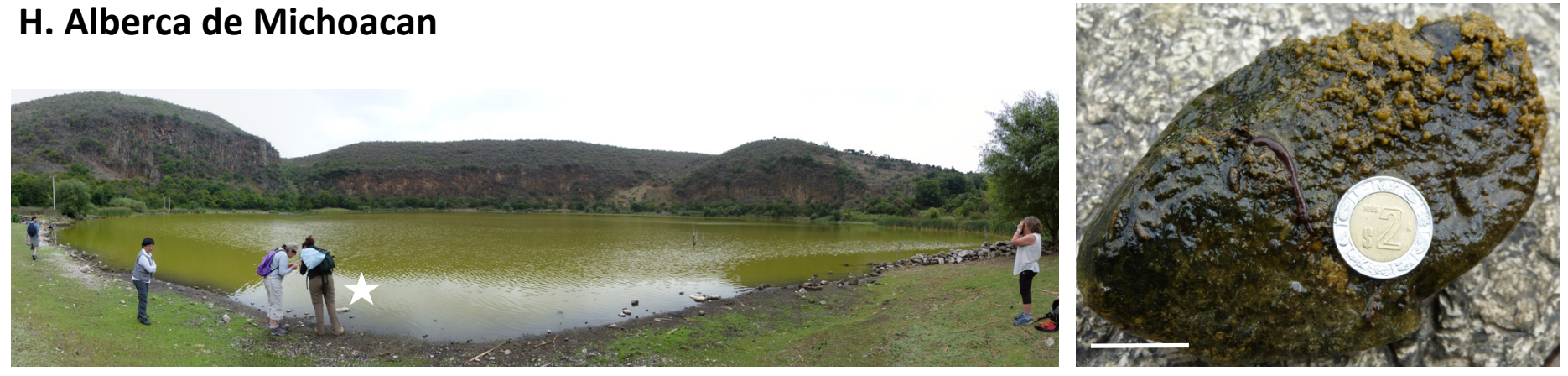

\section{Alberca de los Espinos}
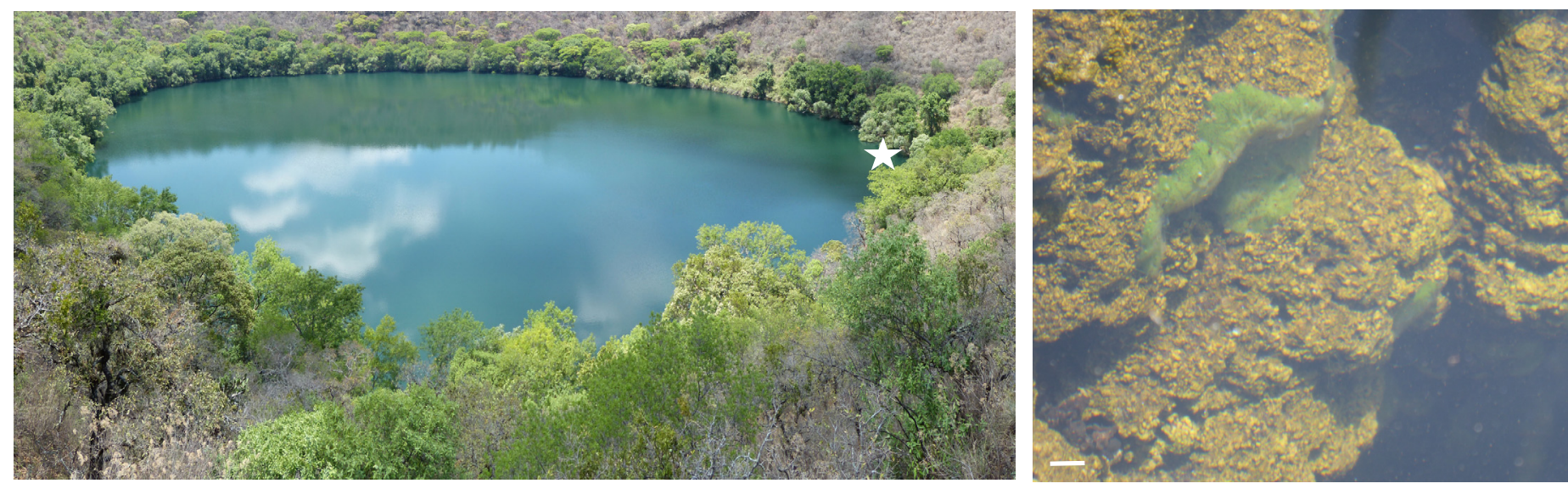

Figure S1 (cont.). Mexican crater lakes visited during this study. Sampling points in the lakes are indicated by stars and representative microbialite samples collected at the different lakes are shown. Scale bar, $2 \mathrm{~cm}$. A. Alchichica. B, Atexcac. C, La Preciosa. D, Quechulac. E, Tecuitlapa. F, Aljojuca. H, Alberca de Michoacan. I, Alberca de los Espinos. J, Rincon de Parangueo. K, Zirahuen. 


\section{J. Rincon de Parangueo}
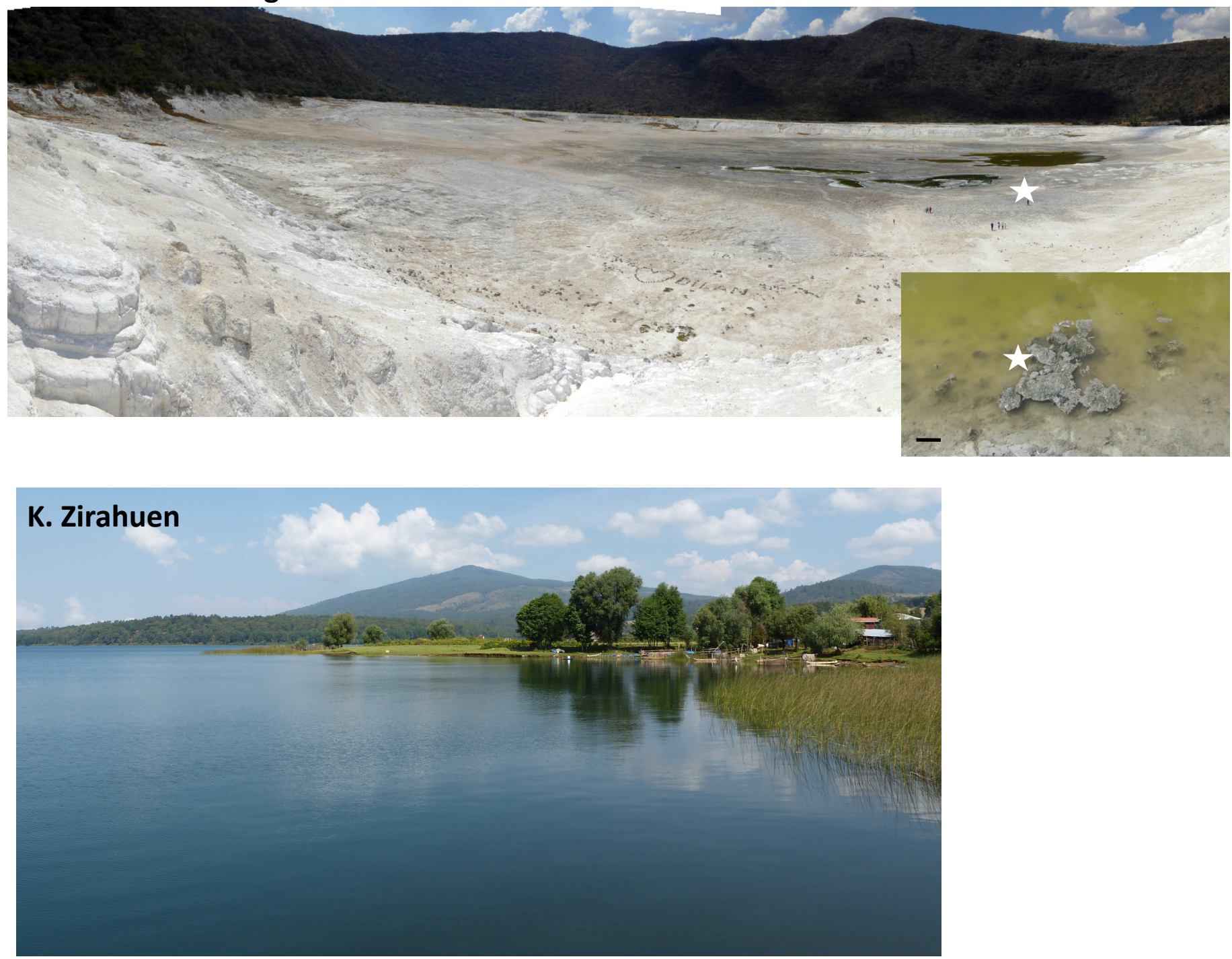

Figure S1 (cont.). Mexican crater lakes visited during this study. Sampling points in the lakes are indicated by stars and representative microbialite samples collected at the different lakes are shown. Scale bar, $2 \mathrm{~cm}$. A. Alchichica. B, Atexcac. C, La Preciosa. D, Quechulac. E, Tecuitlapa. F, Aljojuca. H, Alberca de Michoacan. I, Alberca de los Espinos. J, Rincon de Parangueo. K, Zirahuen. 
A

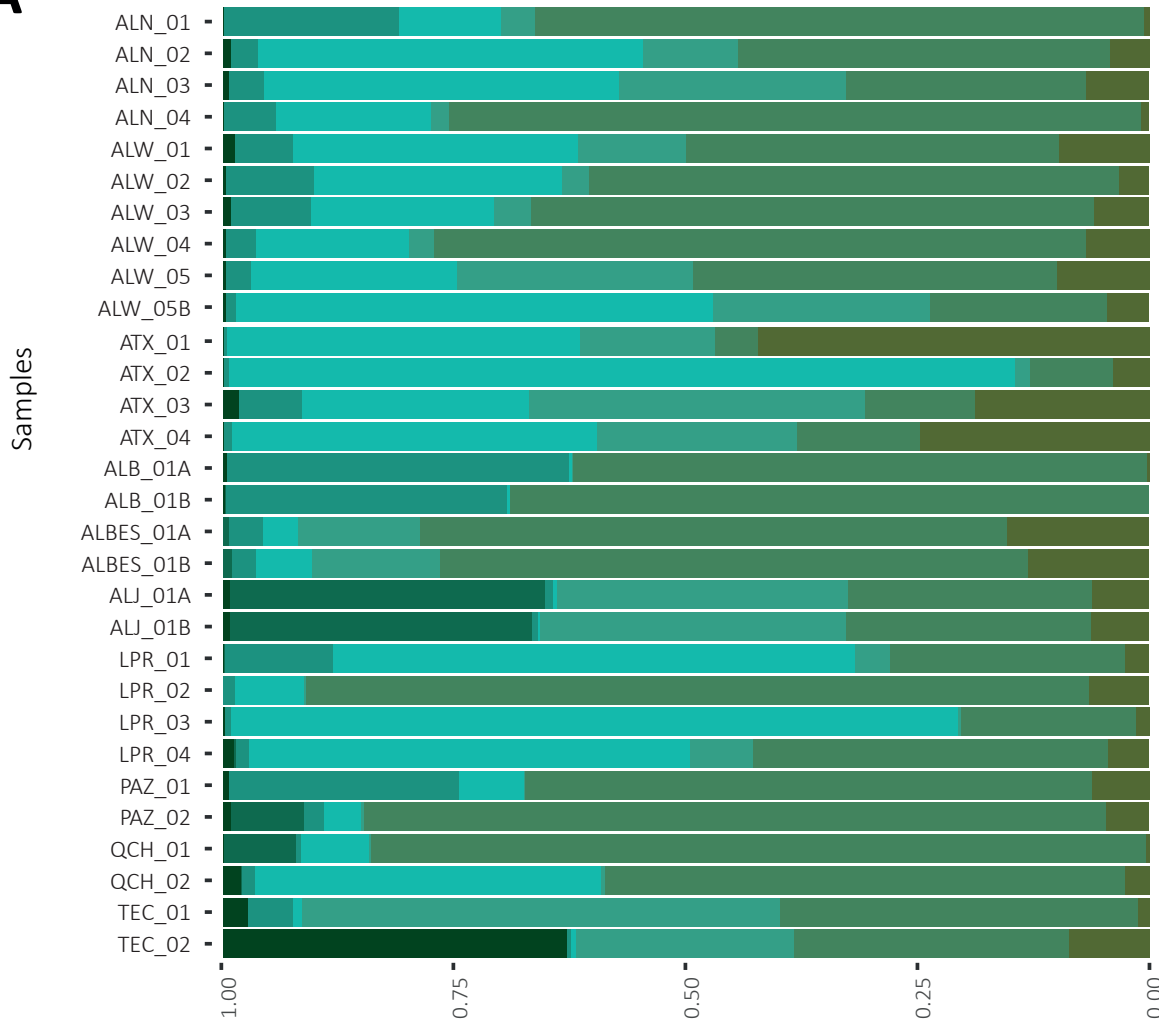

B

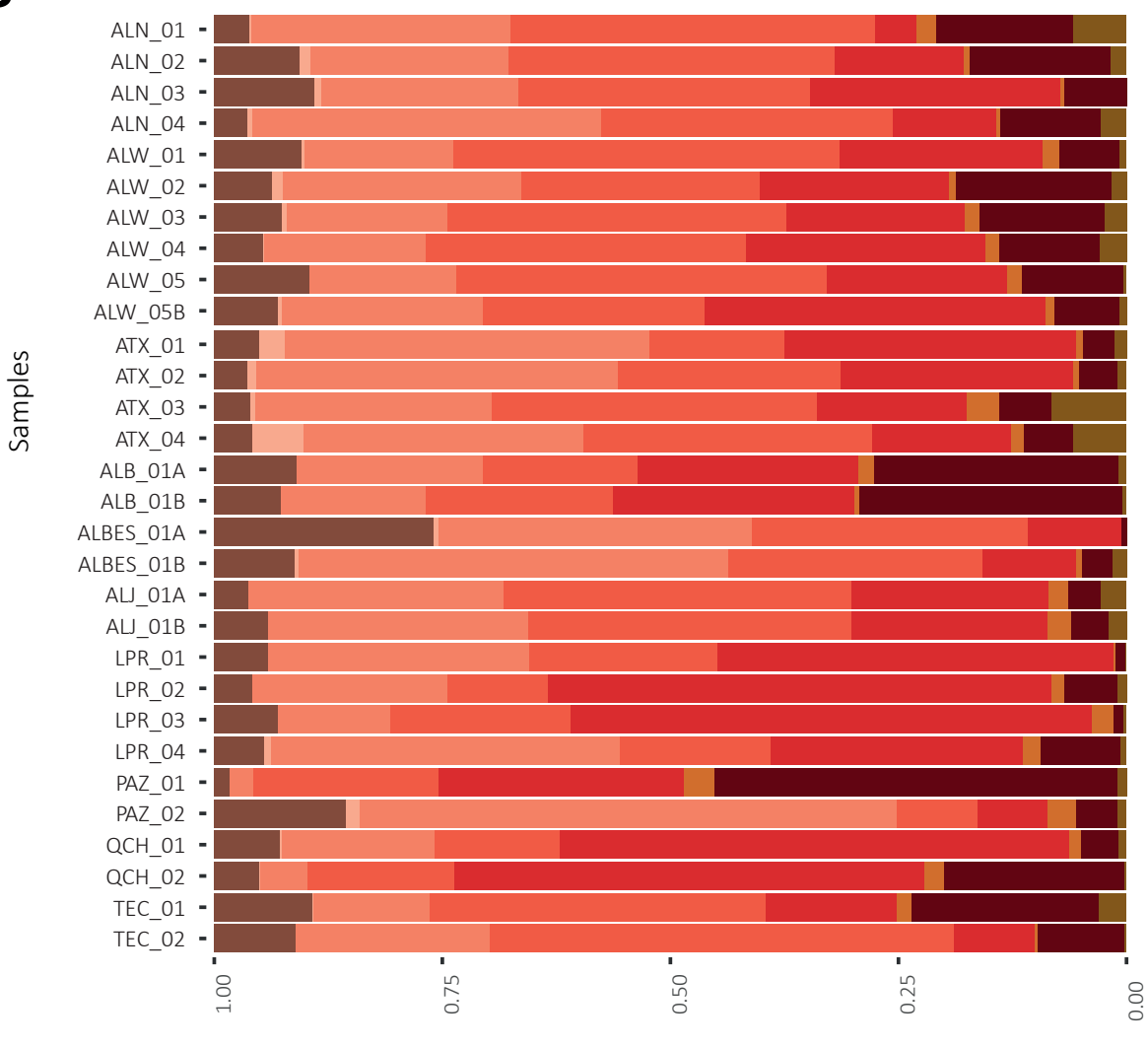

Frequency of reads
Cyanobacteria

- Chroococcales

Chroococcidiopsidales

Nostocales

Oscillatoriales

Pleurocapsales

Synechococcales

Other Cyanobacteria

Alphaproteobacteria

Caulobacterales

Parvularculales

- Rhizobiales

Rhodobacterales

Rhodospirillales

Rickettsiales

Sphingomonadales

Other Alphaproteobacteria

Figure S2. Relative proportion of 16S rRNA gene sequences belonging to different orders of Cyanobacteria and Alphaproteobacteria. A, Cyanobacteria. B, Alphaproteobacteria. Sample descriptions are detailed in Supplementary Table 2. 
A

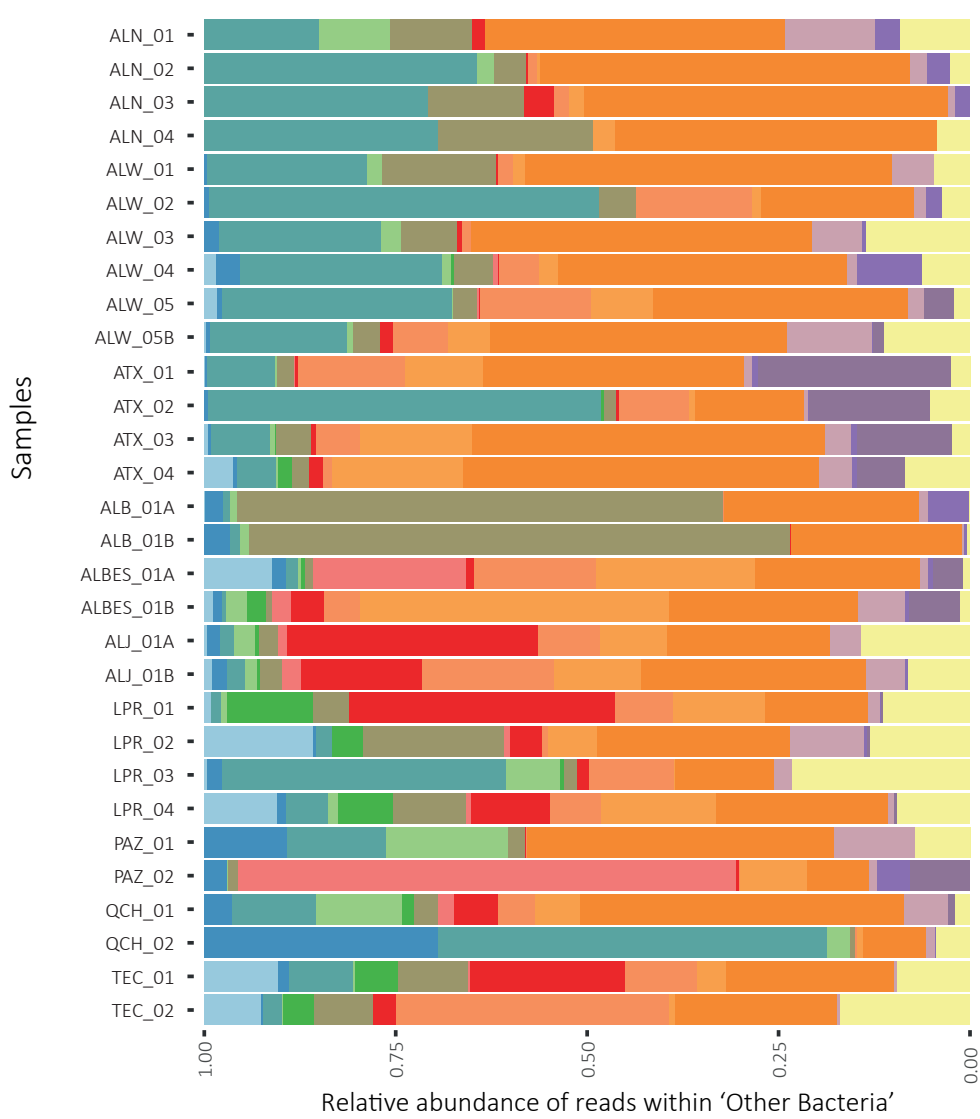

Aminicenantes

Armatimonadetes

BRC1

Chlorobi

Deferribacteres

Firmicutes

GAL15

Ignavibacteriae

Latescibacteria

Nitrospirae

Other Bacteria

Parcubacteria

Saccharibacteria

SBR1093

Spirochaetae

B

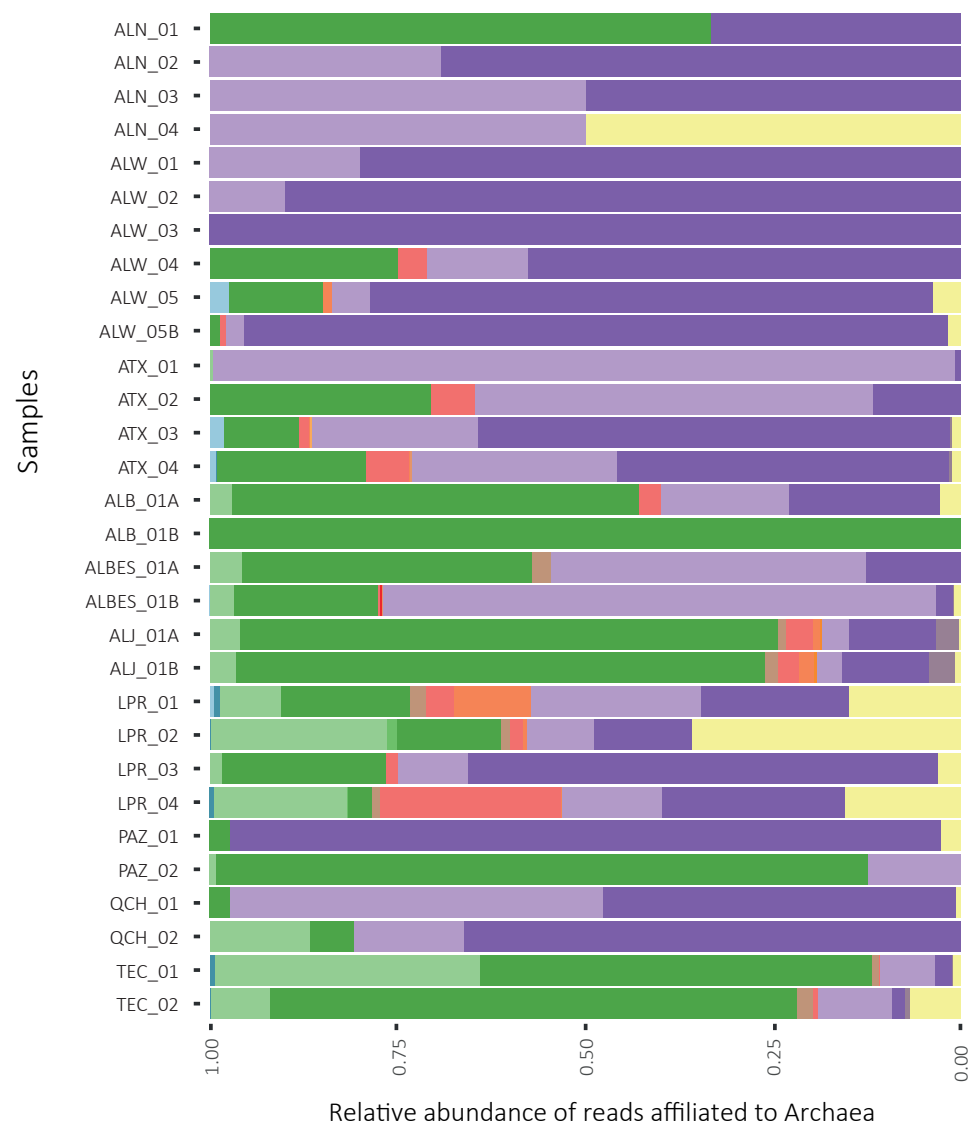

Aenigmarchaeota

Altiarchaeales

Ancient Archaeal Group

Bathyarchaeota

Diapherotrites

Euryarchaeota

Hadesarchaea

Lokiarchaeota

Marine Hydrothermal Vent Group

Miscellaneous Euryarchaeotic Group

Nanohaloarchaeota

Parvarchaeota

pMC2A209

Thaumarchaeota

Woesearchaeota

WSA2

Unclassified Archaea

Relative abundance of reads affiliated to Archaea

Figure S3. Relative proportion of 16S rRNA gene sequences corresponding to bacterial taxa listed as 'Other Bacteria' and 'Archaea' in Figure 2A. A, 'Other bacteria'. B, Archaea. Sample descriptions are detailed in Supplementary Table 2. 


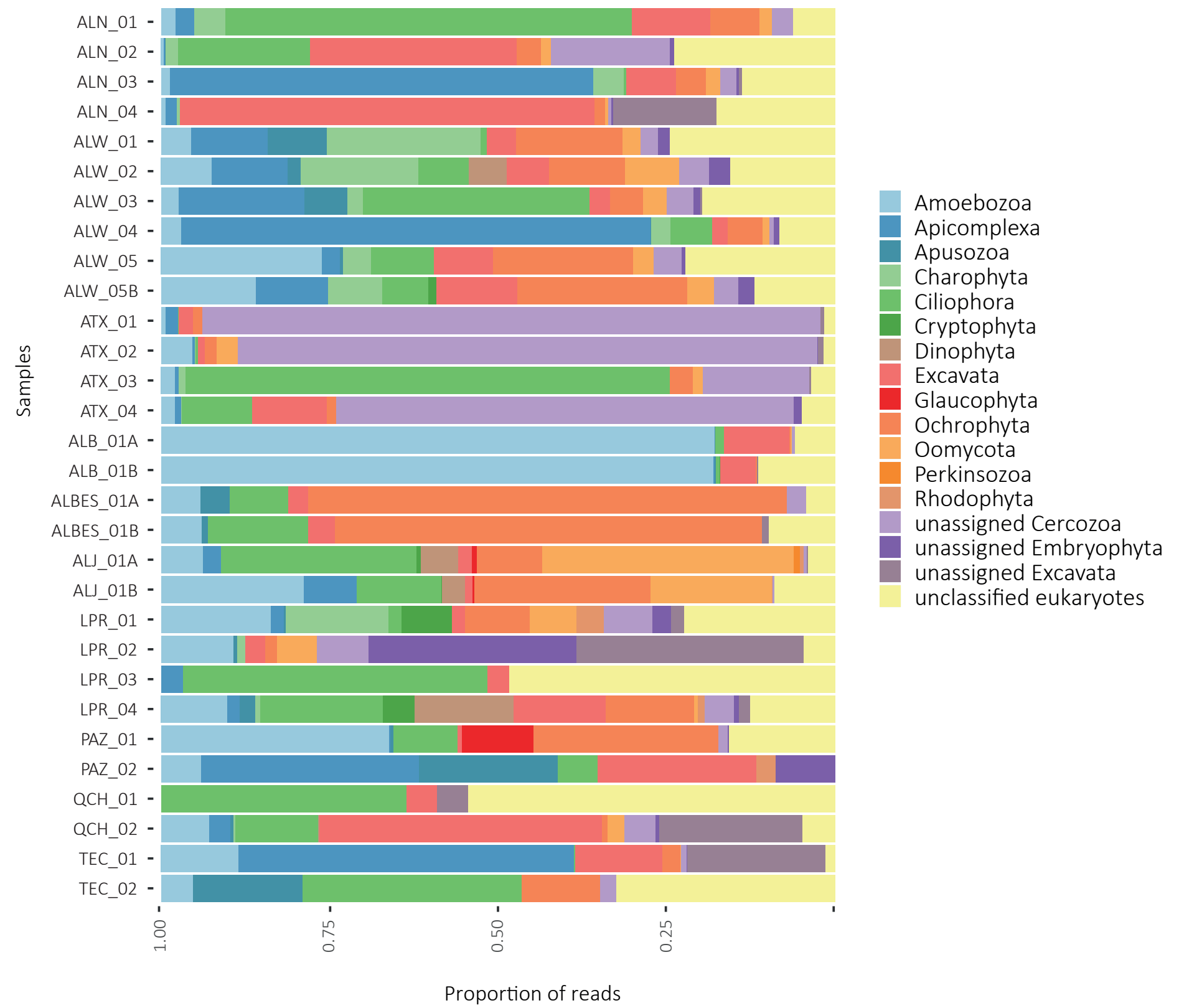

Figure S4. Relative proportion of 18S rRNA gene sequences within the category 'Other eukaryotes' in Figure 2C. Sample descriptions are detailed in Supplementary Table 2. 
A

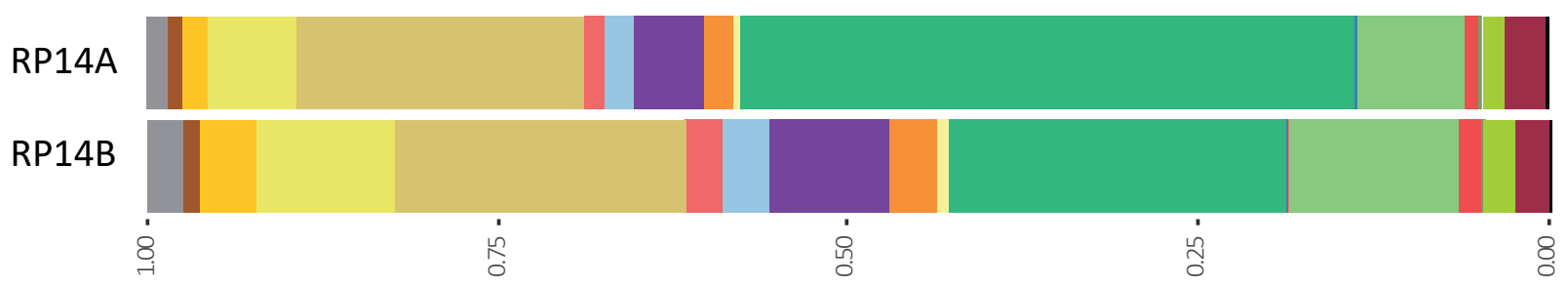

Proportion of prokaryotic reads

\begin{tabular}{llll}
\hline Acidobacteria & Cyanobacteria & Firmicutes & Euryarchaeota \\
Actinobacteria & Deinococcus - Thermus & Spirochaetae & Woesearchaeota \\
Alphaproteobacteria & Deltaproteobacteria & Tenericutes & Other archaea \\
Bacteroidetes & Gammaproteobacteria & Thermotogae \\
Betaproteobacteria & Planctomycetes & Other bacterial taxa \\
Chloroflexi & Verrucomicrobia &
\end{tabular}

B

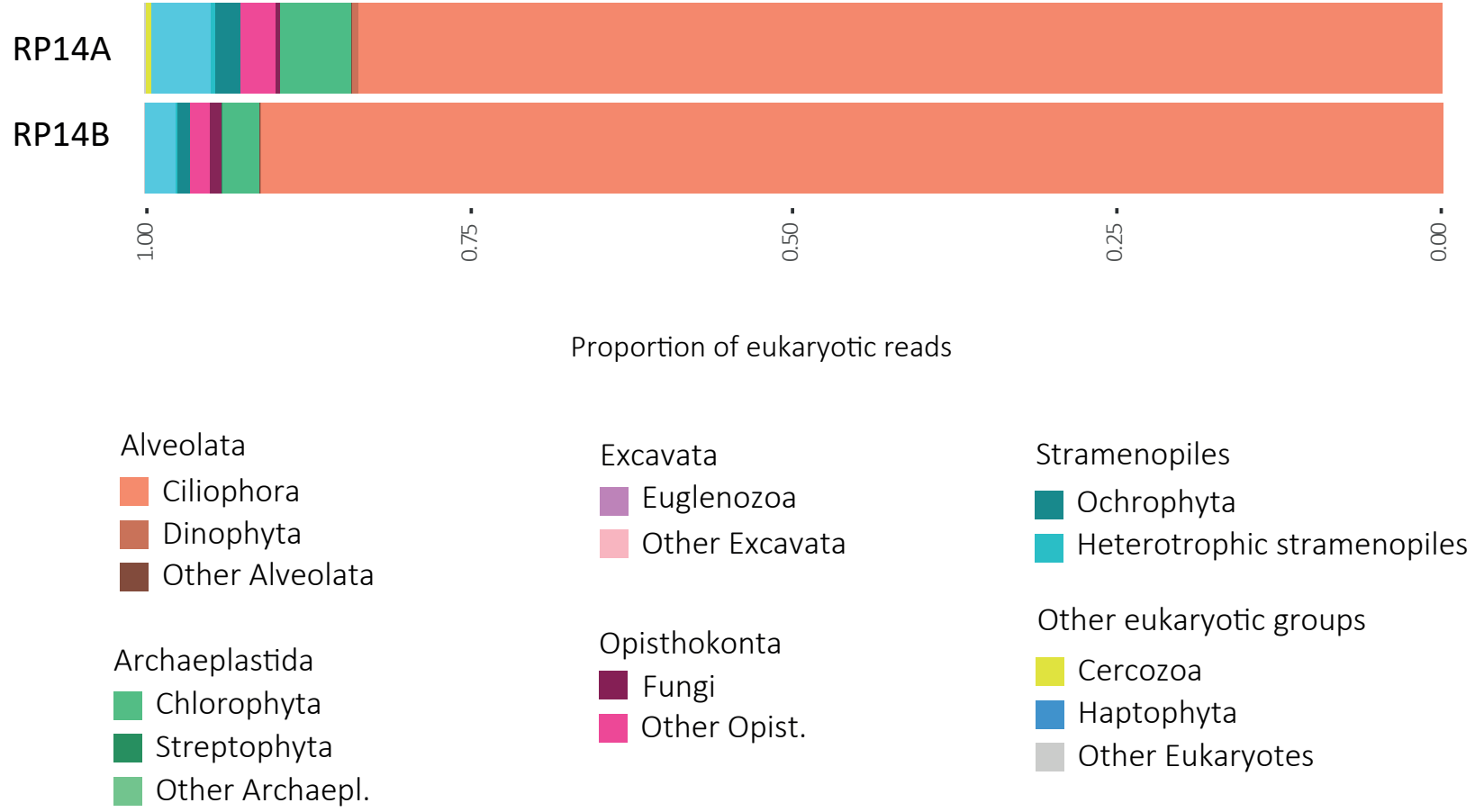

Figure S5. Community composition in Rincon del Parangueo microbial mats. Relative proportion of prokaryotic 16S rRNA gene sequences (A) and eukaryotic 18S rRNA gene sequences (B). 


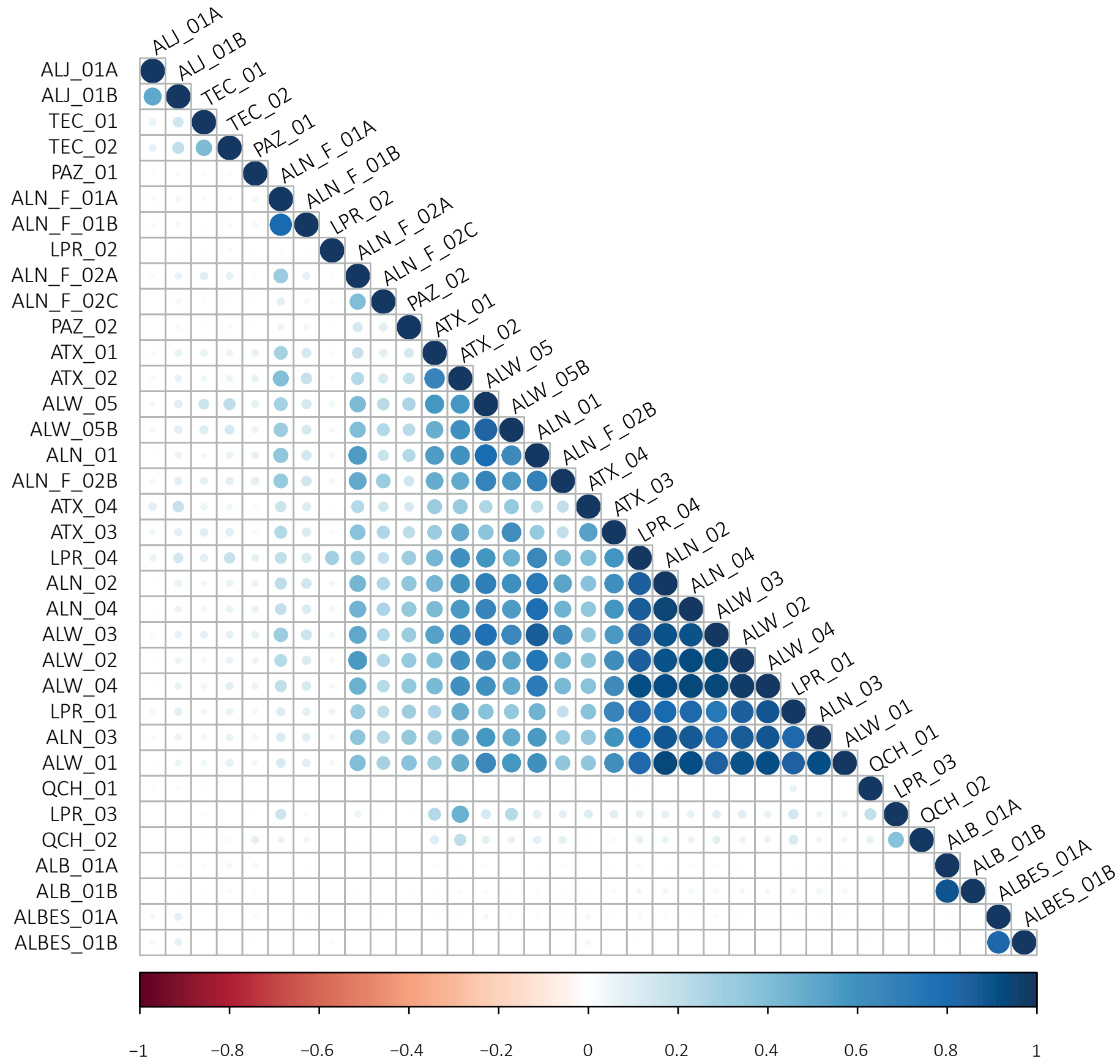

Figure S6. Correlation matrix based on Bray Curtis distances between the different microbialite samples collected from 9 lakes in a gradient of alkalinity at the Transvolcanic belt in Mexico. Lake and sample names are fully described in Figure 1 and Supplementary Table 2. 


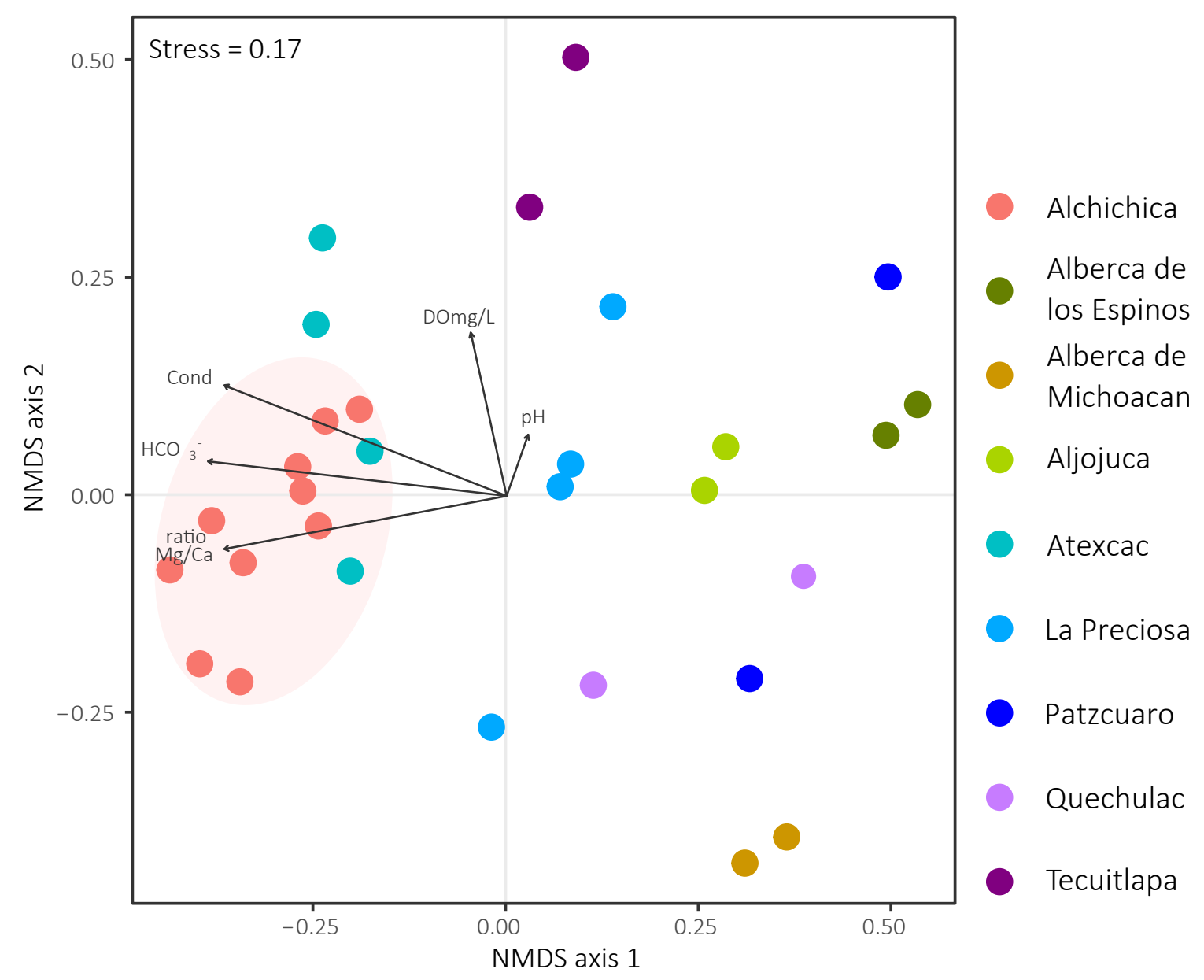

Fig. S7. Non-metric multidimensional scaling (NMDS) biplot of microbialite communities including a projection of the most influential parameters. The original NMDS is seen in Fig.3. 
A

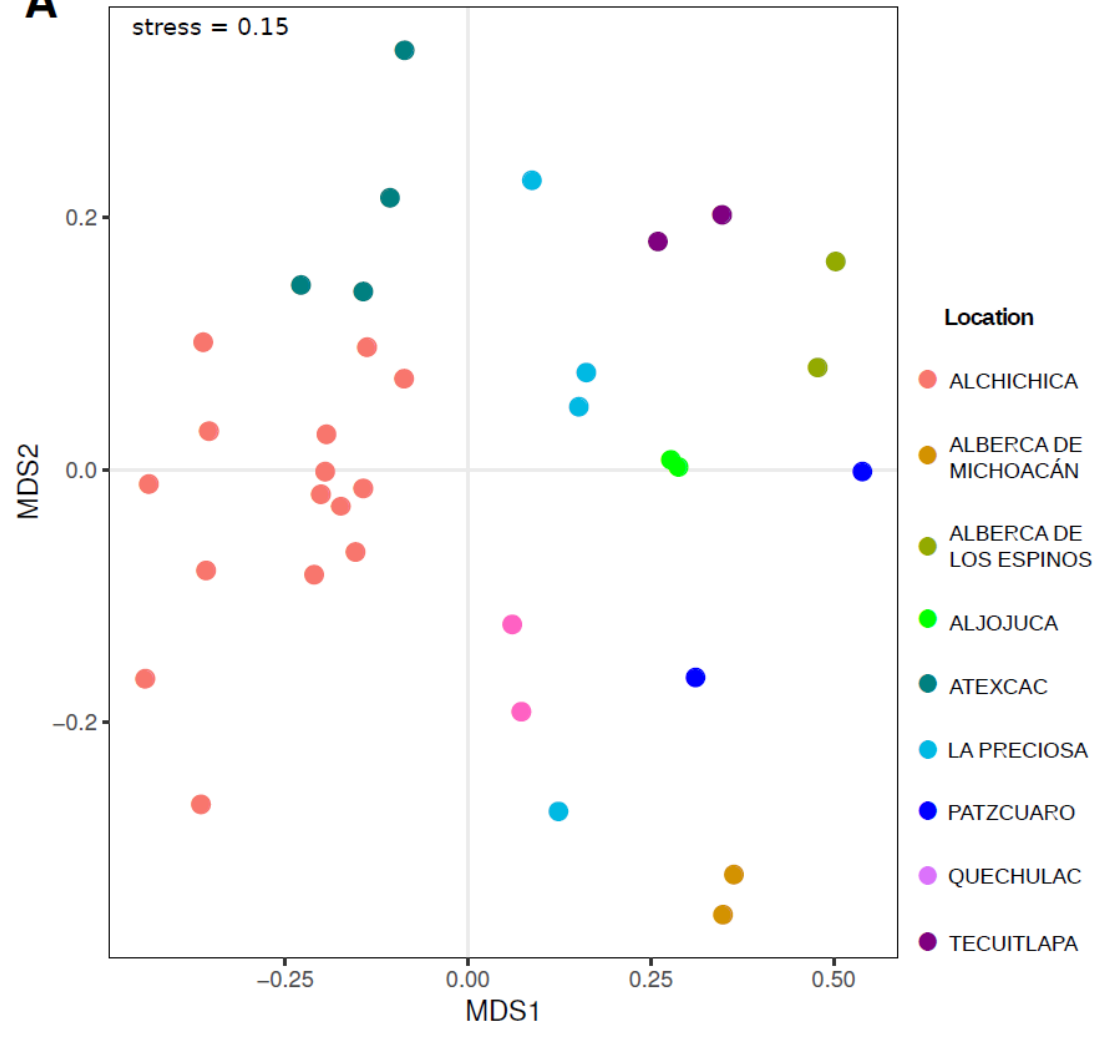

C

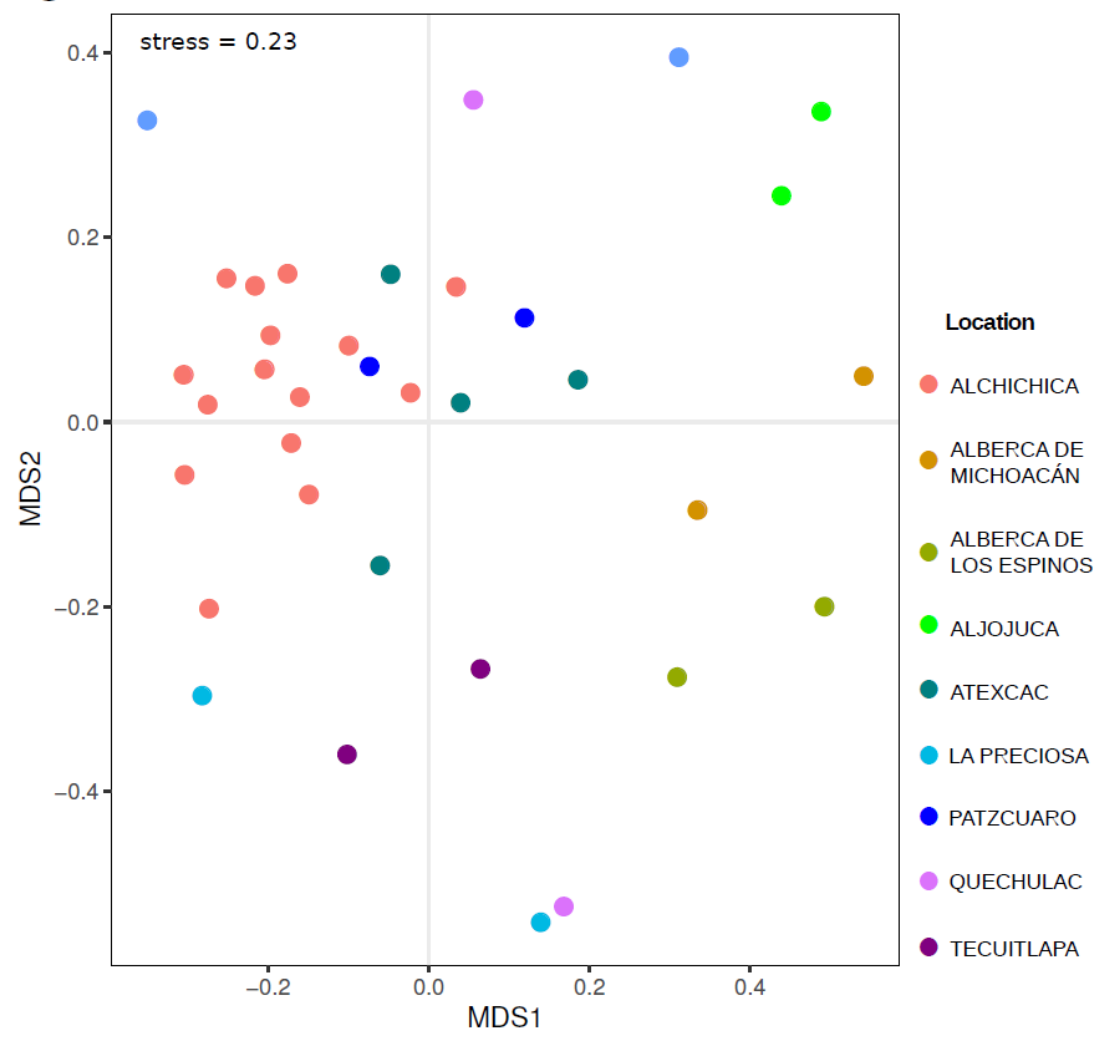

B

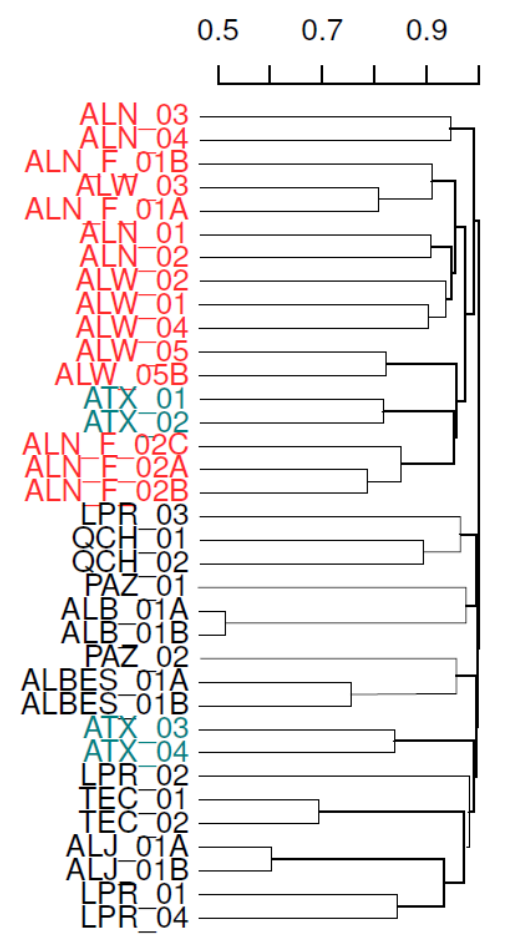

D

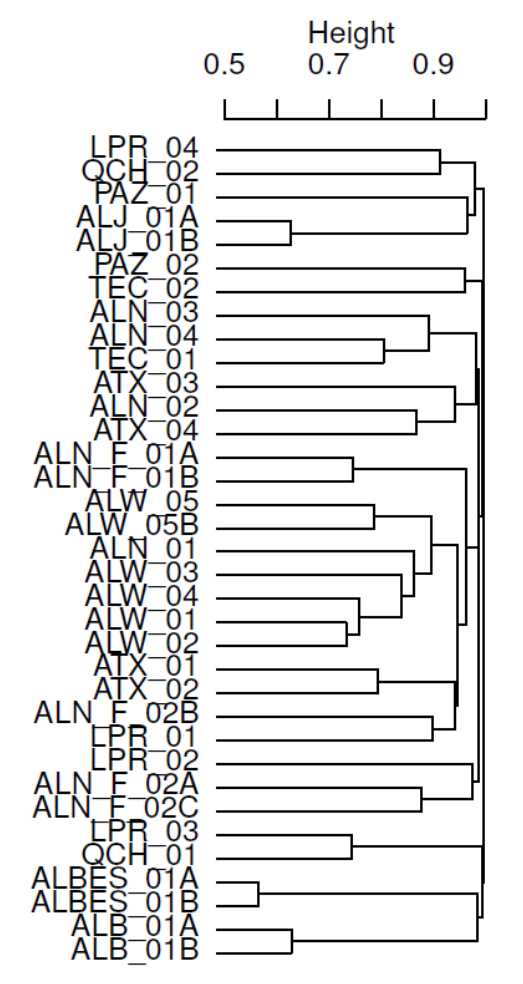

Figure S8. Comparison of microbialite samples based on prokaryotic and eukaryotic communities based on Bray Curtis distances. A, Non-metric multidimensional scaling (NMDS) biplot using prokaryotic 165 rRNA gene data. B, Hierarchical clustering based on prokaryotic community data. C, NMDS biplot of the eukaryotic $18 S$ rRNA gene data. D, Hierarchical clustering based on eukaryotic community data. 

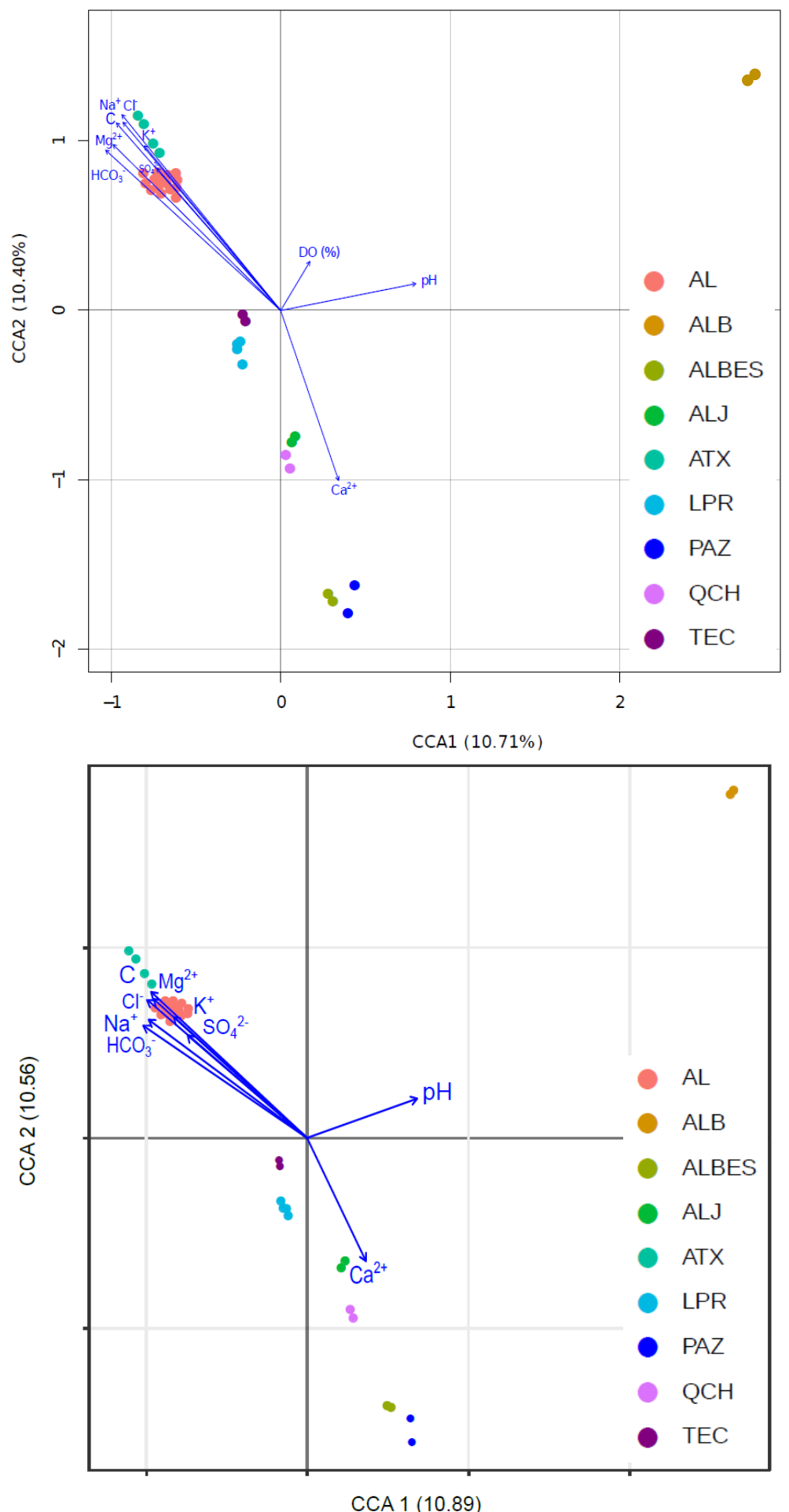

Figure S9. Canonical-correlation analysis (CCA) biplot of the entire microbialite community (prokaryotic and eukaryotic amplicon sequences) and the prokaryotic community as a function of the set of measured environmental parameters: dissolved oxygen (DO\%), $\mathrm{pH},\left[\mathrm{Ca}^{2+}\right],\left[\mathrm{HCO}_{3}{ }^{-}\right],\left[\mathrm{Mg}^{2+}\right],\left[\mathrm{Na}^{+}\right]$, Conductivity $(\mathrm{C}),\left[\mathrm{Cl}^{-}\right]$, $\left[\mathrm{SO}_{4}{ }^{2-}\right]$ and $\left[\mathrm{K}^{+}\right]$. Full lake names are given in Figure 1. 

by Zeyen et al. (2017). Depth - mbws (meters below water surface); DO, dissolved oxygen.

\begin{tabular}{|c|c|c|c|c|c|c|c|c|c|c|c|c|c|c|c|c|c|}
\hline & $\begin{array}{l}\text { Altitude } \\
\text { (m) }\end{array}$ & $\begin{array}{l}\text { Depth } \\
\text { (mbws) }\end{array}$ & $\mathrm{pH}$ & $\begin{array}{r}\text { Conductivity } \\
(\mathrm{ms} / \mathrm{cm})\end{array}$ & $\begin{array}{r}\text { Salinity } \\
\text { (PSU) }\end{array}$ & Alkalinity & $\begin{array}{c}\text { Temperature } \\
\left({ }^{\circ} \mathrm{C}\right)\end{array}$ & $\begin{array}{r}\text { Pression } \\
\text { (mbar) }\end{array}$ & $\begin{array}{l}\text { DO } \\
(\%)\end{array}$ & $\begin{array}{r}\text { DO } \\
(\mathrm{mg} / \mathrm{l})\end{array}$ & $\begin{array}{l}\mathrm{Ca}^{2+} \\
(\mathrm{mM})\end{array}$ & $\begin{array}{r}\mathrm{K}^{+} \\
(\mathrm{mM})\end{array}$ & $\begin{array}{l}\mathrm{Mg}^{2+} \\
(\mathrm{mM})\end{array}$ & $\begin{array}{l}\mathrm{Na}^{+} \\
(\mathrm{mM})\end{array}$ & $\begin{array}{c}\mathrm{Cl}^{-} \\
(\mathrm{mM})\end{array}$ & $\begin{array}{l}\mathrm{SO}_{4}{ }^{2 \cdot} \\
(\mathrm{mM})\end{array}$ & $\begin{array}{l}\text { ratio } \\
\mathrm{Mg} / \mathrm{Ca}\end{array}$ \\
\hline \multicolumn{18}{|c|}{ Alkaline lakes bearing living microbialites } \\
\hline \multirow{2}{*}{ Alchichica } & \multirow{2}{*}{2345} & 0 & 9.07 & 12.48 & 8.1 & 39.09 & 19.2 & 774.7 & 91.3 & 8.43 & 0.19 & 5.47 & 17.18 & 102.88 & 87.48 & 10.837 & 90 \\
\hline & & 3 & 9.03 & 12.61 & 8.15 & 43.1 & 18.1 & 774.6 & 98.4 & 9.21 & 0.19 & 5.7 & 17.45 & 101.97 & 87.05 & 9.66 & 91.84 \\
\hline \multirow{2}{*}{$\begin{array}{l}\text { La Preciosa (2012) } \\
\text { La Preciosa (2014) }\end{array}$} & \multirow{2}{*}{2340} & 0 & 8.88 & 2.25 & 1.4 & 14.13 & 16.2 & n.d. & n.d. & n.d. & 0.61 & 0.4 & 8.12 & 9 & 9.36 & 1.29 & 13.31 \\
\hline & & 0 & 8.75 & 2.3 & 1.34 & 14.22 & 19 & 772.3 & 81.5 & 7.54 & 0.25 & 0.38 & 8.33 & 7.72 & 9.62 & 1.475 & 33.6 \\
\hline \multirow{2}{*}{ Atexcac } & \multirow{2}{*}{2360} & 0.5 & 8.45 & 11.65 & 7.4 & n.d. & 20.2 & 772 & 87.7 & 7.91 & 0.52 & 2.32 & 22.82 & 79.31 & 109.57 & 2.453 & 44.2 \\
\hline & & 3 & 8.55 & 11.51 & 7.46 & 31.8 & 19.6 & 772 & 82.6 & 7.39 & 0.5 & 2.25 & 22.19 & 77.86 & 109.35 & 2.42 & 44.38 \\
\hline \multirow{2}{*}{ Aljojuca } & \multirow{2}{*}{2371} & 0.5 & 9.14 & 1.27 & 0.7 & n.d. & 20.6 & 771.4 & 68.4 & 6.15 & 0.43 & 0.68 & 2.9 & 8.31 & 1.49 & 0.403 & 3 \\
\hline & & 1.5 & 9.14 & 1.25 & 0.69 & 13.17 & 20.3 & 771.2 & 63.4 & 5.7 & n.d. & n.d. & n.d. & n.d. & n.d. & n.d. & n.d. \\
\hline Tecuitlapa & 2368 & 0.5 & 9.63 & 4.94 & 2.74 & 49.4 & 23.4 & 770.3 & 133 & 11.6 & 0.17 & 3.06 & 0.51 & 51.29 & 6.12 & 1.59 & 3 \\
\hline Quechulac (2012) & \multirow{2}{*}{2345} & 0 & 8.8 & 0.84 & 0.51 & 6.68 & 15.4 & n.d. & n.d. & n.d. & 0.45 & 0.2 & 2.37 & 3.4 & 2.09 & 0.182 & 5.27 \\
\hline Quechulac (2014) & & 0 & 8.92 & 0.86 & 0.45 & 6.55 & 22.5 & 770.9 & 87.2 & 7.58 & 0.22 & 0.18 & 2.33 & 3.32 & 2.48 & 0.197 & 10.59 \\
\hline Alberca de Michoacan & 1475 & 0.5 & 9.32 & 0.398 & 0.21 & 4.28 & 21 & 802.6 & 88.8 & 7.17 & 0.4 & 0.38 & 0.91 & 1.36 & 0.17 & 0.01 & 2.28 \\
\hline Alberca de los Espinos & 2022 & 0.5 & 8.67 & 1.25 & 0.65 & 7.64 & 23 & 808.3 & 70.7 & 5.96 & 0.92 & 0.68 & 2.55 & 5.04 & 4.77 & 0.003 & 2.77 \\
\hline Patzcuaro & 2044 & 0.5 & 8.94 & 1.09 & 0.5 & 10.62 & 28.5 & 797.8 & 95.1 & 7.44 & 0.61 & 0.4 & 8.12 & 9 & 9.36 & 1.296 & 13.3 \\
\hline \multicolumn{18}{|c|}{ Living microbialites not observed } \\
\hline Rincon de Parangueo* & 2075 & 0.5 & 9.8 & 165 & n.d. & 1520 & 35 & 822.4 & 16 & 1.25 & n.d. & 130 & n.d. & 193.2 & 1828.6 & 0.8 & n.d. \\
\hline Zirahuen - rim & 2097 & 0.5 & 8.36 & 0.198 & 0.08 & 1.23 & 22.3 & 797 & 58 & 4.6 & 0.24 & 0.11 & 0.24 & 0.35 & 0.17 & 0.04 & 1 \\
\hline Zirahuen - center & 2097 & 0.5 & 8.65 & 0.144 & 0.08 & n.d. & 22.2 & 797 & 77.5 & 6.51 & n.d. & n.d. & n.d. & n.d. & n.d. & n.d. & n.d. \\
\hline
\end{tabular}

* hydrochemistry information from Armienta et al (2008) 
Supporting Table S2. Sequence statistics for microbialite communities collected at 9 Mexican crater lakes. CdHit97 and 98 correspond to OTU definitions at 97 and 98\% $165 / 185$ (RNA gene sequence identity

Swarm

CdHit97

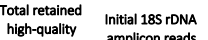

\section{Total retained
high-quality}

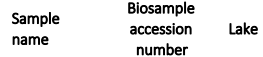

ALW_01 SAMN14596043 Alchichica (West)

ALW_02 SAMN14596044 Alchichica(W)

(1)

SAMN14596047 Alchichica(W)

WAMN14596048 Alchichica (W)

ALN 01 SAMN14596039 Alchichica (Nor

ALN 02 SAMN14596040 Alchichica (N)

ALN_03 SAMN14596041 Alchichica(N)

ALN_04 SAMN14596042 Alchichica(N)

F_01A SAMN14596038 Alchichica(N)

F-01B SAMN1459066 Alchichica(I)

TX_01 SAMN14596054 Atexcac (NW)

$\begin{array}{lll}\text { ATX_02 } & \text { SAMN14596055 } & \text { Atexcac (NW) } \\ \text { ATX_03 } & \text { SAMN14596056 } & \text { Atexcac (SE) }\end{array}$

ATX_03 SAMN14596056 Atexcac (SE)

$\begin{array}{lll}\text { AT__04 SAMN14596057 } & \text { Atexcac (SE) } \\ \text { ALB_01A } & \text { SAMN14596064 Alberca de Michoaćn }\end{array}$

ALB_01B SAMN14596069 Alberca de Michoacán

ALBES_01A SAMN14596065 Alberca de los Espinos

ALBES 01B SAMN14596070 Alberca de los Espinos

AL_01A SAMN14596058 Aljojuca

AL_01B SAMN14596068 Aljojuca

PR_02 SAMN14596035 La Preciosa (N)

SAMN14596052 La Preciosa (W)

LPR_04 SAMN14596053 La Preciosa (W)

PAZ01 SAMN14596062 Patzcuaro

SAMN14596063 Patzcuaro

QCH_01 SAMN14596036 Quechulac

QCH_02 SAMN14596037 Quechulac

$\begin{array}{lll} & \text { SAMN14596059 } & \text { Tecuitlapa } \\ \text { TEC 02 } & \text { SAMN14596060 } & \text { Tecuitlapa }\end{array}$

\section{$\begin{array}{lll}32340 & 14899 & 121634\end{array}$}

71247

46376

36824

81434

44127

5729

19663

19663
129125
79647

67422

20366

71842

37617

92315
72797

71842

27475

108084

53617

38849

31806
32145
2659

45340

.

17602

$\begin{array}{rr}191765 \\ 2795 & 69572\end{array}$

112114

112235
220310

174688

(2)

83261

03671

75669

136836

153311

224459

178294

16368

350456

117210

29809

12586

68840

\begin{tabular}{l|ll}
42299 & 1521 & 7 \\
43087 & 737 & 8 \\
33661 & 1574 & 9 \\
49676 & 1193 & 13 \\
31176 & 1567 & 43 \\
54069 & 2537 & 74 \\
34203 & 632 & 2 \\
51100 & 750 & 5 \\
19654 & 498 & 4 \\
33340 & 450 & 2 \\
47832 & 1971 & 14 \\
32160 & 864 & 1 \\
60642 & 1752 & 10 \\
49061 & 1137 & 11 \\
17408 & 1957 & 124 \\
41952 & 2735 & 225 \\
62453 & 1807 & 25 \\
28245 & 1805 & 1 \\
17905 & 1079 & 34 \\
28710 & 2183 & 13 \\
39631 & 2461 & 98 \\
57226 & 3298 & 137 \\
77804 & 2781 & 64 \\
36469 & 1211 & 43 \\
2978 & 1303 & 32 \\
96341 & 3704 & 109 \\
33213 & 1519 & 10 \\
7989 & 1305 & 33 \\
2250 & 1631 & 14 \\
60922 & 2202 & 20 \\
12979 & 1044 & 45 \\
8408 & 871 & 48
\end{tabular}

Eukar
OT
3
341
432
392
47
432
503
3
4
421
342
45
46
613
547
334
49
694
549
338
334
1007
1143
5
321
15
89
493
201
127
631
281

$\begin{array}{llll}\text { Prokaryotic Eukaryotic } & \text { Bacterial } & \text { Archaeal Eukaryotic } & \text { Prokaryotic } \\ \text { singletons singletons OTUS OTUs OTUs } & \text { singletons }\end{array}$

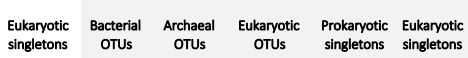

\begin{tabular}{|c|c|c|c|c|}
\hline & 59604 & 1389 & 6 & 6399 \\
\hline 298 & 71039 & 696 & 8 & 6791 \\
\hline 997 & 55130 & 1421 & 9 & 6088 \\
\hline 446 & 89931 & 1112 & 14 & 8474 \\
\hline 736 & 51222 & 1466 & 49 & 5976 \\
\hline 2198 & 96199 & 2330 & 72 & 9079 \\
\hline 326 & 71138 & 619 & 3 & 6206 \\
\hline 331 & 114385 & 730 & 5 & 8180 \\
\hline 92 & 34899 & 488 & 3 & 4184 \\
\hline 101 & 54248 & 427 & 2 & 5227 \\
\hline 4234 & 104204 & 1884 & 15 & 6361 \\
\hline 600 & 57198 & 837 & 1 & 4456 \\
\hline 2523 & 144860 & 1681 & 13 & 8724 \\
\hline 1185 & 68000 & 1094 & 11 & 7865 \\
\hline 930 & 44178 & 1856 & 128 & 3187 \\
\hline 3230 & 96399 & 2726 & 239 & 6016 \\
\hline 2645 & 93298 & 1632 & 27 & 7076 \\
\hline 2520 & 186782 & 1615 & 1 & 4803 \\
\hline 510 & 132696 & 1035 & 37 & 3584 \\
\hline 2964 & 110516 & 2216 & 163 & 4883 \\
\hline 1028 & 37007 & 2293 & 91 & 6245 \\
\hline 3210 & 117732 & 3087 & 141 & 10009 \\
\hline 4270 & 133882 & 2706 & 70 & 10266 \\
\hline 984 & 125617 & 1209 & 46 & 3553 \\
\hline 873 & 7276 & 1291 & 36 & 843 \\
\hline 2915 & 225507 & 3442 & 112 & 14495 \\
\hline 1548 & 72827 & 1453 & 10 & 4761 \\
\hline 1405 & 18431 & 1227 & 27 & 2072 \\
\hline 1087 & 4373 & 1624 & 16 & 665 \\
\hline 3599 & 175943 & 2130 & 22 & 8261 \\
\hline & 36900 & 1393 & 82 & 2046 \\
\hline
\end{tabular}

\begin{tabular}{|c|c|}
\hline 2406 & 2011 \\
\hline 51285 & 857 \\
\hline 39699 & 649 \\
\hline 66874 & 748 \\
\hline 36735 & 495 \\
\hline 71940 & 430 \\
\hline 54660 & 1468 \\
\hline 86085 & 720 \\
\hline 25200 & 1555 \\
\hline 37874 & 1157 \\
\hline 79617 & 1541 \\
\hline 40529 & 2458 \\
\hline 106538 & 1814 \\
\hline 52080 & 1180 \\
\hline 32435 & 1916 \\
\hline 76690 & 2820 \\
\hline 67131 & 2400 \\
\hline 146732 & 3260 \\
\hline 101381 & 1750 \\
\hline 84070 & 1764 \\
\hline 27874 & 1069 \\
\hline 90360 & 2310 \\
\hline 98867 & 2827 \\
\hline 98714 & 1214 \\
\hline 5196 & 1331 \\
\hline 173559 & 3599 \\
\hline 52925 & 1663 \\
\hline 13894 & 2163 \\
\hline & \\
\hline 136420 & 1264 \\
\hline 26451 & 1479 \\
\hline
\end{tabular}

$\begin{array}{ccc}7421 & 145 & 51336 \\ 8205 & 181 & 61620 \\ 7031 & 474 & 47900 \\ 9856 & 208 & 79181 \\ 6741 & 411 & 44373 \\ 10134 & 1075 & 85061 \\ 7624 & 164 & 63661 \\ 9795 & 156 & 100358 \\ 4687 & 50 & 30233 \\ 6357 & 61 & 46228 \\ 8309 & 2289 & 93166 \\ 5661 & 274 & 49314 \\ 11388 & 1371 & 126933 \\ 9799 & 614 & 60638 \\ 3866 & 479 & 38578 \\ 7307 & 1603 & 87128 \\ 8275 & 1195 & 80651 \\ 5780 & 1246 & 168015 \\ 3261 & 243 & 118217 \\ 4624 & 1428 & 98631 \\ 6820 & 488 & 32918 \\ 10403 & 1587 & 104949 \\ 12363 & 2104 & 117911 \\ 4740 & 376 & 113061 \\ 1094 & 431 & 6274 \\ 17721 & 1464 & 201523 \\ 4636 & 670 & 63492 \\ 2367 & 740 & 16313 \\ 863 & 513 & 3635 \\ 9486 & 1924 & 157390 \\ 2191 & 394 & 31886 \\ 1594 & 471 & 13960\end{array}$


Supporting Table S3. D iversity indexes of microbial communities from microbialites collected at 9 Mexican crater lakes. D: Simpson index; H': Shannon-Wiener index; J': Pielou's evenness; S: Species richness.

$$
\text { Diversity indices (global) Diversity indices (only Prokaryotes) Diversity indices (only Eukaryotes) }
$$

\begin{tabular}{|c|c|c|c|c|c|c|c|c|c|c|c|c|c|c|c|c|c|c|c|}
\hline $\begin{array}{l}\text { Sample } \\
\text { name }\end{array}$ & ke & D & $\mathrm{H}^{\prime}$ & $J^{\prime}$ & Chao1 & $\mathrm{ACE}$ & $S$ & D & $H^{\prime}$ & $J^{\prime}$ & 1 & ACE & $S$ & D & $\mathrm{H}^{\prime}$ & $J^{\prime}$ & Chao1 & ACE & $S$ \\
\hline W_01 & chichica (West) & 0,8 & 3,3 & 44 & 560 & 623 & 869 & ,99 & & 83 & 2060 & 2092 & 1528 & 0,65 & 1,47 & 0,25 & 469 & 482 & 341 \\
\hline ALW_02 & ica (W) & 0,83 & 3 & 0,42 & 615 & 1706 & 1177 & 0,88 & & 0,50 & 1020 & 1063 & 745 & 0,65 & 1,56 & 0,26 & 592 & 637 & 432 \\
\hline ALW_03 & (W) & 94 & 4,68 & 0,62 & 452 & 399 & 975 & ,98 & 5,49 & 0,75 & 1808 & 1780 & 1583 & 0,68 & 1,68 & 0,28 & 669 & 38 & 392 \\
\hline ALW_04 & W) & 8 & 3,26 & 0,44 & 180 & 145 & 1684 & 0,94 & 4,88 & 0,69 & 1459 & 1436 & 1206 & 0,65 & 1,55 & 0,25 & 723 & 722 & 478 \\
\hline LW_05 & $(W)$ & ,93 & 28 & 0,56 & 3001 & 3112 & 2042 & 0,97 & 4,95 & 0,67 & 2280 & 2373 & 1610 & 0,7 & 1,86 & 0,31 & 707 & 728 & 432 \\
\hline LW_05B & Ich & 93 & 2 &, 53 & 226 & 4261 & 3114 &, 93 & 4,69 & 0,60 & 3451 & 3443 & 2611 & 0,68 & 1,69 & 0,27 & 742 & 804 & 503 \\
\hline ALN_01 & Ach & 0,88 & 3,07 & 0,44 & 410 & 1421 & 1010 & 0,79 & 3,11 & 0,48 & 797 & 791 & 634 & 0,69 & 1,73 & 0,29 & 617 & 586 & 376 \\
\hline ALN_02 & Ich & 88 & 45 & 0,48 & 63 & 1667 & 1231 & 0,97 & 5,06 & 0,76 & 921 & 917 & 755 & 0,71 & 2,02 & 0,33 & 759 & 91 & 476 \\
\hline ALN_03 & 1) & 84 & 3,2 & 0,47 & 63 & 1511 & 923 & ,98 & 5,09 & 0,82 & 686 & 714 & 502 & 0,7 & 1,94 & 0,32 & 842 & 371 & 421 \\
\hline LN_O4 & Ich & 0,86 & 3,1 & 0,46 & 191 & 1258 & 794 & 0,83 & 3,64 & 0,60 & 623 & 648 & 452 & 0,7 & 2 & 0,34 & 583 & 656 & 342 \\
\hline ALN_F_01A & Ich & 0,97 & 4,93 & 0,63 & 144 & 3200 & 2435 & 0,98 & 5,05 & 0,67 & 2437 & 2486 & 1985 & 0,67 & 1,79 & 0,29 & 680 & 591 & 450 \\
\hline ALN_F_01B & $1 c h$ & & 3,48 & 0.48 & 234 & 2168 & 1325 & 0,98 & 4,96 & 0,73 & 1342 & 1309 & 865 & 0,64 & 1,67 & 0,27 & 869 & 348 & 460 \\
\hline ATX_01 & tex & 0,94 & 4,39 & 0,56 & 358 & 3296 & 2375 & 0,93 & 4,31 & 0,58 & 2337 & 2293 & 1762 & 0,7 & 2,04 & 0,32 & 1033 & 1038 & 613 \\
\hline ATX_02 & Atex & 94 & 3,93 & 0,53 & 659 & 2678 & 1695 & 0,94 & 3,92 & 0,56 & 1783 & 1747 & 1148 & 0,69 & 1,84 & 0,29 & 868 & 930 & 547 \\
\hline ATX_03 & & & & 0,63 & & & & & & & & 2826 & 2081 & 0,68 & 1,94 & 0,33 & & & \\
\hline ATX_04 & Atexca & 0,98 & 5,53 & 0,68 & 4082 & 4217 & 3456 & 0,99 & 6,03 & 0,75 & 3380 & 3494 & 2960 & 0,72 & 2,27 & 0,37 & 745 & 764 & 496 \\
\hline ALB_01A & ıcán & 0,95 & 4,57 & 0,58 & 3587 & 3606 & 2526 & 0,94 & 4,19 & 0,56 & 2600 & 2672 & 1832 & 0,72 & 2,48 & 0,38 & 961 & 914 & 694 \\
\hline ALB_01B & dacán & 0,96 & 4,79 & 0,62 & 3170 & 3250 & 2355 & 0,95 & 4,39 & 0,59 & 2391 & 2436 & 1806 & 0,72 & 2,51 & 0,40 & 721 & 758 & 549 \\
\hline ALBES_01A & Albe & & 4,1 & & 204 & 2327 & & & & 0,60 & 1727 & 1820 & & 0,7 & & 0,36 & & 11 & 338 \\
\hline ALBES_01B & los Espinos & 0,96 & 4,9 & 0,63 & 3401 & 3512 & 2655 & 0,97 & 5,00 & 0,65 & 2926 & 3019 & 2321 & 0,7 & 2,11 & 0,36 & 479 & 500 & 334 \\
\hline ALJ_01A & Aljoj & 0,96 & 5,36 & 0,65 & 4961 & 4982 & 3566 & 0,98 & 5,82 & 0,74 & 3765 & 3789 & 2559 & 0,72 & 2,54 & 0,37 & 1207 & 1215 & 1007 \\
\hline ALJ_01B & Aljoj & 0,98 & 5,81 & 0,69 & 5700 & 5802 & 4578 & 0,98 & 5,72 & 0,70 & 4296 & 4430 & 3435 & 0,73 & 2,84 & 0,40 & 1342 & 1318 & 1143 \\
\hline LPR_01 & $-\mathrm{C}^{-1}$ & & & & 4412 & 4514 & 3419 & 0,98 & 4,88 & 0,61 & 3554 & 3657 & 2845 & 0,61 & 1,44 & 0,23 & & 839 & 574 \\
\hline & & & & & 1832 & 1784 & & 0,99 & 5,72 & 0,80 & 1353 & 1337 & 1254 & 0,59 & 1,36 & 0,24 & & 48 & 321 \\
\hline LPR_03 & W) & 96 & 4,87 & 0,67 & 2365 & 2487 & 1494 & 0,96 & 4,72 & 0,66 & 2047 & 2183 & 1335 & 0,71 & 2,11 & 0,42 & 323 & 285 & 159 \\
\hline LPR_04 & (W) & 0,95 & 5,41 & 0,64 & 5630 & 5745 & 4712 & 1,00 & 6,51 & 0,79 & 4351 & 4438 & 3813 & 0,71 & 2,14 & 0,31 & 1308 & 1362 & 899 \\
\hline PAZ_01 & atroure & 0,97 & 5,08 & 0,67 & 2781 & 2784 & 2022 & 0,99 & 5,38 & 0,73 & 2107 & 2056 & 1529 & 0,72 & 2,35 & 0,38 & 652 & 701 & 493 \\
\hline PAZ_02 & atzc & 0,96 & 4,5 & 0,61 & 1882 & 1933 & 1539 & 0,96 & 4,38 & 0,61 & 1587 & 1625 & 1338 & 0,69 & 1,85 & 0,35 & 310 & 352 & 201 \\
\hline QCH_01 & Quec & 0,94 & 5,01 & 0,67 & 2439 & 2535 & 1772 & 0,93 & 4,95 & 0,67 & 2192 & 2283 & 1645 & 0,68 & 1,84 & 0,38 & 262 & 267 & 127 \\
\hline QCH_02 & ulac & 0,95 & 4,66 & 0,58 & 3433 & 3448 & 2853 & 0,93 & 4,38 & 0,57 & 2548 & 2580 & 2222 & 0,72 & 2,3 & 0,36 & 896 & 858 & 631 \\
\hline TEC_01 & ecuitlapa & 0,95 & 4,42 & 0,61 & 2107 & 2054 & 1370 & 0,95 & 4,40 & 0,63 & 1636 & 1610 & 1089 & 0,71 & 2,04 & 0,36 & 464 & 433 & 281 \\
\hline TEC & ecuitlapa & 0,94 & 4,57 & 0,65 & 1572 & 1590 & 1096 & 0,98 & 4,88 & 0,72 & 1268 & 1300 & 919 & 0,63 & 1,58 & 0,31 & 308 & 281 & 177 \\
\hline
\end{tabular}


Supporting Table S4. Identification, phylogenetic affinity and relative abundance of prokaryotic OTUs identified in microbialite samples from Mexican crater lakes.

(large Table, downloadable in excel format only) 
Supporting Table S5. Identification, phylogenetic affinity and relative abundance of eukaryotic OTUs identified in microbialite samples from Mexican crater lakes.

(large Table, downloadable in excel format only) 
Supporting Table S6. Pairwise permanova comparison of the distribution and ratio of the different metabolic activities considered (metabolic profile) between the different collection sites. The column 'corrected p.value' shows the p.value adjusted with a Bonferroni correction in order to prevent type I errors.

pair of lakes compared

AlchichicaNorth vs AlchichicaWest AlchichicaNorth vs Atexcac AlchichicaNorth vs Alb.Michoacan AlchichicaNorth vs Alb.Espinos AlchichicaNorth vs Aljojuca AlchichicaNorth vs LaPreciosa AlchichicaNorth vs Patzcuaro AlchichicaNorth vs Quechulac AlchichicaNorth vs Tecuitlapa AlchichicaWest vs Atexcac AlchichicaWest vs Alb.Michoacan AlchichicaWest vs Alb.Espinos AlchichicaWest vs Aljojuca AlchichicaWest vs LaPreciosa AlchichicaWest vs Patzcuaro AlchichicaWest vs Quechulac AlchichicaWest vs Tecuitlapa Atexcac vs Alb.Michoacan Atexcac vs Alb.Espinos Atexcac vs Aljojuca Atexcac vs LaPreciosa Atexcac vs Patzcuaro Atexcac vs Quechulac Atexcac vs Tecuitlapa Alb.Michoacan vs Alb.Espinos Alb.Michoacan vs Aljojuca Alb.Michoacan vs LaPreciosa Alb.Michoacan vs Patzcuaro Alb.Michoacan vs Quechulac Alb.Michoacan vs Tecuitlapa Alb.Espinos vs Aljojuca Alb.Espinos vs LaPreciosa Alb.Espinos vs Patzcuaro Alb.Espinos vs Quechulac Alb.Espinos vs Tecuitlapa Aljojuca vs LaPreciosa Aljojuca vs Patzcuaro Aljojuca vs Quechulac Aljojuca vs Tecuitlapa LaPreciosa vs Patzcuaro LaPreciosa vs Quechulac LaPreciosa vs Tecuitlapa Patzcuaro vs Quechulac Patzcuaro vs Tecuitlapa Quechulac vs Tecuitlapa

\begin{tabular}{|c|c|c|c|}
\hline egrees & & & \\
\hline $\begin{array}{c}\text { of } \\
\text { freedom }\end{array}$ & SumsOfSqs & F.Model & R2 \\
\hline 1 & 0.53807397 & 5.4941033 & 0.40714846 \\
\hline 1 & 0.866046 & 10.6604195 & 0.63986501 \\
\hline 1 & 0.58505412 & 9.0699985 & 0.69395559 \\
\hline 1 & 0.31466848 & 3.47646 & 0.46498744 \\
\hline 1 & 0.47570408 & 5.7950504 & 0.59163048 \\
\hline 1 & 0.6839712 & 5.4784805 & 0.47728273 \\
\hline 1 & 0.48395866 & 4.7075273 & 0.54062734 \\
\hline 1 & 0.36251703 & 2.7013009 & 0.40310097 \\
\hline 1 & 0.3808768 & 4.6129764 & 0.53558447 \\
\hline 1 & 0.16927051 & 1.7130127 & 0.17636266 \\
\hline 1 & 0.20944096 & 2.2396231 & 0.27181135 \\
\hline 1 & 0.05367329 & 0.4841713 & 0.07466973 \\
\hline 1 & 0.07517921 & 0.714369 & 0.10639407 \\
\hline 1 & 0.2886491 & 2.1947144 & 0.21527964 \\
\hline 1 & 0.26002364 & 2.1841524 & 0.26687582 \\
\hline 1 & 0.11369416 & 0.812214 & 0.11922908 \\
\hline 1 & 0.27735078 & 2.6274843 & 0.30454814 \\
\hline 1 & 0.18214773 & 2.7489818 & 0.407318 \\
\hline 1 & 0.16348268 & 1.7717898 & 0.30697406 \\
\hline 1 & 0.07616653 & 0.9084342 & 0.18507617 \\
\hline 1 & 0.20080309 & 1.5934555 & 0.2098459 \\
\hline 1 & 0.31352181 & 2.9984577 & 0.4284455 \\
\hline 1 & 0.13643122 & 1.0034906 & 0.20055811 \\
\hline 1 & 0.30409168 & 3.6063091 & 0.47412076 \\
\hline 1 & 0.10625556 & 1.5216305 & 0.43208125 \\
\hline 1 & 0.17377416 & 3.2801218 & 0.62122086 \\
\hline 1 & 0.14583229 & 1.107548 & 0.21684535 \\
\hline 1 & 0.11481177 & 1.216065 & 0.37812202 \\
\hline 1 & 0.11902957 & 0.7571674 & 0.27461785 \\
\hline 1 & 0.31557529 & 5.8510581 & 0.74525727 \\
\hline 1 & 0.08673398 & 0.8260582 & 0.2923005 \\
\hline 1 & 0.19980185 & 1.2671267 & 0.24057267 \\
\hline 1 & 0.15244063 & 1.0410337 & 0.3423289 \\
\hline 1 & 0.09531547 & 0.4555683 & 0.18552459 \\
\hline 1 & 0.19386132 & 1.8296711 & 0.47776194 \\
\hline 1 & 0.08216008 & 0.5504679 & 0.12096952 \\
\hline 1 & 0.09644639 & 0.7443007 & 0.2712169 \\
\hline 1 & 0.07597185 & 0.3949233 & 0.1649002 \\
\hline 1 & 0.14126317 & 1.585408 & 0.44218344 \\
\hline 1 & 0.08951518 & 0.5266458 & 0.1163435 \\
\hline 1 & 0.06833656 & 0.3393617 & 0.07820545 \\
\hline 1 & 0.21571572 & 1.4406657 & 0.26479585 \\
\hline 1 & 0.11660767 & 0.4987375 & 0.1995958 \\
\hline 1 & 0.14606763 & 1.1189779 & 0.3587643 \\
\hline 1 & 0.15540863 & 0.8038603 & 0.2866977 \\
\hline
\end{tabular}

\begin{tabular}{|c|c|}
\hline p.value & $\begin{array}{l}\text { Correcte } \\
\text { d p.value }\end{array}$ \\
\hline 0.013 & 0.715 \\
\hline 0.033 & 1 \\
\hline 0.06666667 & 1 \\
\hline 0.13333333 & 1 \\
\hline 0.06666667 & 1 \\
\hline 0.032 & 1 \\
\hline 0.06666667 & 1 \\
\hline 0.13333333 & 1 \\
\hline 0.06666667 & 1 \\
\hline 0.176 & 1 \\
\hline 0.07 & 1 \\
\hline 0.686 & 1 \\
\hline 0.694 & 1 \\
\hline 0.127 & 1 \\
\hline 0.085 & 1 \\
\hline 0.543 & 1 \\
\hline 0.072 & 1 \\
\hline 0.13333333 & 1 \\
\hline 0.2 & 1 \\
\hline 0.4 & 1 \\
\hline 0.162 & 1 \\
\hline 0.06666667 & 1 \\
\hline 0.4 & 1 \\
\hline 0.13333333 & 1 \\
\hline 0.33333333 & 1 \\
\hline 0.33333333 & 1 \\
\hline 0.33333333 & 1 \\
\hline 0.33333333 & 1 \\
\hline 1 & 1 \\
\hline 0.33333333 & 1 \\
\hline 0.66666667 & 1 \\
\hline 0.33333333 & 1 \\
\hline 0.66666667 & 1 \\
\hline 0.66666667 & 1 \\
\hline 0.33333333 & 1 \\
\hline 0.53333333 & 1 \\
\hline 1 & 1 \\
\hline 0.66666667 & 1 \\
\hline 0.33333333 & 1 \\
\hline 0.6 & 1 \\
\hline 0.6 & 1 \\
\hline 0.2 & 1 \\
\hline 1 & 1 \\
\hline 0.66666667 & 1 \\
\hline 1 & 1 \\
\hline
\end{tabular}


Supporting Table S7. Pairwise permanova comparison of the metabolic profile between the different microbialite categories. Categories according to Zeyen et al. (2017). The column 'corrected p.value' shows the p.value adjusted with a Bonferroni correction in order to prevent type I errors.

WellDev: well developped microbialites, samples from Alchichica, Atexcac

LivMicrob: living microbialites, samples coming from Alberca de los Espinos, La Preciosa, Aljojuca, Quechulac, Patzcuaro and Tecuitlapa Alb.Mich: Alberca de Michoacan

Pairs

WellDev vs Alb.Mich WellDev vs LivMicrob Alb.Mich vs LivMicrob

$\begin{array}{cccccc}\begin{array}{c}\text { Degrees of } \\ \text { freedom }\end{array} & \text { SumsOfSqs } & \text { F.Model } & \text { R2 } & \text { p.value } & \begin{array}{c}\text { Corrected } \\ \text { p.value }\end{array} \\ 1 & 0.2582386 & 1.643389 & 0.09314476 & 0.138 & 0.828 \\ 1 & 0.364692 & 2.313454 & 0.07631774 & 0.06 & 0.36 \\ 1 & 0.1819269 & 1.31646 & 0.08592596 & 0.307 & 1\end{array}$


Supporting Table S8. List of prokaryotic OTUs present in microbialites from at least 8 out o the 9 lakes sampled ('core' OTUs).

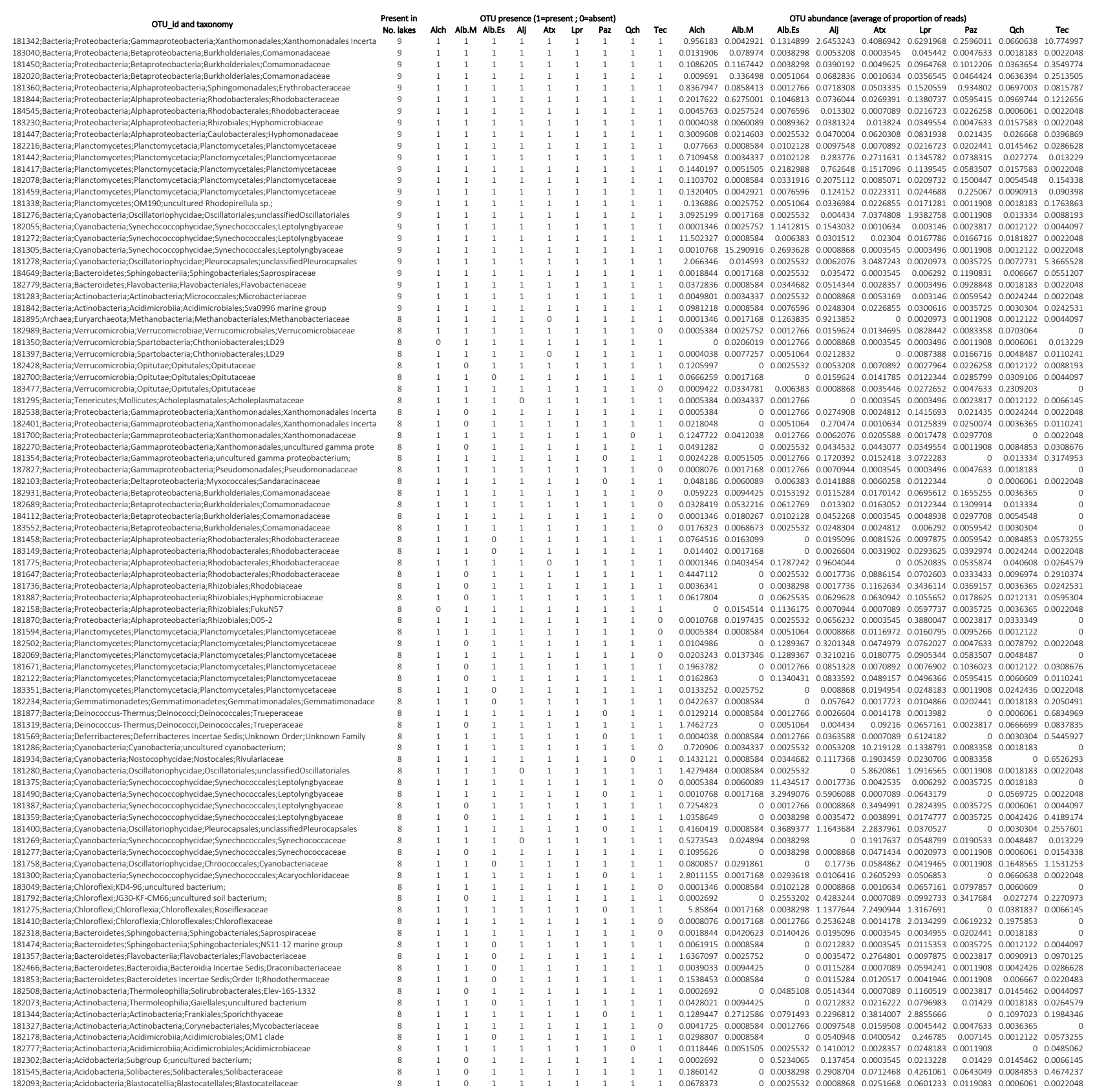




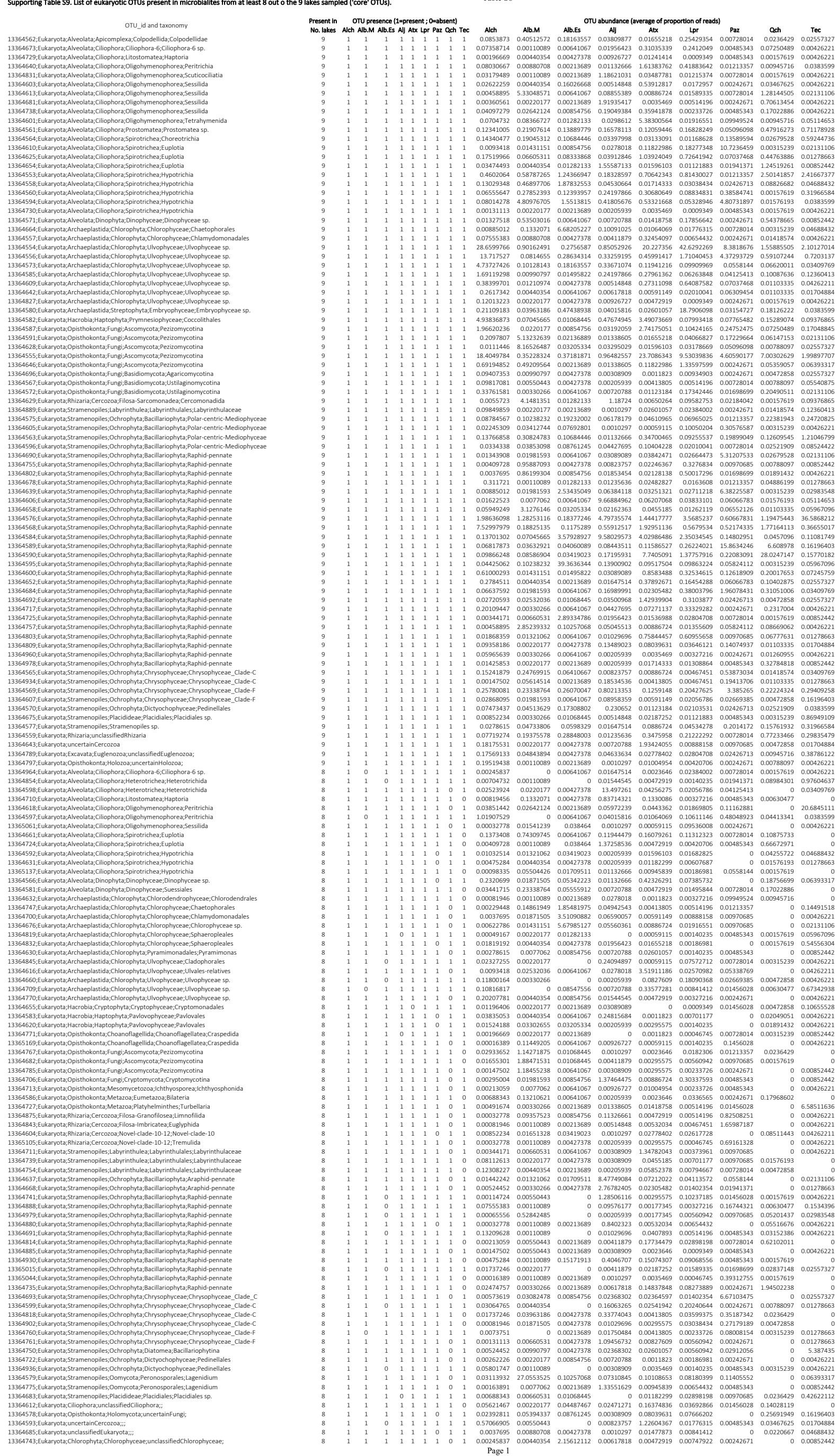

